Portland State University

PDXScholar

Dissertations and Theses

Dissertations and Theses

1988

\title{
Adolescent Shoplifting and Situational Stimuli
}

James A. Chambers

Portland State University

Follow this and additional works at: https://pdxscholar.library.pdx.edu/open_access_etds

Part of the Social Policy Commons, Urban Studies Commons, and the Urban Studies and Planning Commons

Let us know how access to this document benefits you.

\section{Recommended Citation}

Chambers, James A., "Adolescent Shoplifting and Situational Stimuli" (1988). Dissertations and Theses. Paper 1333.

https://doi.org/10.15760/etd.1332

This Dissertation is brought to you for free and open access. It has been accepted for inclusion in Dissertations and Theses by an authorized administrator of PDXScholar. Please contact us if we can make this document more accessible: pdxscholar@pdx.edu. 
ADOLESCENI SHOPLIFTING AND SITUATIONAL STIMUI

by

JAMES A. CHAMBERS

A dissertation submitted in partial fulfillment of the requirements for the degree of

\section{DOCTOR OF PHILOSOPHY in \\ URBAN STUDIES}

Portland State University

(C) 1988 
TO THE OFFICE OF GRADUATE STUDIES:

The members of the Committee approve the dissertation of James A. Chambers presented December 2, 1987.

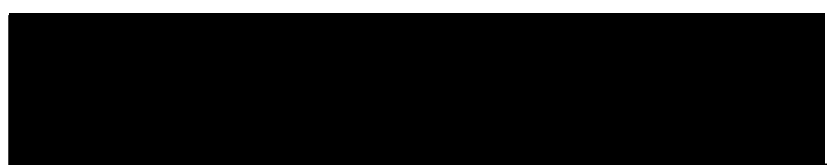

Charles Tracy, Chairman

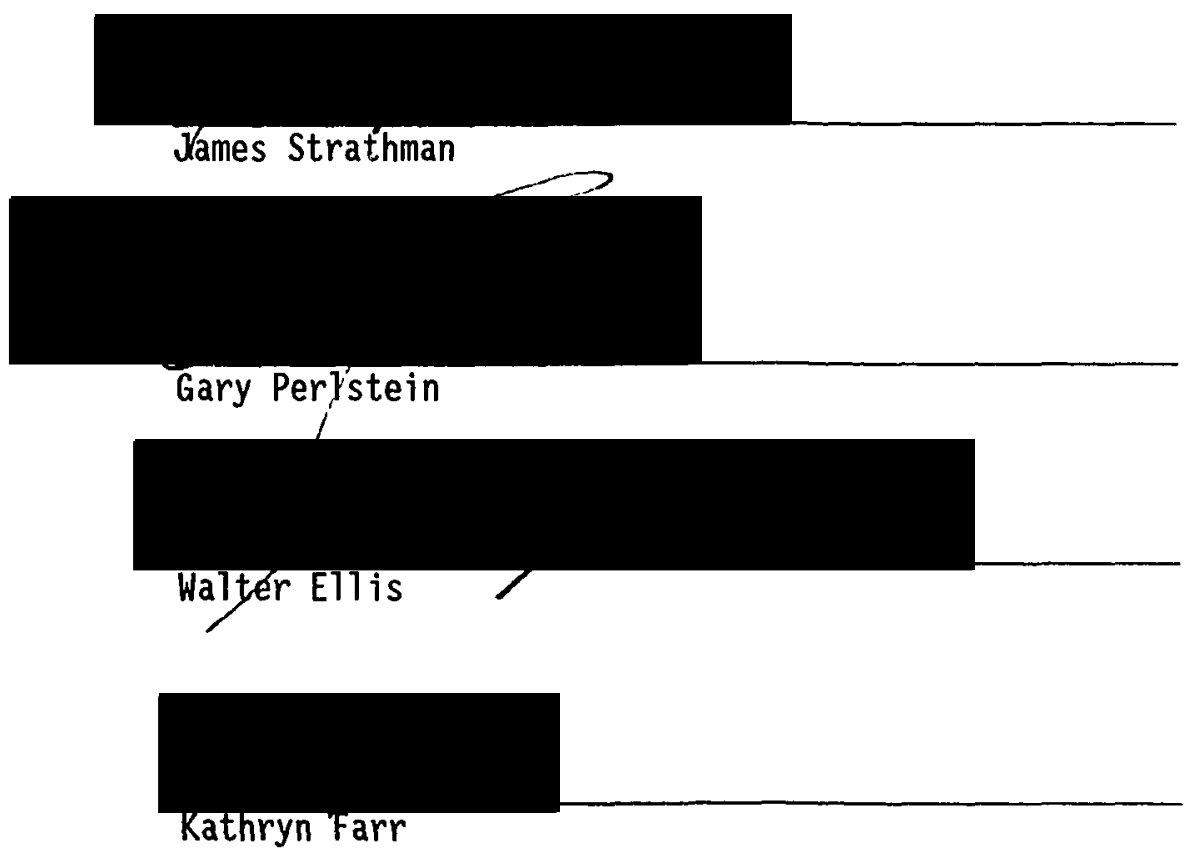

APPROVED:

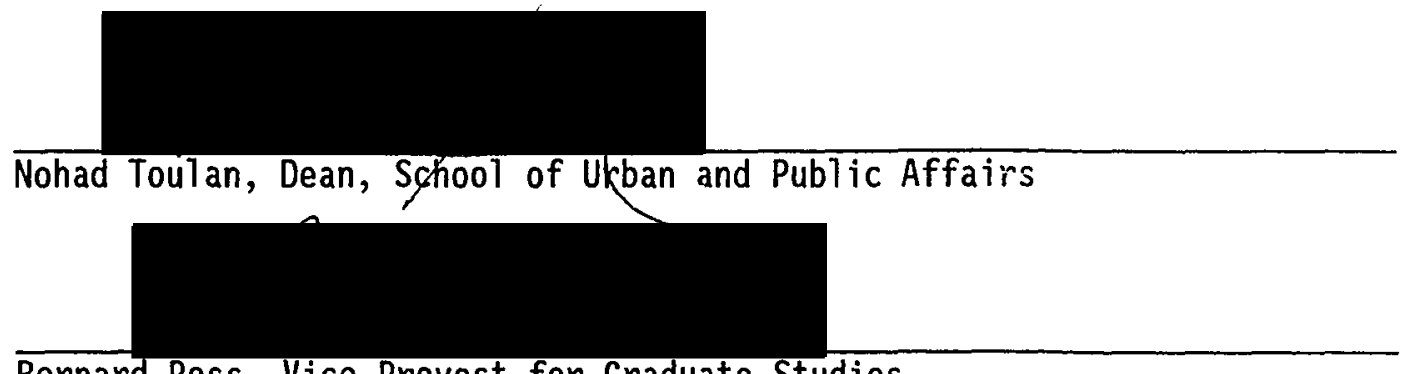

Bernard Ross, Vice Provost for Graduate Studies 
()1988

James A. Chambers

All Rights Reserved 
AN ABSTRACT OF THE DISSERTATION OF James A. Chambers for the Doctor of Philosophy in Urban Studies presented December 2, 1987.

Title: Adolescent Shoplifting and Situational Stimuli.

APPROVED BY MEMBERS OF THE DISSERTATION COMMITTEE:

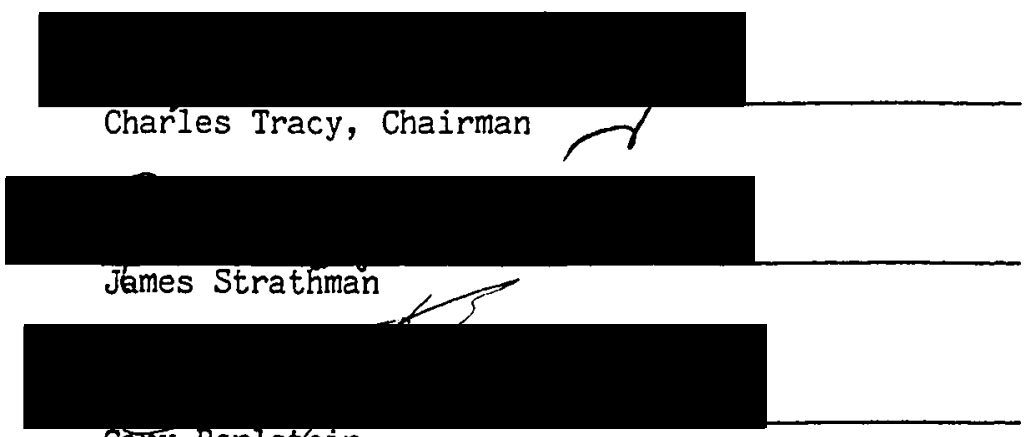

Găry Perlstein

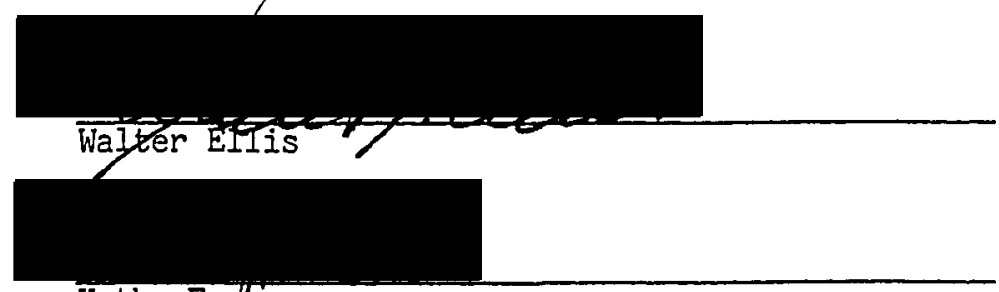

Kathy Farlf

Adolescent shoplifting has provoked limited and somewhat controversial perspectives within the sociological and psychological literature. These controversies center around the empirical variables used for analysis. A companion argument focuses on the subjective and objective measurement of these variables.

This research explicated variables from the sociological literature to test their relationship, using multiple linear regression, to adolescent shoplifting behavior. These variables and situational stimuli were operationalized in a simultaneous model to demonstrate a proximate 
occurrence of the attitude-situation-behavior reciprocal. This reciprocal is a learning theory which suggests that direct and vicarious experiences accompanied by rewards and punishment, in one's environment, lead to the acquisition of specific beliefs, attitudes and behavior toward a situation. This research contends that beliefs and attitudes toward the situation, rather than the bonding, peer association and other factors, shape adolescent shoplifting behavior. The situational stimuli variables were perceived empirically as being the major reciprocal element that maximized and/or minimized the adolescent's attitude toward shoplifting. The reciprocals are expressed as: $S F=f(B, P A, P A, P R, N, N, A T T, S$, Age, Race $)$.

An anonyomous self-report questionnaire was administered to $\mathrm{N}=312$ Portland adolescents ranging in ages between 13 and 17 . These youths were sampled at various neighborhood youths service centers, mall stores and Fred Meyer. The S-R elicited the youths' perceptions and attitudes to the explicated dimensions of the variables.

The research results confirmed the situational stimuli correlate for adolescent 'snitch' shoplifting. Statistical results validate the progressive involvement and drift propositions. 
TABLE OF CONTENTS

PAGE

ACKNOWLEDGEMENTS ................................ vi

LIST OF TABLES ................................. vii

LIST OF FIGURES . . . . . . . . . . . . . . . $\mathrm{x}$

CHAPTER

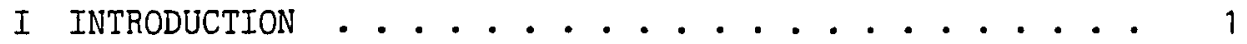

Background of Shoplifting Behavior ........ 3

Some Causative Factors . . . . . . . . . 5

Research Problem and Analytical Questions . . . . 8

Definitions .................. 9

II A SELECTED REVIEW OF THE LITERATURE . . . . . . . . . 11

Historical Observations . . . . . . . . 11

Demographic Factors . . . . . . . . . . 13

Techniques for Committing and Preventing Shoplifting • 21

Merchants' Response ............. 23

Sociogenic Perspectives . . . . . . . . 24

Social Status ............. . . 25

Social Control . . . . . . . . . . 27

Social Learning . . . . . . . . . . 32

Conflict.................. 34

Situational Perspective ......... 35

Psychogenic Perspective . . . . . . . . 39 
CHAPTER

Summary . . . . . . . . . . . . . . 52

III THE RESEARCH DESIGN • . . . . . . . . . . . . . 54

Research Questions . . . . . . . . . . 54

Data Collection ............... 56

Data Analysis . . . . . . . . . . . . 65

IV RESULTS . . • . . . . . . . . . . . . . . 80

Sample Characteristics . . . . . . . . . 80

Partialling of the Variables . . . . . . . . . 82

Explanatory Power of Variables . . . . . . . . 86

Testing the Analytical Model . . . . . . . . 90

Answering the Research Question . . . . . . . . 94

Summary of Findings . . . . . . . . . . . 100

V CONCLUSION . . . . . . . . . . . . . . . . . . 101

Relation of Results to Other Studies . . . . . . 102

Limitations of the Study . . . . . . . . . 103

Implication of Findings . . . . . . . . . 103

REFERENCES . . . . . . . . . . . . . . . . . . 105

APPENDICES . . . . . . . . . . . . . . . . . . . . 120

I POPULATION CHARACTERISTICS . . . . . . . . . . . . 120

II PARTIALLING OUT VARIABLES . . . . . . . . . . . 123

III QUESTIONNAIRE . . . . . . . . . . . . . . . 129 
ACKNOWLEDGMENTS

An undertaking of this magnitude is possible only when you have quality direction and help. To this end I wish to express my profound appreciation to: Dr. Charles Tracy, who not only chaired this effort but was a valuable friend throughout my academic endeavor; Dr. Gary Perlstein, who always made time and provided intellectual balance for three long years; Dr. James Strathman, who simplified this effort, displayed faith in my academic ability and is a valued friend ( $I$ pray to have the calm in the turbulence which he always displays); Dr. Walter Ellis, who gave more time and empathy than any student should reasonably expect (without his understanding and patience, this effort would have terminated far short of the goal); Dr. Kathy Farr, for her intellectual insight; Dean Toulan; Kyung Hwa Kim, who served as a trusted friend and a competent computer technician with some urging; Connie Speigel, whose editing skills are insurmountable; Gail Venturini and Andra Hohlenstein who helped with the surveys; and my colleagues who offered moral support and compassion. My deepest appreciation is to my best friend, care giver, permanent 'roomie' and wife, without whose caring and concern, not to mention her typing, this task could not have evolved in any form except orally. 
I Race, Age, Sex Distribution and Percentage Comprising Sample Population ............ . . 81

II Age, Sex and Those Who Admitted To Shoplifting and Non-shoplifting at the Stipulated Malls ...... 81

III Stated Site and Frequency of Shoplifting 1982-1986 . . . 82

IV Partialling out the Bonding Elements ......... 83

V Partialling out the Peer Association Elements . . . . . . 84

VI Partialling out the Needs Elements . . . . . . . . 84

VII Partialling out the Parental Relationship Elements . . . 85

VII Partialling out the Attitude Elements . . . . . . . 85

IX Attitude (AT4) Regressed on the Attitude Sub-elements . . 86

$X$ Parental Relationship Instrument (PR) Regressed on the Parential. Relationship Sub-elements . . . . . 87

XI Bonding Instrument (B) Regressed on Bonding Sub-elements . 87

XII Situational Instrument (S) Regressed on the Situation Sub-elements ............. 88

XIII Peer Association Instrument (PA1, PA2) Regressed on the Peer Association Sub-elements . . . . . . . 88

XIV Result of the Pred Scores on the Peer Association Subelements Expressed in Beta Weights ........ 89 
XV Need Instrument (N3, N4) Regressed on the Need Subelements ................... . 89

XVI Result of the Pred Scores on the Need Sub-elements as Expressed in Beta Weights . . . . . . . . . . 90 


\section{LIST OF FIGURES}

FIGURE

PAGE

1. Bonding Level, Attitude and Predicted Behavior . . . . 29

2. Differential Association Applied to a Specific Behavior . . 34

3. Units Used for Analysis . . . . . . . . . . 64

4. Multidimensional Individual Stated Characteristics (image)

and the Theorized Impact of the Situation and the

Behavior on that Image .......... . . 74

5. Bonding Level and Expected Behavior . . . . . . . 78

6. Simultaneous Model ............... 98 
CHAPTER I

\section{INTRODUCTION}

Shoplifting is a socio-economic and legal problem in the United States, the exact dimension of which remains largely undetermined because the reporting of its occurrence is not uniform. Nevertheless, it is common knowledge that shoplifting results in the loss of millions of dollars annually to both retailers and consumers. Such theft lessens the profit of businesses and increases the cost to consumers who are forced to share in the added risks and expenses to retailers (Bradford and Balmaceda, 1982:248). The magnitude of the problem can be partially seen by U.S. Department of Justice estimates that put shoplifting losses to business at approximately 40 billion dollars for the period 1974 to 1978 (1979:27-31). Moreover, national statistics suggest that the problem is getting worse. In 1984, 13 percent of all reported larceny-theft cases were shoplifting, reflecting an increase of approximately 25 percent over the previous five years. According to Oregon data for 1981-86, shoplifting losses, after recovered property was accounted for, amounted to an annual cost of almost one-half million dollars.

While the economic and legal implications of shoplifting are somewhat clear, the social implications are less so. Who engages in shoplifting, for what reasons, and under what conditions are questions that are difficult to answer--yet need answering. To do so, we need to 
know much more than is currently known about the characteristics of individuals who commit acts of shoplifting. One group--urban adolescents --has been selected for this study in the hope that a better understanding of their attitudes and perceptions will provide greater insight into the phenomenor of shoplifting.

The extent of shoplifting by adolescents is not well defined. Some studies indicate that juveniles may represent the largest group of shoplifters, with estimates ranging from 20 to 50 percent. For example, a Small Marketers Aids report (1978:2) contends that juvenile offenders account for an estimated 50 percent of all shoplifting. Another study conducted in 1979-80 and covering 20 states revealed that, among high school and college student respondents, almost half admitted to having shoplifted (Robertson, 1980). A 1980-81 study conducted by French surveyed 100,671 students about shoplifting behavior and attitudes. The sample was more than double that of Robertson's and was drawn from 38 states with respondents aged 9 to 22. Juveniles comprised 90 percent of the population-- 41 percent were pre-high school and 49 percent were high school age. Of the total sample, almost one-half admitted to having shoplifted at least once. In Oregon, during 1981-86, juveniles made up approximately 30 percent of those persons whose arrest cleared the annual average of more than 16,000 shoplifting cases reported to the police (LEDS, 1981-86).

The reasons given by many adolescent shoplifters tend to place them in the category of amateurs. Most acts seem to be unplanned and, when planned, seem to be based on thrill and 'get even' motives (French, 1981). Other studies seem to support the notion that the majority of 
shoplifters are amateurs or 'snitchers', who steal petty items that total up to large losses (Cameron, 1964).

It is quite possible that there are many different motivations for shoplifting behavior. Klemke (1982) identified four motivational factors--economic, sporting, peer pressure and illicit gain. A clearer understanding of these motives in the context of situational stimuli confronting shoplifters may be an aid to merchants in protecting their environment and reducing their losses.

The findings in this dissertation help to increase the body of knowledge about adolescent shoplifting by clarifying the relationship between personal characteristics and selected situational factors that are believed to influence shoplifting behavior.

\section{BACKGROUND OF SHOPLIFTING BEHAVIOR}

The writings of Byrnes, Eldridge and Watts represent the beginning of a trend toward using typologies to classify shoplifters. The three most commonly used are: amateur, professional and kleptomaniac. The kleptomaniac is generally considered to be the least common, and few arrests involve this type of shoplifter (Buckman, 1979: 51).

The Small Marketers Aids (1978:2) contends that there are other distinct types of shoplifters:

Juvenile Offenders: Youngsters account for about 50 percent of all shoplifting. They may steal on a dare or simply for kicks. Frequently they expect that store owners and courts will go easy on them because of their youth. They may enter stores in gangs in an attempt to intimidate management further.

Impulse Shoplifters: Many 'respectable' people fall into this category. They have not premeditated their thefts, but a sudden chance (such as an unattended dressing room or a blind aisle in 
a supermarket) presents itself, and the shopper succumbs to temptation.

Alcoholics, Vagrants and Drug Addicts: Abnormal physical need can drive people to theft as well as to other crimes. These criminals are often clumsy or erratic in their behavior and may be easier than other types of shoplifters to detect.

Kleptomaniacs: This type of shoplifter is motivated by a compulsion to steal, usually with little or no actual use for the items stolen and, in many cases, is able to pay for them.

Professionals: Since the professional shoplifter is in the busiriess of theft, he or she is usually highly skilled and hard to spot. Professionals generally steal items which will quickly be resold to an established fence. They tend to concentrate on highdemand, easily-resold consumer goods such as televisions, stereos and other small appliances.

The professional, or 'booster', may case a store well in advance of the actual theft. They may be hard to prosecute because many belong to underworld organizations which are very effective in raising bail and providing defense counsel in court.

In summary, the typical shoplifter seems to be an amateur who acts on impulse. Arrest data indicate that juveniles comprise a significant portion of arrested shoplifters, with males dominating this group.

Because most of what is known about shoplifters is based on store apprehension data, there is a real possibility that this knowledge is heavily influenced by apprehension and prosecution policies which may differ across stores, companies, and local governmental jurisdictions. Without knowing more about who is not being arrested, and without knowing how representative the stores are where the studies have been conducted, the existing body of knowledge about shoplifting is severely limited. 
SOME CAUSATIVE FACTORS

The few studies of shoplifting that have been conducted have produced a set of factors that seems to be related, with varying degrees of strength, to such behavior by both adults and adolescents. Some of the more common factors are:

1. Family: There is widespread belief that 'bad kids' come disproportionately from 'bad families'. This perceived relationship is so commonly held that the occasional 'bad kid' from a 'good home' provokes considerable attention and dismay. And yet, little is known about the specific relationship between the dynamics of family life and adolescent misbehavior.

It is generally believed that an unhappy home is the source of a wide range of undesirable behavioral and personality outcomes for the children involved. An unhappy home implies trauma, and often, a loss of security.

Parental involvement, including dimensions such as parental understanding, influence and communication with the child, has been considered to affect the behavior of adolescents.

Another aspect is family interaction which indicates the extent to is which family members share in common leisure activities. As such, it is an expression of family solidarity and integration.

The extent to which parents control the conduct of their children, both within the family and outside the home, has also been considered to be important in terms of its impact on adolescent misbehavior, including shoplifting. 
2. Race: Some persons who have studied theft have posited a connection between race and shoplifting. Race is frequently used as a predictor of criminal activity, and it has been assumed that there would be more blacks and other minority groups involved in shoplifting. There have been few studies which have actually assessed the effects of race on shoplifting.

3. Socio-economic status: This factor has long been recognized as a useful predictor of theft and usually attributes this crime, and others, to lower-economic persons. The available evidence, however, suggests that shoplifting is committed by persons from the middle class as well. Won and Yamamoto (1968) found that over three-fourths of the shoplifters in their sample were persons from the middle-income bracket, yet this income level represented only one-third of the population at the time. They discovered that shoplifters came from all occupational categories, but almost two-thirds were manual laborers. Cameron (1964) also noted that many arrested shoplifters were manual laborers.

4. Sex: Conflicting data have been reported on the relative incidence of shoplifting among males and females. Griffin's (1978) findings indicate that adult male and female apprehensions tend to be closely approximate. However, anong juveniles, males comprised 64 percent of his sample, while females made up the rest. Data from the Bellingham Police Department (Washington) indicate that adult males and juvenile females represent equal proportions of all apprehended shoplifters for the year 1977 (Shave, 1979). These two groups also accounted for 56 percent of all police arrests that year. The findings of both Griffin and Shave indicate that males predominate in juvenile 
shoplifting, but among adults females comprise the largest group.

5. Environment and Situational Factors: In comparing the type of retail establishment with the percentage of crimes committed within each establishment, Morton (1975) found that department stores account for 41 percent of the total retail sales in the U.S., but account for 61 percent of all shoplifting crimes. Drug stores represent 6 percent of all retail sales and suffer 10 percent of losses to shoplifting. Grocery stores comprise 42 percent of retail sales and experienced only 21 percent of criminal losses. Data directly related to shoplifting losses were not included in the study.

The size of the business establishment is another factor believed to have a substantial impact on shoplifting rates. Smaller stores generally do not have extensive security systems nor the security personnel found in larger department stores and therefore are more susceptible to shoplifting. The Department of Commerce speculates that small businesses (receipts under $\$ 5$ million) suffer 3.2 times more crime, including shoplifting, than businesses with receipts over $\$ 5$ million (Shave, 1978).

Since many smaller businesses have a profit margin of only three or four percent, shoplifting losses could conceivably cause a business to fail. However, in a report by the Small Business Administration (1969), small businesses reported relatively few losses due to shoplifting. In contrast, larger businesses are generally able to document a portion of their losses through apprehension data and shrinkage rate. Certainly the large retail stores in the major metropolitan areas are more likely to be the target of choice by shoplifters. 
The environmental design or floor layout of a store may also be an important factor. The physical environment may affect perceptions of risk of detection and of accessibility to merchandise. For example, security personnel avoid placing high priced items near exits or out of sight of employees. Areas of the store that offer seclusion or are beyond surveillance are believed to invite shoplifting.

RESEARCH PROBLEM AND ANALYTICAL QUESTIONS

The general problem this study attempts to ameliorate is the lack of useful understanding about adolescent shoplifting. This problem was analyzed by addressing the following three specific questions:

1. To what extent do the traditional variables in the literature explain impulse (snitch) shoplifting by adolescents?

2. To what extent does the attitude of the shoplifter influence impluse (snitch) shoplifting by adolescents?

3. To what extent do situational forces influence impulse (snitch) shoplifting by adolescents?

Data were collected primarily from a sample of adolescents using an anonymous, self-report questionnaire. The framework for this study is structured around two premises: (1) the variables of socio-economic status, sex, age peer association, prior delinquent behavior and parental influences do not adequately explain the occurrence of shoplifting among adolescents, and (2) selected situational stimuli factors and attitudes toward the stimuli increase the ability to explain shoplifting behavior.

Therefore, this research is directed by the argument that the 
primary explanation for impulse shoplifting by adolescents is situational stimuli and their attitude toward these stimuli.

The research strategy involved an assessment of: (1) the attitudes of adolescent shoplifters and nonshoplifters toward a limited number of situational stimuli found at selected stores in the Portland metropolitan area, and (2) the statistical value of the predictive variables thought to explain shoplifting behavior.

\section{DEFINITIONS}

The following definitions of terms and concepts were used in this research:

1. Adolescents: youths ranging in age from 13 to 17 .

2. Personal background or antecedent factor: various factors (e.g., race, sex, bonding level and psychological attributes) that youths bring to a particular situation.

3. Bonding level: the extent to which an adolescent feels morally bound to common social goals within a particular culture, e.g., obeying formal and informal laws because an adolescent believes that is the proper thing to do or the way to behave.

4. Impulse (snitch) shoplifter: a person who steals property from within a store, but who does not frequent a store with the intention of stealing.

5. Environmental design: the physical layout of a store which may influence shoplifting behavior, e.g., small portable 
items left unsecured, nonfunctioning security cameras, and attractive merchandise stored near exits.

6. Need: an adolescent's perception of his or her personal economic well-being.

7. Neutralization: contrived justification for behavior which is consistent with self-image status or past behavior, e.g., youths who are apprehended for shoplifting perceiving their behavior as non-serious or a game.

8. Parental relationship:, the adolescent's perception of the intensity, duration and closeness of his or her relationship with a parent, and the extent of confiding with a parent.

9. Peer influence: perceived influence of friends or siblings who may or may not be shopiffers.

10. Shoplifting: the stealing, for personal gain, of property from retail stores. Attempted shoplifting is not included.

11. Situational stimuli: the impression, intended or unintended, that is given off by the environmental design of a retail store within a specific location; e.g., the perception of lax security or uncertainity of prosecution, if arrested.

12. Target hardening: security devices designed to delay or deter a shoplifter, e.g., locks on display cases, operating surveillance cameras and merchandise fitted with alarms. 
CHAPTER II

\section{A SELECTED REVIEW OF THE LITERATURE}

Almost all behavior can be explained, by social scientists, in probabilistic terms. Simply stated, if ' $x$ ' is present, ' $y$ ' will follow, if allowances are made for intervening factors with a certain probability. Regardless of how sophisticated or simply stated, delinquent behavior, like shoplifting, is generally thought to be the result of numerous factors which have a peculiar relationship to the behavior (Gibbons, 1977).

There is some dissent from this etiological perspective within the scientific community (Teeter and Reinemann, 1950). While there is consensus that the causes of most delinquent acts vary from individual to individual, such dissent arises over the question of whether it is possible to isolate common factors to account for specific behavior.

This chapter examines the literature related to shoplifting in general, and to adolescent shoplifting in particular, with special attention given to the traditional sociogenic and psychogenic 'causative' factors. Through this literature a foundation is laid for identifying the common variables associated with adolescent shoplifting.

\section{HISTORICAL OBSERVATIONS}

While shoplifting has increasingly been viewed as a crime of epidemic proportions, it is not a crime exclusive to modern times. There 
are recordings of shoplifting since the beginning of retail shops around the year 627 A.D. (Edwards, 1958).

Shoplifting became a specific topic of interest to professionals in the early eighteenth century. There are some reports of shoplifters working in triplets as early as 1597. Studies also frequently mentioned the impulsive lady or juvenile lifting small items for personal use. The noncommercial or 'kleptomaniac' shoplifter is noted, and the first distinction between the professional and the kleptomaniac sinoplifter is made by Byrnes (1886). In a later publication (Eldridge and Watts, 1897), the professional shoplifter was distinguished from the amateur, who usually acted on impulse, and also from the kleptomaniac.

A primary difference between the crime of shoplifting in the eighteenth century and shoplifting today is the severity of the punishment. In the early eighteenth century, shoplifting became such a problem for English shopkeepers that the death penalty was envoked as a deterrent to the crime. Obviously, shoplifters are no longer executed for their crimes, and a large percentage of apprehended shoplifters today are not even prosecuted. To some extent, this is because juveniles have comprised the largest percentage of apprehensions in the United States, dating back to 1911 (Edwards, 1958). While the severity of punishment for shoplifting has lessened, the pervasiveness of the phenomenon has become an issue of critical importance within the retail sector. 
DEMOGRAPHIC FACTORS

Apparently, shoplifting starts at a rather young age, but may not continue over the years. Boyd and Harrel1 (1975), for example, attempted to develop a profile of the teenage shoplifter. Their questioning of individuals indicated that shoplifting first occurs, on the average, at age 10 . However, many subjects reported a termination of involvement in shoplifting activities at age 12 .

Shave's (1978) data indicate that shoplifting becomes significant at the age of 11 , with $4.7 \%$ of juvenile offenders in this age group. Fifteen was the peak age, with $19.5 \%$ of the offenses occurring then. Declination is evident at ages $16(15.96 \%)$ and $17(13.4 \%)$. Robin (1963), in a study of shoplifting in three major Philadelphia department stores, found that juvenile comprised $58.1 \%$ of the total apprehensions. However, some security experts point out (Edwards, 1958; Astor, 1970) that apprehensions may not be a true indicator of juvenile involvement in shoplifting. The assumption that juveniles, as a group, make up the majority of shoplifters is believed to lead to closer surveillance of this age group. This implies that a disproportionate number of teenagers are apprehended. Furthermore, younger shoplifters may be less skilled at concealment and other behaviors needed to avoid detection.

The studies of Cameron (1964), Robin (1964), Klemke (1982) and Won and Yamamoto (1968) indicate that: (1) shoplifting behavior is increasing; (2) shoplifters fall into two categories, 'snitchers' and 'boosters'; (3) female shoplifters out-number male shoplifters; (4) approximately $90 \%$ of the shoplifters can be classified as 
'snitchers'; (5) while juveniles commit a lot of shoplifting, the full extent of their involvement is unclear; and (6) juvenile shoplifting is not relegated to a specific socio-economic or racial class.

A number of authors (Holcomb, 1973; Chilimsky, 1978; Angelino, 1959; Boyd and Harrel1, 1975) argue that juvenile amateurs appear to be the most common type of shoplifter, and that most of their shoplifting seems to be impulsively motivated.

Other studies have yielded conflicting results with regard to the age category in which most apprehensions fall. A study conducted by Stores Mutual Protective Association in New York City involving 4,000 apprehensions by six large department stores found that most shoplifters were under 20 years of age (National Retail Merchants Association, 1976). Alternatively, analysis of data from five Pennsylvania supermarket chain stores (Serdahely, 1977) indicate that juveniles 10 to 17 comprised $21.19 \%$ of the total number of apprehensions, while persons in the 18 to 25 age group comprised $15.5 \%$.

Griffin found that $70 \%$ of all persons apprehended in supermarkets in the Southwest were under the age of 30 . Serdahely's findings indicate that the largest group of offenders $(30.7 \%)$ were over 50 years of age. More recent Philadelphia data are consistent with Griffin's findings. Statistics from the Citizens Crime Commission of Philadelphia (1979) indicate that for the years 1976-1978, the majority of persons apprehended for shoplifting were in the 10-25 age range (a range of $78.0 \%$ to $79.0 \%$ for the three-year period).

The majority of empirical studies (Griffin, 1978; Shave, 1978; Cameron, 1964; Boyd and Harrell, 1975; Klemke, 1982) indicate that 
juveniles make up the single largest group of shoplifting of fenders.

Roger Griffin, for example, of Commercial Service Systems, Inc., has conducted annual surveys on shoplifting in the southwest region of the country. His work is comprised mainly of descriptive trends and statistics aimed at identifying shoplifting patterns and improving prevention strategies. In 1978, Griffin's data base consisted of 22,533 apprehensions, with $76 \%$ occurring in 709 supermarkets, $16 \%$ in 146 drug stores, and $8 \%$ in 52 discount stores. Griffin found that $70 \%$ of those apprehended in supermarkets were under 30 years of age, with $36 \%$ of these being juveniles under 18 years of age, and $9.1 \%$ being children under the age of 12 .

Shave (1978) conducted a study of 24 retail outlets in the state of Washington for the years 1972-1976 and determined that $60 \%$ of the apprehensions were for juveniles under 18 years of age. The majority of Shave's data was obtained from department and general merchandise stores. A 1980 study by French noted that teenagers are 2.5 times more likely to be caught shoplifting than are adults.

Although retail records may offer a biased picture of the offender, nonetheless, Shoplifter's Retail apprehension records support the view that most shoplifters are amateurs with no particular distinguishing characteristics other than age (N.E.P., 1980). There is a rather widespread stereotype of the shoplifter as being a juvenile, or at least youthful. So far as apprehended shoplifters go, this stereotype is correct, but it seems likely that, because of the stereotype, there are above-average levels of apprehension for this group as well. According to Klemke's research, shoplifting behavior among 
subjects in his study peaked during the pre-adolescent period and declined as the youth grew into adolescence. Although Klemke focused on non-metropolitan youths, a particular profile of the shoplifter emerges from his study. The salient characteristics of this profile are: (1) the male was slightly more active in shoplifting than the female; (2) he was generally under ten years of age; (3) the offender perceived himself as having problems with parents and school; (4) he personally internalized the label 'trouble maker'; (5) he knew significant others who were or had been involved in this behavior; $(6)$ he engaged most often in a form of behavior which was classified, generally, as the 'snitch' variety; (7) he frequently reported shoplifting as a form of behavior; and (8) most of the items shoplifted were inexpensive (under $\$ 2.00$ in value).

Klemke found that most of the adolescents who shoplifted did so sporadically. This finding was consistent with Cameron's (1964), who also found that the behavior declined as youths proceeded through adolescence.

Cameron studied shoplifters apprehended by a Chicago department store and a sample of women referred to Chicago courts for the same behavior. She found that: (1) approximately 4/5ths of the apprehended thieves were women; (2) shoplifters had a somewhat lower socio-economic status than non-shoplifters; (3) black shoplifters offended in the same porportion as their percentage of the city's population; (4) reporting practices in the stores were inconsistent; (5) there was a variance in the sentences or penalties meted out based on race; (6) known shoplifters comprised a small proportion of the thieves; (7) shoplifting 
behavior was not a by-product of neurosis, psychosis or compulsion;

(8) amateur female shoplifters stole as a way to augment their budgets;

and (9) respectable people engaged in the behavior.

Robin (1963) analyzed apprehended shoplifters from three large department stores in Philadelphia, and his findings paralleled those of Cameron. He also found that shoplifting losses attributed to adolescents were generally less than those of adults. ${ }^{1}$ At odds with Cameron's finding, Robin found approximately $50 \%$ of the shoplifters to be black, a disproportionately high ratio to the city's population of blacks. He also found that the incidence of juvenile shoplifting was greater than Cameron reported. ${ }^{2}$ His findings concurred with Cameron's on the point of juvenile shoplifting as a group activity. ${ }^{3}$ From this finding, Cameron suggested that juvenile shoplifting, as a group activity, probably led individuals to become adult shoplifters. However, Gibbons suggests that this hypothesis may be without merit (1977: 457).

The studies which have addressed the race of the shoplifter have not consistently supported the proposition that race is a predictor of shoplifting activity. Statistics from the Seattle Law and Justice Department (Shave, 1978) show that $66 \%$ of apprehended juvenile shoplifters were white and $34 \%$ were classified as 'non-white'. Astor

${ }^{1}$ Robin found that juveniles accounted for $58.1 \%$ of all known shoplifters.

2 Robin reported that the mean value of goods stolen by juveniles ranged from $\$ 6$ to $\$ 8$, compared to $\$ 14$ to $\$ 16$ by adults.

3 There are no reliable data on this issue in the U.S. studies, however Robin reported that $75 \%$ of the juveniles, compared to $23 \%$ of the adults, worked in groups, the vast majority being dyads. These individuals were aiders and abetters. 
(1970), in his observations of 1,647 shoppers, indicated that whites and non-whites stole with equal frequency. In Cameron's (1964) study of shoplifting in Chicago, blacks and whites were found to participate in shoplifting in proportion to their representation in the larger population. Robin's (1964) Philadelphia study showed an almost equal distribution of white and black shoplifters. The Shave and Griffin studies cited earlier did not present data on the racial attributes of offenders.

The majority of shoplifting studies indicated a preponderance of females among apprehended shoplifters, although female adolescent offenders are no more frequently apprehended than male adolescent offenders. The extent to which females are involved in shoplifting is interesting from the point of view that crime, in general, is a predominately male activity. Explanations of why females are more inclined to shoplift are varied and conflicting.

In a study of supermarket shoplifting, Robin (1963) concluded that 'ordinary citizens' engaged in shoplifting. In a study of Chicago supermarkets Robin (1964) found that the majority of those apprehended for shoplifting, mainly homemakers, had enough money on their person to pay for the item(s).

Cameron (1964) contended that shoplifters tend to represent a cross-section of the population in terms of socio-economic indices. She suggested that lower class youths represent a somewhat higher percentage of involvement than upper and middle class youths. The most significant deduction from Cameron's effort is the perception that 
shoplifting behavior is not solely a province of amoral or criminalistic individuals.

Gibbons (1977) suggested that neither socio-economic class nor family background appears to be significantly correlated to 'snitch' (impulse) shoplifting.

Won and Yamamoto (1968) found that the majority of shoplifters they studied in Honolulu were numerically and proportionately from the middle socio-economic class. ${ }^{4}$ Klemke (1982) found that youths with lower class backgrounds had a statistical tendency to shoplift more often than those with higher class backgrounds.

May characterized the typical British juvenile shoplifters as, ...those from the poorer class homes, dirty looking, poorly clad, of ten both parents out working, a lack of control...the raggly muffins, those poorly put on, untidy, unkept. (1978:150)

While this romantic but seemingly inaccurate Dickensonian portrayal is popular, Gibbens, et al. (1971) plotted socio-professional categories of shoplifters that showed a good fit with distribution in the general population. The deciding factor seems to be not one of genuine need but instead, one of greed at all social class levels. According to Cameron's (1964) study, most recovered shoplifted items were luxury items whose purchase could not be justified in the family budget. Small, easily concealable items are believed to be a prime target for shoplifting, regardless of price.

In a survey of Washington State grocery stores (Shave, 1978), meat, cigarettes and liquor were common targets for shoplifting, both

${ }^{4}$ Despite Won and Yamamoto's findings, there is no additional statistical suggestions to support a claim that shoplifting is a particular middle class activity. 
because of their high sale price and their high resale price on the street. Items frequently stolen from department stores include jewelry, clothing, leather goods and expensive sportswear. Drug stores suffer loss of cosmetics, records, vitamins and toys.

In a department store study (Citizens Crime Commission of Philadelphia, 1979), men's clothing was found to be the type of merchandise most commonly stolen. Theft of clothing, in general, has been steadily increasing since 1976. In 1976, clothing comprised $65.1 \%$ of all merchandise recovered in Philadelphia. The years 1977 and 1978 produced increases of $69.9 \%$ and $73.3 \%$ respectively. However, concealment of clothing may be more difficult than smaller objects and thus more readily apparent. Shoplifters of clothing and other large objects may be apprehended more frequently than shoplifters of smaller items. This selection bias would result in a distortion of estimated rates for various items.

Security personnel involved in the apprehension of shoplifters have concluded that upwards of $90 \%$ of all shoplifters have the cash or credit cards to pay for stolen items (Edwards, 1958; Weinstein, 1975). This fact, coupled with a large majority of shoplifters coming from the middle class, has been used to suggest that shoplifting may be the result of perceived deprivation of higher quality goods and services. This is also consistent with the finding that the majority of items recovered from shoplifters are not practical but added Iuxuries. Many security personnel blame the need/want tension created by advertising and merchandising campaigns of mass media as significant factors in producing shoplifting and employee theft (Astor, 1971). 
TECHNIQUES FOR COMMITTING AND PREVENTING SHOPLIFTING

Little research has been conducted to assess the impact of various retail environments on shoplifting, while much effort has gone into proper environmental design in recent years.

Evolving self-service stores are believed to be one of the greatest single factors contributing to apparent increases in shoplifting. These stores, designed to minimize the number of personnel required for maintenance and to allow shoppers easy access to merchandise for browsing, may also increase the possibility and incidence of shoplifting. Very little data is available on the most common type of retail establishments victimized. While it is generally believed that the self-service store layout is the most inviting to shoplifting behavior, large retailers in major metropolitan areas are experiencing heavy shoplifting losses. The threat of shoplifting seems to be present across a wide spectrum of retail environments.

Some comparisons on urban versus suburban chain stores have been made, but they have yielded contradictory results. In a 1978 poll of Chicago area department stores it was revealed that suburban units experienced only half the shrinkage problem that urban branches did (Chain Store Age, Sept. 1978). A U. S. News and World Report (1978) quoted a similar finding. A national survey of small businesses (Small Business Administration, 1969) reported that shoplifting losses were dispersed evenly among the non-ghetto central city, suburbs and rural areas. However, with regard to the ghettos, there were $10-11 \%$ more reported shoplifting in these areas. 
There are probably as many different methods of shoplifting as there are shoplifters. Many articles have been written describing particular methods for concealing merchandise (National Retail Merchants Association, 1976: Cobb, 1973; Faria, 1977; Shave, 1978). However, some of these methods are more popular than others. The more commonly used methods of concealment include the following:

1. Umbrellas, bags, cases and large purses of any kind.

2. Wearing the stolen clothing under the shoplifter's own outer garments.

3. Hooks and pockets inside coats.

4. Jewelry worn out of stores.

5. Using a long coat or skirt to conceal articles between the legs.

6. 'Grab and run' technique.

7. More than one shoplifter in a team effort to distract store personnel and other customers while the other steals merchandise.

8. 'Booster box': a wrapped package with an open flap to conceal stolen articles.

9. Packaged items, such as cereal, emptied to conceal smaller, more expensive items.

10. Newspapers, magazines or books used to conceal items. According to Cameron's (1964) study, most recovered shoplifted items were luxury items, whose purchase could not be justified in the family budget. Small, easily concealable items are believed to be a prime target for shoplifting, regardless of price. 
MERCHANT'S RESPONSE

Many large stores have used in-store detectives to observe and apprehend shoplifters. The application varies: some have used uniformed guards and some plainclothes detectives, some used men while others preferred women. The reported effectiveness of the security personnel varies. In his report on responses from merchants on the problem of shoplifting, Axelrod (1976) stated that the use of mixed plainclothes and uniformed security personnel is preferred as a deterrent to shoplifters.

Curtis (1969) and Kirsch (1972) claimed that the utilization of guards resulted in greater losses because other store personnel were less observant. Guards were also perceived as hostile figures who were bad for business. The literature reviewed included statements which generally concurred that increases in security personnel are essential if reduction of shoplifting is to occur.

Pinkerton's Inc. was hired to curtail severe shoplifting in a university bookstore (Neville, 1972). Although other systems of surveillance had been used, they had had poor results. The resulting inhouse detective program resulted in a significant reduction of losses. A New York department store used security 'mod squads', small groups of security personnel of all ages dressed in contemporary fashion, in an attempt to combat shoplifting (Slom, 1971). They reported over 1000 arrests in one year. Security personnel do apparently result in an increase in the apprehension of shoplifters.

Many merchants, particularly in smaller stores, do not use guards. Rather, they choose to either ignore the problem or to rely on store 
personnel to maintain security against theft (Axelrod, 1976). Linga and Keinke (1974) showed that, under experimental conditions, the presence of another person had a strong inhibiting effect on stealing behavior.

Some of the shortcomings of using employees, as pointed out by Axelrod (1976), were that: (1) it resulted in an inefficient use of employees, (2) employees usually were not properly trained, (3) merchants were often cautious in apprehending shoplifters for fear of financial risk and liability, and (4) merchants feared impaired employee morale in the event of an injury.

Some use of employees, even with other deterrents, is generally the preferred procedure. Baylen (1975) stated that the observant employee is the best deterrent to shoplifting, and LaBurtis (1975) reported studies that showed a statistically significant relationship between high shoplifting incidence and related employee shortcomings.

\section{SOCIOGENIC PERSPECTIVES}

The sociogenic perspective of delinquency is centered on two analytically distinct problems: the forms or types and the rates of delinquency in a society, and the causative explanation for the differential patterns of its occurrence by specific youths.

In order to arrive at plausible explanations, sociologists analyze first the nature of the macro-system and then the micro-relationships of youths, and how these play out in the broader society. Delinquency is then explained as the result of associations between the individuals' macro and/or micro-relationships. 
Hirschi provided a succinct and clear typology of the sociogenic perspectives utilized to explain delinquent behavior when he stated that:

Three fundamental perspectives on delinquency and deviant behavior dominate the current scene. According to strain or motivational theories, legitimate desires that conformity cannot satisfy force a person into deviance. According to control or bond theories, a person is free to commit delinquent acts because his ties to the conventional order has somehow been broken. According to cultural deviance theories, the deviant conforms to a set of standards not accepted by a larger or more powerful society. (1969:31)

Social Status

The majority of delinquency theories tends to focus upon the social system's characteristics, the formation of conduct norms, assessment of individual behavior and the sanctioning process.

Barron (1955), for example, contended that much of delinquent behavior can be explained as a clash of values in a pluralistic society, in personality, individualism, disrespect for law and order, exploitiveness and other ingredients central to the American way of life.

C. Wright, Mills pointed out some of the problems inherent in these perspectives in his book on social pathologies when he said:

An individual who does not approximate these [socially approved] standards is said to be unadjusted. If he does not concern himself with living up to them, he is said to be demoralized or disorganized. (1942:19)

Another example of this paradoxical thinking is found in the sociological literature, specifically in its handling of class. Most sociologists do not use labels such as 'immoral' or 'uncivilized' in writing about the lower class. They do, however, refer to the lower class as inadequately socialized, using such terms as 'unintegrated', 'immature', 
'pathological' and 'disorganized'. 5

To apply strain and subcultural theories ${ }^{6}$ to shoplifting behavior

${ }^{5}$ Although sociologists have a fairly good understanding of the effects of deprivation upon the lower class individual, there are criticisms by some conflict theorists of their propensity to apply subjective labels to those people. Why not describe the total society as 'pathological' if it is, indeed, necessary to use this adjective, when there is some evidence that society's pathology serves to differentiate these people and contribute to the class behavior which is of concern.

Davis, Allison and Dollard were clearly aware of the problem with subjective labels.

The most basic differences in habit formation between adjacent social classes are those between lower class and lower-middle class. The patterns of behavior in these two groups... are so widely different that it is the common fractice, even of sociologists, to speak of the lower class as 'unsocialized', from their middle class point of view. (1940:24)

The issue of the sociologist's perception of lower class people becomes a factor in the explanation of behavior only when it fails to account for the differences in social circumstances and situations that may render delinquency necessary.

6 The literature treats subculture as being a separate theoretical perspective. This phenomenon has been of interest since the works of Shaw and McKay, Thrasher and Miller. Operationally the theoretical perspective is not that clear cut. Consider: sociological theories that focus primarily on the characteristics of the social system, formation of conduct norms, assessment of individual performances and group sanctioning processes are either congruent, anomic or subcultural in perspective. Congruence theories contend that the social system is in a state of harmony or that homeostatis is achieved when there exists realistic means for achieving the prescribed success-goals. Delinquency here is the result of an unbalance in the setting. Stress and strain occur as by-products when individuals feel alienated, engaged in innovative explorations and elicit nocongruent behavior, including delinquency. Individuals confronting this disequilibrum have concerns over status, life style, values and other problems in the attempt to fit in. One postulate of 'differential opportunity' (Cloward and Ohlin, $1960)$ is: delinqueni subcultures are formed when there are great discrepancies between culturally desireable goals among lower class youths, and the limited opportunities they have of obtaining these goals through legitimate means. Cohen, a sub-cultural theorist, formulated a status deprivation hypothesis which focuses on values, beliefs, etc. to advance theory.

Conflict theories see society as a product of accommadation among continually contesting groups with opposing goals and perspectives. Force and constraint maintained by the dominant group produce a stability as a sort of moving equilibrium among changing distributions of power, wealth and status. (Johnson, 1974) 
the crucial questions become: (1) Do the adolescent subcultural values differ significantly from the cultural values? (2) Are metropolitan youths who engage in this behavior more prone to do it than nonmetropolitan youths because they have more shoplifting opportunities? (3) In the behavioral process, what effect does the metropolitan area have vis-a-vis the non-metropolitan area on the attributes (psychological, social or economic) which are deemed necessary in order to produce the 'strain' which is believed to lead to shoplifting? (4) Is one attribute, or a combination of several, more important than the others, and if not, then how do all of these attributes function to generate this particular behavior?

Merton (1938) argued that crime and deviancy result from the inability of everyone to achieve equal success; consequently, they can be structurally induced. Cloward and Ohlin (1960) revised Merton's typology which suggested the possible ways that an individual could adapt to the interface of goals and means (Merton, 1938), to focus upon the lower class youth's struggle to accumulate monetary wealth.

Social Control

The social control theories which have emerged in recent years implicitly suggest how middle class youths should behave. One of these is Hirschi's (1969) social bond theory which argued that the individuals' social bond with society is maintained through the level or degree of attachment, commitment, involvement and beliefs. ${ }^{7}$

7 According to some theorists, social and personal control is predicated on the level of bonding one has to the social order. [continued at bottom of next page] 
Hirschi (1969) believed that the social bond was comprised of four elements: attachment, commitment, involvernent and belief. Attachment could be measured, he felt, by looking at the extent of attachment to significant others. ${ }^{8}$ Commitment was perceived as the investment a youth makes in conventional behavior. Involvement is the behavioral side of commitment. Belief is a commitment to the social order, common values and rules.

Shoplifters, in Hirschi's social control schema, would be perceived as individuals whose allegiance to a belief system has not been properly developed, or has become weakened. 9 owing to this condition, these individuals feel free to behave as they choose (an opposing argument to Matza's (1957) 'techniques of neutralization' explanation for delinquency. ${ }^{10}$ In Hirschi's words,

7 cont.: Delinquency, in this schema, is either the result of a failure of the bond to tie the individual to the social order, or of its attenuation, enabling the individual to engage in delinquency (See: Toby, 1957; Briap and Piliavis, 1965; Matza, 1964).

8 Analysis of longitudinal data shows that socialization variables, e.g., lack of parental supervision, parental rejection and parent-child involvement, are among the most powerful predictors of juvenile conduct problems, delinquency and possibly shoplifting (see e.g., Loeber, 1986; Olsen, et al, 1983; Rittenhaus and Miller, 1984; T'ims and Masland, 1985; Loeger and Stoutmaner-Loeber, 1986; Kraus, 1973; Richman, Stevens and Grahan, 1982; Fischer, et al, 1984).

${ }^{9}$ Greenwood (1968) contended that stealing tends to be correlated with later delinquency. Glueck and Glueck (1930) cited poor supervision and lack of affection or family cohesion as strong predictors of delinquency. Farrington (1983) also found poor child rearing practices to be associated with delinquency.

${ }^{10}$ In an extended statement on neutralization, David Matza recognized that individuals operated on a continuum between the extremes of freedome and restraint. Although some individuals act more freely than others, they exist in relative relationship between the two extremes. Drift, Matza supposed, is a position midway between freedom and 
...many persons do not have an attitude of respect towards the rules of society; many persons feel no moral obligation to conform regardless of personal advantage. Insofar as the values and beliefs of these persons are consistent with their reelings, and there should be a tendency towards consistency, neutralization is unnecessary; it has already occurred. (1969:74)

By Hirschi's assertion, those who are inclined to shoplift do so because it is congruent with their overall attitude (See Figure 1).

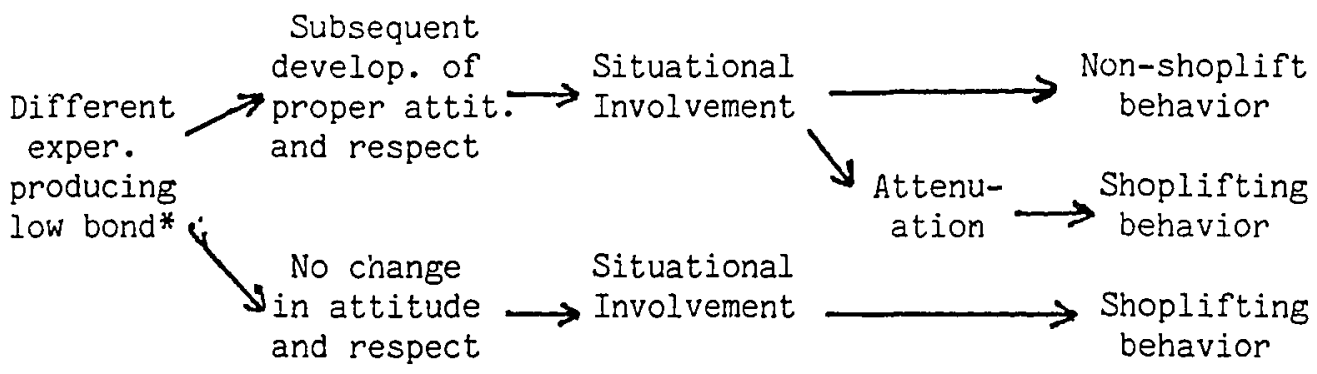

Figure 1: Bonding level, attitude and predicted behavior.

${ }^{10}$ cont.: constraints, a condition in which the individual flirts unevenly with one or the other, thereby drifting between criminal and non-conventional action.

Although drift is a normal result of neutralization, which makes delinquency possible or permissible, the result is not necessarily actual delinquency (See: Matza, 1964:27-28; Williams, 1960:20; Sykes et al, 1961: 712-719).

As a pre-offense activity, not just an excuse mustered after being caught, Taylor, et al, stated that neutralizations are "...not merely ex post facto excuses or rationalizations invented for the authorities' ears, but rather phrases which actually facilitate or motivate the commission of deviant actions by neutralizing a pre-existing normative constraint." (1973:176)

*The experiences are the result of 'lax', 'inadequate' or 'poor' supervision (See: Hirschi in Weischeit and Culbertson, 1980:160). Haskell offered a plausible explanation of how the extenuation of bonding factors could lead to socialization with peers who share similar bonding characteristics and problems (1960-61). He contended that bonding extenuation occurred when: (1) the youth applies the standards taught and experienced at school by peers to conditions at home and surmises that the family and/or the home standards differ significantly or are undewireable; (2) there is a low probability of succeeding at school; (3) there is a dysjunction between the home and school in regard to goals and motivation; (4) the youth perceives 'self' as being an economic burden; (5) he/she has a perception of inferiority among family members and seeks out a group where the perception is negated; 
The most glaring weaknesses with Hirschi's argument center around the general notion of what it is that constitutes an adolescent's perception of proper attitude and respect toward the rules of society, and whether or not commitment, attachment and beliefs designed to measure these perceptions actually constitute acceptance. Additionally, do youths perceive these 'attitudes' and 'respect' as constituting legitimate demands by the social order? More importantly, bonding theory fails to adequately account for the occurrence of delinquent behavior which cannot be attributed to the bonding level and the subsequent impact that this behavior may have on the bonding level. 12 Nevertheless, a closer examination of the shoplifting literature is needed to determine whether it is true that youths who are initially strongly bonded engage in less shoplifting behavior than those who are less bonded. A ramification of this line of thinking makes the assumption that the bond level, and therefore the behavior, remains static. Theoretically however, these could change over time as the result of

${ }^{11}$ cont.: (6) gravitation is toward others sharing similar perceptions; (7) new reference groups are formed which constitute a delinquency subculture.

While the above conditions reveal much about the parent-child relationship of lower-class youths, they particularly shed light upon the extent to which the family is capable of sanctioning behavior that is not in the direction of conformity as well as indicating the importance of the family and the school in preventing non-conforming behavior.

${ }^{12}$ Cohen (1955) depicted one of the weaknesses of using a concept like legitimate social demand in his discussion of the formation of juvenile offenders among the working class. He contended that, rather than being a group of individuals engaged in the demeaning of the social order, these youths merge together in response to their shared problems which tend to center around their low status and ability to handle the demands of the social order. In this process the demands may be perceived as never having been or no longer being relevant. 
bonding experiences, situational involvements and attitudinal changes toward bonding conditions.

Reckless (1973) contended that the individual's strong self concept and high tolerance for frustration (inner containment) and the social norms, values and effective supervision (external containment), help him or her resist temptations of internal 'pusher' (restlessness) and the external 'pulls' (the lure of deviant sub-cultures, minority status and unemployment).

There is a perception that for these lower class youths to be 'socialized', they must engage in activities that prepare them to conform to middle class standards. Critics of Cohen (1955) and Miller (1958) have questioned whether lower class youths really aspire to be middle class.

While criminologists have made detailed studies of race, ${ }^{13}$ poverty and other factors ${ }^{14}$ and their correlate to delinquency, they basically fail to explain the impact of the delinquent behavior on the individual. Most accounts depict these individuals as being in pursuit

13Blumstein and Graddy (1982) and Greenwood, et al., (1983) demonstrated that race is clearly associated with the risk of delinquency.

${ }^{14}$ Income, social class and the size of the family are deemed to be clearly related to delinquency (See: L. C. Gould, 1969:325-335; J. P. Murray, 1983:17-26). Schuster points out a problem of attempting to correlate income, social class, etc., to serious versus non-serious offenders because these terms are subject to misuse. In his study a large portion of those whose arrests were for supposed violent events, upon closer inspection, revealed that minor events occurred with little harm, i.e., hair pulling incidents and neighborhood fistfights. For other youths a rserious' arrest was for behavior which could have been more appropriately labeled truant or incorrigible (See: R. L, Schuster, 1982: $27-37)$. 
of hedonism. It seems logical to assume that individuals who commit and recommit delinquent acts derive some satisfaction from the behavior. However, this perspective makes the assumption that people are capable of making rational decisions which are akin to a cost-benefit analysis prior to acting.

Social Learning

Sutherland (1939), for many years, was the most influential theorist in United States criminology. His efforts reveal an environmental bias when examining why people learn to act in specific ways.

Differential association theory, ${ }^{15}$ a learning theory, contends that delinquent behavior is learned through association with those who have already learned and nurtured it. What is taught is not only the delinquent behavior but also the values, attitudes and skills associated with it. When a violator's behavior is altered to the extent that it results in a delinquent or criminal act, there is normally a link to

15 The theory of differential association has been sharply criticized, and Sutherland, in a 1944 paper, "The Swan Song of Differential Association", acknowledged that some of the criticisms of this theory were valid.

Without critiquing Sutherland's work, it is sufficient for my purpose here to point out Birenbaum and Sagarin's criticism of his failure to give proper weight to the role of mass media.

Although it is true that some forms of deviant behavior require a good deal of skill in order to perform the act and no be apprehended...this is not true of other forms. But even those acts requiring skill are of ten learned alone, by trial and error. Developing his theory before the television years, Sutherland underestimated the effect of the mass media as a major criminogenic force. Television never tells anyone to do anything 'wrong', but it depicts wrong, suggests it, makes known that it is taking place, shows how it is done, and offers it as an alternative to anyone watching and listening. Then it gives the arguments against that alternative... (1976:9) 
primary associations with people who share the same or similar sentiments.

... Sutherland perceived the family and/or gang as the source of learning and social behavior, including delinquent behavior. In this context, the individual learned how to define different situations as either appropriate law-abiding or law-breaking behavior. How individuals defined a particular situation depended upon how early in life the definitions of the situations were learned, the frequency of enforcement and the importance of the definition to the individuals. Shoplifting, in the concept of the theory of differential association, is one of the possible types of behavior which can result from a weak family socialization process. ${ }^{16}$ More specifically, the process points out a conflict in the youth's operating milieu due to a weakness in the functioning of the family (Figure 2). Exposure to this type of milieu is said to manifest itself in the form of the youth's inability or failure to acquire pro-social norms and to subsequently associate with similar delinquents who provide delinquent definitions. This process is believed to determine which youths are led into shoplifting behavior and/or other delinquent behavior.

$16_{\text {When operationalizing differential association, the weak family }}$ condition arises when the youth fails to acquire pro-social norms and, as a consequence, associates with other delinquents and acquires delinquent definitions. This is a process the youth undergoes prior to becoming involved in delinquent behavior (Refer to Hepburn, 1963). 


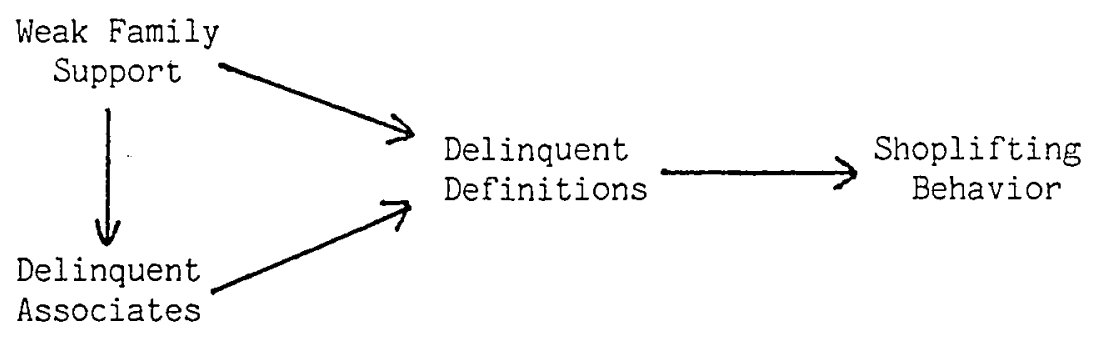

Figure 2. Differential association applied to a specific behavior.

The problems with this schema can be demonstrated by focusing on the delinquent associations and the family support elements. Gibbons states that: (1) shoplifters come from what is traditionally described as a 'conventional' family unit; and (2) insofar as peer associates are concerned, youths who engage in this type of behavior do not necessarily receive peer support or encouragement for their behavior 11977:453). In fairness to Sutherland who was silent on the issue of adolescent shoplifting, he was quite articulate on the issue that causation resides in the individual's milieu.

Conflict

Dahrendorf (1958) and Vold (1958) popularized conflict theory. However, they warned it should not be stretched too far in the attempt to explain the varying forms of criminal behavior. Vold pointed out there are situations in which criminality is a normal response by normal people struggling in normal situations, attempting to maintain an accustomed way of life. Clinard and Quinney (1967) provided a linkage between the efforts of Lemert and Dahrendorf-Vold. Despite this transition, Turk (1978) sees 'power' as the root of conflict. 
Wirth (1964) believes that people who are accused of misconduct, in a culture-conflict situation, behave in a manner which is rational and self-justified.

Our conduct, whatever it may consist of, or however it might be judged by the world at large, appears moral to us when we can get the people who we regard as significant in our social world to accept it. One of the most convincing bits of evidence for the importance of the role played by culture conflict in the cases that have come to my attention is the frequency with which delinquents, far from exhibiting a sense of guilt, make the charge of hypocrisy... (1964:28)

Wirth set forth the hypothesis that,

...the physical and psychic tensions which express themselves in attitudes and in overt conduct may be correlated with culture conflict. This hypothesis may, to be sure, not always prove fitting. (1964:43)

Merton (1938) rejected the notion that man is a bundle of impulses seeking immediate gratification, who would succeed if not controlled by or imprisoned in society. Instead, he saw considerable consensus of value among individuals, even in a conflict ridden and pluralistic society. He concluded that the attempt to bring forth a single theory to explain all instances, all people and all types of behavior, may be too ambitious.

\section{SITUATIONAL PERSPECTIVE}

The ability to predict behavior using situational stimuli is enhanced if past behavior to similar stimuli reveals a consistency with present behavior. However, behavioral congruence is only one facet of gauging situationally-induced behavior and this measure becomes less relevant if past behavior involves irrelevant information and dimensions when applied to current situational stimuli. Therefore, responses to 
previous situational facilitants may or may not be indicators of future behavior.

In order to address behavioral ambiguity or inconsistency, it becomes necessary to analyze the individual's attitudes toward the facilitants and his/her behavior, simultaneously. Analyses of this nature would ferret out the relevant information and elements, and permit the researcher to compare phenomena that are similar. The expected conclusion from this type of operation should be one of behavioral consistency .

Most personality theorists and many social psychologists agree with this perspective. However, Gergen (1968, 1971) presented a case against behavioral consistency. He argued that to expect behavioral and cognitive consistency when differing situational stimuli are encountered would be intrinsically unnatural and, moreover, this would result in limiting the range of self-defining qualities and behaviors necessary for effective social interaction. While Gergen pointed out an important problem encountered in the attempt to relate behavior to an individual's characteristics and the situation, there still exists a need to develop additional theoretical statements which would extend both Gergen's position and his empirical assessment. Gergen was silent on past and present behavioral tendencies, given the same stimuli. Perhaps he felt that there is no such thing as similar stimuli over time.

Situational analysis, ${ }^{17}$ using both the individual's stated characteristics and the situational stimuli, has not been previously

17 A number of empirical studies attest to the importance of situational forces albeit rather unsystematically (e.g., Burt, 1925;

[continued at bottom of next page] 
used as a basis for examining a theoretical explanation for adolescent shoplifting behavior. A critique of such a model, at this point is, therefore, impossible. This caveat aside, situational analysis permits the researcher to address causal explanations of behavior by permitting him to place more attention on the situational variables and less on the individual constructs. In other words, the format enables the reseacher to discern whether specific situational stimuli impact the individual's constructs, and if so, to determine whether they would be useful in examining this particular type of behavior.

The major advantage of this approach is that one is forced to rely upon the respondents' actual perceptions of their milieu rather than the researchers' perception of how the individuals do or should perceive their milieu. Hence, the bias in perception, if any, is shifted from the researcher to the subject.

Owing to the differences in phenomenological context or observational perspective, individuals may interpret situational impressions and activities differently. Nevertheless, it is assumed that individuals will reference their actions in a fashion which is consistent with past behavior. A situational stimuli paradigm, on the other hand,

17 cont.: Hartshorn and May, 1928; Farrington and Knight, 1979; Wolfgang, Figlio and Sellin, 1972; Mansfield, Bould and Namenwirth, 1974; Cohen and Felson, 1979; Walsh, 1978).

An adequate theory using situational forces must have at least two components: first, a description of the nature and distribution of shoplifting opportunities (Sparks, 1980), and second, an account of how shoplifters' decisions are affected, not merely by facts of personal history, but also by the circumstances and the attitudes to the situation. This theoretical perspective views adolescents as choosing to take advantage of naturally arising opportunities, or as deliberately creating opportunities (cf., Clark, 1982), rather than being passive actors (Taylor, Walton and Young, 1973) compelled to behave delinquently by deeply rooted causes. 
provides a perspective which enables the researcher to analyze the causal explanations individuals construct to explain their behavior as being logical and natural within the context.

Emanating from this perspective is the suggestion that individuals do not always, if ever, have control over the way they behave. Rather, they are pushed and pulled by stimuli designed to minimize their control. Although the argument of free will versus determinism is not the focus of this paper, it is mentioned to demonstrate the difficulty of operationalizing variables which inherently express values and beliefs without considering the latitude of freedom that is available to an individual to exercise them. This consideration is important when variables are used to explain behavior. ${ }^{18}$

The theorists do not speak to the issue of free will or rationality, but instead they argue that youths in general, in their

${ }^{18}$ It is acknowledged that whatever the determining factors for shoplifting, it is felt that they are tied, in some way (not totally explained), to the bonding level and the social controls that an individual experiences. If this is true, one can logically argue that social control (one by-product of bonding) subjects the individual to manipulation and a negation of free will, and that shoplifting may not be elective behavior.

Although it is acknowledged that there may be some degree of control over that which we choose to do and when we choose to comply, to have some semblance of social order, recognition of this fact predicates our level of bonding which, in turn, allows us, to a large degree, to be manipulated and molded. If compliance is not by choice, how important are the antecedent factors for analyzing delinquent or other types of behavior? Conversely, if we believe that social order has minimal impact on behavior, then causation can be traced to a single or a combination of variables. However if we argue that individual shoplifting behavior is an intentional act then qualify that intention by acknowledging that there are conditions or events over which the individual has no control, then total exculpation of the behavior is impossible. 
interactions, drift in and out of delinquent behavior, depending on the situation.

Despite this explanation, the fact remains that its use as a basis to explain shoplifting behavior leaves us wondering how this interaction works. Which situations are necessary to push youths into a position from which they feel they cannot extricate themselves? What is it about a specific situation that leads a youth to engage in shoplifting behavior rather than abstain from it?

If there exists a push-pull effect which can be attributed to the situation, then opportunity theory (Spergel, 1964; Stichcombe, 1964; Gould, 1969:716-718; or Knudsen, 1970:316-325, specifically postulate \#15: as the distance between classes narrows, forms of class delinquency and crime will become less defined) appears to be a logical place to look in an effort to determine what the situation does and does not offer from an inducement perspective.

\section{PSYCHOGENIC PERSPECTIVE}

Psychologically there appears to be no clear syndrome which would characterize the shoplifter. However, there is some agreement that certain narrow personality traits that bear directly on offenders tend to be associated with delinquent acts (Sutherland \& Cressy, 1978: 164165; Eysenck \& Eysenck, 1978:197-199). It is unclear whether such traits are descriptive of shoplifters.

The literature suggests that if behavior can be attributed to psychological traits, the offender can then use them to rationalize behavior. However, Arnold and Brungart (1983:164-165) and Tannenbaum 
(1977:15) suggest that those traits deemed to be causative factors for behavior would be more appropriate if they were conceptualized as measures and used to gauge delinquent tendencies, rather than be advanced as causes of delinquency.

Lowrey agreed with this perspective and wrote,

...despite extensive research and many ingenious efforts to delimit them, there are no such entities as 'delinquent' or 'criminal' personalities. To be sure, there are delinquents and criminals and, naturally, each has a personality, normal or abnormal... (Lowrey, 1944:794).

Despite Lowrey's protestation, research continues to attempt to determine if there are specific characteristics that predispose certain individuals to delinquency. It is imperative that these studies be evaluated to discern their possible contribution toward the explanation of shoplifting behavior.

Abrahamsen described the psychological state of delinquent as follows:

...many of them are neurotic, suffer from phobias, show compulsive behavior patterns, or appear to be rigid in their behavior. Some are mentally defective; some show signs of the beginning of a psychosis; others may show vague symptoms of a character disorder. All of them, however, are emotionally underdeveloped (1960:61).

While the validity of Abrahamsen's assessment may be questionable, the salient point here is that we can deduce, among the combination of factors which are deemed to be responsible for the creation and playing out of delinquent behavior, that the psychological ones are considered by some social scientists to be important. These psychological factors can be characterized as existing within the individual, yet displayed in the individual's personal social environment. How the psychological and sociological factors interact provides a basis for suggesting how an 
individual would or should react to specific situational stimuli.

Some literature suggests that shoplifting is performed by proportionately more women than other crime. ${ }^{19}$ It has come to be considered the female offense. The involvement of women in most crimes has been explained by recourse to personal maladjustment rather than to social circumstance. When the number of women involved increased, the crime itself took on the trappings of feminity; it became a crime requiring psychoanalytic interpretation.

Gibbens, et al, (1971) reported that, of the 886 women shoplifters they followed up ten years after their initial offence, only $8.4 \%$ were institutionalized for mental health reasons. ${ }^{20}$

Perhaps the reasons why women have received clinical scrutiny for their criminal behavior stems from traditional misconceptions about women and men. Women are statistically under-represented in crime figures; this fact alone may augment the assumption that female crimes require explanations different from those which account for male crime. The rationale here is that because so few women commit crimes, those who do must be disturbed. The traditional view is that it is 'normal' for a certain percentage of men to engage in crime as a natural extention of their 'aggressiveness' and 'competitiveness'. It is traditionally

${ }^{19}$ In 1978 in the United Kingdon, $55.7 \%$ of all females of guilt were shoplifters. The statistics reveal that more and more women are being found guilty of shoplifting. Unfortunately U. S. statistics do not give a breakdown of crime as sensitive asthose available in the U. K. However, Simon (1975) noted that in $20 \%$ of all females arrested, larceny and theft ranked highest. (See Knudten, 1970:240; Eysenck, 1964:689; Hall \& Lindzey, 1960:457; Trasler, 1962:71, 74)

${ }^{20}$ Comparable figures are unavailable for women previously involved in violence, prostitution, etc., but if they were, it is doubtful if the proportion of mentally ill would be any higher. 
considered abnormal for a woman, due to her reputed 'passive' and 'cooperative nature', to engage in these antisocial impulses. Therefore sex-role appropriateness is used to provide 'special' explanations. Perhaps, by treating criminal women as 'sick', society can write off serious statements about increasing dissatisfaction with position and Iifestyle among women, and the consequential increase in their crime rate.

These stereotypical and subjective views of a woman's personality and character render her fair game for psychiatric scrutiny, despite evidence of psychological well being to the contrary. Psychologically, women are seen to be more excitable, more emotional and more submissive. Thus, even healthy women fit more easily with the mental illness model than do men.

A historical analysis of the clinical interpretations of shoplifters tends to parallel general fashions and movements in psychiatry. 21 Throughout the last 100 years the motivational base appears to have shifted in line with current thought about the nature of mental illness. However, these theories are not derived from broad empirical studies, but from clinicians' experiences in the treatment and interpretation of particular cases. Whether we can generalize from such cases is open to speculation.

While it is generally felt that most shoplifters do not suffer from serious emotional or interpersonal problems, they are thought by

${ }^{21}$ For a review example of shoplifting and mental illness see: Gibbens, T.C.N., C. Palmer and J. Prince 1971. "Mental Health Aspects of shoplifting", British Medical Journal, Vol. 3: 612-615; and Campbe11, Ann 1981. Girl Delinquents, New York: St. Martin Press. 
some to be economically disadvantaged (Yates, 1986). Therefore the primary motivation for the less serious form, petty shoplifting, might be for personal gain.

Other writers (e.g., Arboleda-Foreq, Durie and Costello, 1977; Cupchik and Atcheson, 1984; Meyers, 1970; Ray, Solomen, Doncaster and Mellina, 1983) have demonstrated that there are other motivating factors in addition: to personal gain. These factors ranged from being a release valve for stress or dissatisfaction to being delusional or psychotic (Arboleda-Floreq, et al, 1977). Moore (1984) identified five distinct motivational patterns. Beck and McIntyre (1977) reported that the college age 'chronic' shoplifters they studied exhibited delinquency-prone personalities. Patterson (1980) contended that stealing constitutes short-term behavior payoff which can be characterized as getting one's 'kicks' or a sense of excitement.

Historically the concept of kleptomania developed from behavior observed in the 19th century. Pinel and Esquirol formulated the concept of an 'instinctive impulse' and they described the 'instinctive monomanias' (Gibbens and Prince, 1962:68). The original monomanias were alcoholism, firesetting and homicide (Kaplan, et al., 1980:821). Kleptomania was added to these by Mathey, and Marc (1838). Bizarre, worthless thefts by the rich and higher social class (including Victor the King of Sardinia and Henry IV of France) were described and were thought to be the result of mental illness (Arieff and Bowie, 1947:565). Shoplifting and kleptomania are associated although kleptomania is rarely seen (Gibbons, 1962:68). Previous studies have also examined the association between shoplifting and obsessive-compulsive illness 
(Gibbens and Prince, 1971:612-614; Medlicott, 1968:183-188; Russell, 1973:77-79). Phobias of a compulsion to shoplift have been described in middle-aged women (Gibbens, 1962:68).

Shoplifting has also been linked to aberrant sexual behavior as part of a fetishism syndrome. Psychoanalytic interpretations of motivation and the symbolism of the objects stolen have concluded that shoplifting and sexuality may be associated. Steckel (1911) described kleptomania as 'an ungratified sexual instinct' and also described an association between kleptomania and homosexuality. Fenichel (1945) described a woman who obtained overt sexual pleasure mainly through masturbation to fantasies of shoplifting; sexual frustration has been described as a factor in some female shoplifters (Gibbens, 1962:68).

Revenge, hypoglycemia, amnesia, and 'absent-mindedness' have all been described in association with shoplifting (Cunningham, 1975:101106). Previous studies indicate that adult shoplifters are mainly women, and a large percentage are middle-aged, middle-class and perimenopausal (Russell., 1973:77-79). Depression is described as the most common psychiatric disorder seen in shoplifters (Medlicott, 1968:183188).

Robin (1963) contended that adolescents who succumb to snitching are experiencing either psychological aberrations of some sort (i.e., neurosis), or some type of compulsion. He based the compulsion thesis on the marked increase in shoplifting frequency he observed occurring during the last three months of the calendar year. Robin presented an unintended specious case for the correlation of psychological maladies and shoplifting. He demonstrated that the frequency of occurrences is 
more prevalent in the last quarter of the calendar years. Owing to this frequency, he contended that the behavior could be attributed to some type of compulsion or an increase in detection. However, alternative reasons may account for this frequency, other than psychological aberrations.

The results of a study this author conducted for a youth service center in 1985 on 200 youths referred for shoplifting offences revealed that the highest reported frequency was for May and June (see Appendix II). While plausible explanations for these results can be offered, psychological aberration or compulsion would not be among them. If these two psychological manifestations were not spuriously related to shoplifting, or not more than serendipitous finding, then the pattern of shoplifting frequency would be more uniform over the calendar year. Aichhorn best summarized the psychogenic perspective when he stated that, "There must be something in the child himself which the environment brings out in the form of delinquency." (1955:15) Although it is difficult to substantiate a claim that delinquents are pathologically maladjusted, his second assumption regarding the function of environment and its role in the causation of delinquency deserves additional analysis.

A general criticism of the psychoanalytic theories has been advanced by Gibbons, who wrote:

...psychoanalytic theories involve contentions about the workings of instinctual sources of empirical verification. These instinctual main-springs of lawbreaking are said to be unconscious ones that the offenders are unaware of. Only a trained psychoanalyst is qualified to investigate these motivational forces, therefore other observers are unable to see them in operation. Second, psychoanalytic arguments about lawbreaking are relatively unfashionable at present. (1976:75) 
Psychoanalysis contains a set of vital insights about delinquents and criminal development which is: (1) moral conduct or delinquency is organically related to the structure of an individual's personality; (2) a person's moral posture is linked to the kind of relationship with his/her parents; (3) a person's moral posture is largely unconscious; and (4) adult personality is partly shaped by childhood experiences.

A review of the literature suggests that criticisms of psychoanalytic theories may be without foundation. ${ }^{22}$ For example, criminologists tend to criticize the past attempts of psychoanalysts to single out one fundamental motive in human behavior (i.e., psychic engergy). ${ }^{23}$

22 Abrahamson (1960:24) contended that all elements which bring about crime are specific or vague strains and stresses in the person, in the situation, or in both, eliciting certain reactions which may lead to criminal or delinquent acts.

Sheldon and E. Glueck $(1950: 239)$ found that $51.4 \%$ of the delinquents and $44.3 \%$ of the non-delinquents were mentally abnormal. However, Healy and Bronner (1936:22), when comparing a small group of delinquents with their non-delinquent siblings, found that $91 \%$ of the delinquents and $13 \%$ of the non-delinquents had emotional disturbances.

It is possible to acknowledge the existence of individual personality differences and still attribute major and primary causal significance for behavior to social context and situations. The fact that people react differently to situational stimuli does not mean that the situation is not causing the behavior (Abrahamson, 1960). External pressure may affect people differently, just as internal chemical agents do. Abrahamson says that:

...the main characteristic of the juvenile delinquent is that he acts out... is unable to...postpone immediate gratification... Consequently any pressure from his environment makes him feel anxious... he gains relief by acting out his impluses. (1960:61)

${ }^{23}$ The term 'psychic energy' owes its genesis to St. Paul whose triune of man exceded Jesus' dualistic demarcation between flesh and spirit. In St. Paul's triune, "spirit' (pneuma) was regarded as a divinely inspired life principle, 'soul' (psyche) as man's life in which 'spirit' manifests itself, and 'body' (soma) as the physical mechanism animated by 'soul'. (For additional information, see the works of Lock, Descartes, Leibniz, Aristotle, Hobbes and Humes.) 
This criticism, which focuses on the gaping lacunae in the Ereudian explanation of behavior, was also recognized by Freud. The most obvious gap lies in Freud's inability to explain pathological behavior, since the dynamic explanations intricately linked to this behavior also explain normal behavior, and therefore cannot be used to explain pathological behavior.

These dynamic explanations are what philosophers called 'necessary but not sufficient cause'. For example, rapists and male seducers may be explained in terms of narcissistic needs to gain control, to transcend the Oedipal complex and to gain their father's approval. Motivationally, the objectives may be similar, but the behavior is quite different. Seduction, after all, is still a respectable social activity used to gain pleasure and gratification; whereas subduing someone for sexual pleasure and gratification is not considered to be socially acceptable behavior.

The second lacunae in the Freudian theory is just as problematic as the first because it fails to resolve the problem of why, given certain conflicts from the past, some individuals resolve the conflict by hysterical solution, and others by obsessive resolution. In other words, one solution is confined to the real world (neurosis) while the other abandons reality (psychosis).

Despite these two misgivings, Freud clearly articulated that behavior was motivated and purposeful in that it always moved toward a goal. Because it was purposeful, it lacked randomness, and therefore each action could be explained in terms of some anticipation or desire. Behavioral actions, he contended, could not be understood as phenomena 
in themselves, but rather as actions in a continuum or sequence of events from the past which are leading to a specific future goal.

In this sense, individuals are unaware of the determinants of their behavior because they are determined in the 'unconscious' sphere of the mind. It is not necessary to elaborate on the distinctions of the spheres here except to say that the theory suggests that we are just as likely to respond to situational stimuli for unconscious reasons as we are for conscious reasons.

When we combine the concept of unconscious determinants, the dynamic nature of behavior and the developmental principles, the paradigm which emerges is one of psychic determinism, ${ }^{24}$ forces and counterforces (e.g., reason and cognition) that shield us against the onslaught of passions. This shield is crucial because, to Freud, we are all, in our unconscious minds, pilfers, rapists, incestuals, exhibitionists, voyeurs -- we are all aggressive and homicidal. Therefore, the difference between the criminal and the average citizen is not found in the impulses, but rather in the impulse-control mechanisms.

Establishing a causal relationship between a criminal act and a mental disorder would be equivalent to attempting to psychoanlytically connect acute heartburn to shoplifting. ${ }^{25}$ Whether physical anomalities lead to character defects and subsequent delinquent behavior is

${ }^{24}$ If each piece of behavior is causally related to the past, if one does $Y$ because of an $X(X 1+X 2+X 3$ ad infinitum $)$ that preceded it, and if one is going to explain $Y$ on the basis of $X$, then one is forced to conclude that behavior is determined.

${ }^{25}$ In the Diagnostic and Statistical Manual of Mental Disorder, of the American Psychiatric Association, heartburn is listed as an example of mental. disorder 006-580 Psychological gastrointestinal reaction in DSM1. 
difficult to answer. However, it is clear that the character disorder concept can lead to legal irrationalities because it is the antisocial behavior that an individual exhibits that defines the type and extent of mental illness. 26 Strangely, psychiatrists collectively have never successfully defined mental illness. Their professional opinions range from the assumption that all individuals suffer from mental illness to some degree, to the perception that mental illness is a myth.

Neverthless, psychogenic arguments for delinquent behavior are based on a perceived response by the individual to some kind of strain that exists within the individual. This strain is best conceptualized as the by-product of some type of personality problem, immaturity, and/or mental conflict. Psychologically, it is contended that stress (strain), the by-product of the conflict, is a form of psychic energy which can be both measured and demonstrated to show its positive and/or deleterious effect on behavior.

Cohen stated that, "It is instead becoming increasingly clear that it is the meaning of a potential stressor...that best predict human response."(1980:75) Simmel (1903) also pointed out that a psychic load is both measurable and manageable. The point is some critics of the psychogenic orientation perceive psychic energy solely as an internal attribute whose effect is too difficult to trace in a social situation. Jeffery (1959), a former student of Sutherland, formulated a criminal behavior and learning theory. His 'social alienation' theory

26 The Model Penal Code of the American Law Institute has a section dealing with criminal responsibility, and it states, "The term 'mental illness or defect' does not include an abnormality manifested only by repeated criminal or otherwise antisocial behavior." In 1962 the Code approved attempts to serve as a guide for insanity tests. 
attempted to explain crime by using a three dimensional approach that included the legal, sociological and psychological schools of thought. Jeffery's theory failed to explain how juveniles can become delinquent when they had no prior contacts with delinquent behavior patterns.

The theory of social alienation is in agreement with the current trends of psychological thinking because the difference between criminal and non-criminal behavior can be gauged in terms of personality factors which are expressed in some form of anti-social behavior. Social alienation theory places emphasis on the feeling of rejection, emotional starvation, feelings of insecurity, psychological isolation, hostility and so forth (Cressy, 1969:533-552).27

If we make the assumption that there is too much 'psychologism' in contemporary society, then are we not guilty of relying too much on the bias inherent in our own favored research perspective? Despite the apparent shortcomings of the psychogenic paradigm, psychological theory currently is at a level that would leave one somewhat perplexed if one were to ignore its potential as a useful aid in making some assumptions about human behavior.

One result of this failure would be to provide us with a presupposed view of man through the sole use of sociological theorizing, which would tend to over-stress the stability and integration of society. This would also augment a perception of the individual as being disembodied, conscience-driven, and a status-seeking phantom. If we are to reject the psychogenic hypotheses on the basis of them not

27 For more psychogenic insights see: Burgess, 1966:128-147; D. Glaser, 1956:490; J. Burchard, 1971; L. R. Adams, 1973:458-470; D. Abrahamsen, 1960; H. J. Eysenck, 1960 and 1964. 
being testable to our satisfaction, then perhaps an argument could be advanced that, in scientific fairness, the same criteria should be applied to differential association, sub-culture, strain and cultural transmission theories. 
SUMMARY

F. B. I. statistics and various studies indicate that shoplifting is a serious social and legal problem in the U. S. The most common adolescent form of shoplifting, amateur theft, seems to constitute a large part of the problem, with many motivational factors involved. The literature indicates that there are numerous causative factors for the behavior. There is also a developing body of literature that places the onus on environmental and situational factors.

The amateur (impulse) shoplifter is distinguished from other types on the basis of psychological factors, progessional motivation and forms of deprivation. The literature also makes a distinction between these types of offenders and those who are alcoholics, vagrants and drug addicts, who appear to have different motivational patterns. Shoplifting can begin early in an individual's life, but may be temporary, ceasing before late adolescence or adulthood. One study indicated that the largest number of offenders is 50 years of age and older. Another indicated that youths were 2.5 times more likely to be apprehended for the behavior than other groups of offenders. Various studies by Cameron concluded that $4 / 5$ ths of apprehended shoplifters were women, and shoplifters represented a cross section of the population in terms of socio-economic indices. Won and Yamamoto reported that the majority of shoplifters in their study were disportionately from the middle class. Klemke contended that youths with lower socio-economic backgrounds showed a greater dstatistical propensity to shoplift.

The sociological literature generally suggests that a differentiation in bonding patterns, opportunity, differential association and 
differential learning accounts for delinquent behavior. Therefore, factors, e.g., age, race, socio-economic status, peer influence, parental association, etc., are deemed to be important. There is also a body of sociological and psychological literature which discusses the situation and its stimuli as contributing factors in delinquent behavior.

Psychoanalysis and the psychogenic perspectives contain a number of vital insights about delinquent and criminal behavior. Personality pathologies, psychological maladaptations, e.g., kleptomania, and the role of the environment point to causation residing within the individual. 
CHAPTER III

THE RESEARCH DESIGN

The preceding chapters discussed shoplifting theory and the relevant research regarding shoplifting. It was noted that shoplifting, like many other forms of delinquent behavior, is seen by some theorists to result from social learning or defects in social bonding.

RESEARCH QUESTIONS

The following three questions were formulated:

1. To what extent do such traditional bonding and social variables explain impulse (snitch) shoplifting by adolescents? It was necessary to expand upon this general question.

Hirschi identified four major bonding elements: attachment, commitment, involvement and belief. From these elements the following secondary questions were formulated to test the explanatory power of traditional bonding variables:

1a. Will those adolescents who interact well (strong attachment) with their parents shoplift less than those who interact poorly (weak attachment)?

1b. Will those adolescents who have a strong commitment to relevant, pro-social values s!oplift less than those who have weak commitment?

1c. Will those adolescents who are actively involved in 
scholastic activities shoplift less than those who are not actively involved?

1d. Will those adolescents who believe in the legitimacy of the social order shoplift less than those who do not believe?

Since the social system and order are products of human action, they are subject to continual pressure to transform. Transformation is dependent on the structure and the restructuring of response to the social system. This restructuring is generally the result of interaction with a milieu perceived to be 'defective' to the individual in some fashion. Defects in the milieu are customarily measured by the perception of deprivation experienced by the adolescents and their access to people who can teach them anti-social behavior. Youths who are not subjected to this deprivation experience are expected to engage in shoplifting less frequently. Therefore:

1e. Will those adolescents who do not experience conditions of deprivation shoplift less than those who do experience such conditions?

The literature contains many references to companionship as an important factor in explaining many forms of delinquent behavior. Therefore:

1f. Will those adolescents who do not have delinquent companions shoplift less than those who do have such companions?

Economists have argued that crime is rational in the sense that it provides both psychic satisfaction and material rewards with minimal 
effort, compared with the conventional methods of acquisition.

Therefore:

1g. Will adolescents who do not experience economic need shoplift less than those who do experience such need?

2. To what extent does the attitude influence subsequent behavior, or behavior which is inconsistent with the bonding level?

3. To what extent do situational forces predict attitudes which are inconsistent with bonding level?

\section{DATA COLLECTION}

Because there is some concern regarding the quality of the data collected in past analytical and descriptive studies of shoplifting, a departure from previous methods was deemed necessary. In contrast to store collected and/or police accumulated data, it was felt that a selfreport would improve the accuracy of obtained data. This method of sampling was popularized by Nye and Short. (Nye and Short, 1957; Short and Nye, 1957) This data collection technique has been utilized to expand the understanding of delinquency (Dentler and Monroe, 1961; Hirschi, 1969; Gold, 1970; Williams and Gold, 1972). The use of selfreports minimizes the chance of making errors, in regard to the actual occurrence of shoplifting behavior, which appear to be endemic in store collected and official records.

The superiority of the self-report technique is due to: (1) its ability to gauge the occurrence of behavior rather than putting a reliance on the small porportion of shoplifters who get caught; (2) its ability to systematically gather data about the offenders regardless of 
whether they were apprehended or not; and (3) its ability to analyze comparative data on non-offenders.

Although Hood and Sparks (1970:46-70) and Nettler (1974:73-97)

were critical of the self-report technique, Hardt and Hardt (1977) found a high level of validity in the data collected through this technique. Taking into account the arguments, both pro and con, it was felt that the method was the most appropriate for this research.

Operationalizing Variables

The relationship of nine independent variables to the dependent variable -- shoplifting -- was examined. The operational definitions of the independent variables were:

1. Education: The youths' perception of their performance, teachers' personal evaluation of them, level of participation and attendance. This variable, and others so indicated, is measured and operationalized using the respondents' scaled values ranging from 1 through 7 :

2. Parental Relationship: This relationship is drawn from the adolescent's perception and will be measured in the realms of frequency, closeness and confiding. (Likert Scale values from 1 through 7 are used.)

3. Delinquent Peer Association: Respondents who answer affirmatively to having siblings and/or close friend(s) who have engaged in shoplifting. These cohorts will serve as 'significant others' (Likerttype scale, $1-7)$. 
4. Sex: 1 = male, 0 = female. Operationalized as a dummy variable.

5. Race: 1 = white, 0 = black. Operationalized as a dummy variable.

6. Age: Youths between 13 and 17 years of age. Operationalized as a dummy variable.

7. Situational Stimuli: The adolescents' perception of selected stores, and their perception of how the stipulated stimuli contribute to or negate shoplifting behavior. (Likert-type responses)

8. Need: Reported gross family income, access to economic resources, utilization of those resources, the youths' perception of their social class. (Likert Scale) Deprivation is a relative or subjective individual perception which will be captured by the respondents' responses to scaled items.

9. Attitude: The respondents' response to the stipulated situational stimuli.

10. Shoplifting: Assessed through the individual's responses to 'Have you ever...' items.

\section{Questionnaire Construction}

Attitudes are more easily measured than defined. When social psychologists refer to attitude, they are generally talking about the affect or a preparedness to respond toward a social object or phenomenon.

It is also agreed that attitude involves an evaluation component: for or against, accept or reject, pro or con. Techniques meant to 
measure attitudes generally require an individual to respond in a positive or negative manner to a social object (Guttman, 1944:139-150).

It is not necessary to agree about the definition of attitude in order to measure attitudes. If one wishes to argue that something that has been measured is a property of an attitude, and another person wishes to argue that it is not, they may do so without, in any way, affecting the measurement process or the validity of the resulting measurement scale (Davies, 1972:16).

The questionnaire construction was formulated from the shoplifting, sociological and psychological literature. It was pretested on fifty Sherwood Intermediate and High School students and fifty Portland area youths for item clarity. It was also critiqued by the high school principal and five faculty members from the Sherwood School District, and ten colleagues in the P.S.U. doctoral program.

The questionnaire was structured to obtain adolescents' attitudes toward the explicated causal factors from the literature, those suggested by Klemke and the situational stimuli. These causal factors are:

\section{Need: Shoplifting is a method of acquiring items of monetary} value. Therefore, the economic dimension of the offense must be analyzed. The indicators in the self-report survey are: (1) estimated financial familial well being, [Questions 15, 16, 19, 26, 27, 28]; (2) the youth's independent, not familial well being, [Questions 3, 28, 30]; (3) the youth's individual evaluation of the availability of money for personal extras [Questions 15, 16, 19, 20, 26, 27]; and (4) individual expression(s) of economic motivation for shoplifting. [Questions 
$15,16,19,26,27,28,41,45]$.

Although there are scales to measure economic well-being (e.g., Hollingshead, 1975), these were not used because they fail to take into account the differential living arrangements and the propensity to classify the youths' economic status as a function of the fathers' occupation. These scales also fail to gauge the relative deprivation that youths may perceive which may or may not correspond with their fathers' occupations and/or incomes. Although occupations at the top end of these scales may still intimate economic well-being, there is a question, at least for workers in the Northwest, as to whether these wage earning employees are truly representative of the scale items. There is currently some disparity between job title and earnings. This disparity can be attributed to changes in unionization benefits, titled, lowpaying positions in the service industries, and some low-paying, hightech positions. In order to sidestep this problem I will operationalize the youths' perceptions of their economic well-being which will provide the better gauge of the family's economic status and the adolescent's attitudes toward that condition.

Sex: Sex is understood to be the distinction between the male and female gender. [Question 2]

Race: Majority (white), minority (black). One question was built into the questionnaire to capture these data. [Question 21]

Education: There is an accumulation of research which suggests that school experience may be the most crucial variable underlying the propensity toward delinquency; that lower class males experience more status frustration and, as a result, turn to delinquency due to the 
inability to resolve this frustration. 28

Six questions $[11,12,42,62,63,71]$ were built into the selfreport survey to gauge the youths' school performance. These questions capture some of the dimensions of labeling and the youths' attitude toward it. The questions address the youths' perceived performance and attitudes.

Parental Relationships: Psychiatric and psychogenic research has stressed the importance of the quality of the youths, parental relationship as a factor in delinquency. ${ }^{29}$ Seven questions were used to gauge how the youths' perceived their relationship or affective ties to

parents. [Questions 3, 33, 66, 67, 68, 72, 73]

Delinquent Peer Socialization: Although the reasons vary, juveniles are more likely to shoplift with a friend than are adults (Robin, 1963; Cameron, 1964). Whether these 'close friends' were prior delinquents, served as 'significant others', or acted as the instigator for the behavior is open to question. 30

28 Kelly and Balch, 1971; Polk and Schafer, 1972; Frease, 1973; Kelly and Pink, 1973a; Kelly and Pink, 1973b; Polk, et al., 1974. Cohen emphasized school problems in his status frustration theory.

29 Nye (1958), Hirschi (1973) and Hindelang (1973) see the family as being the youth' 'major source of attachment to the legitimate social order. However, Wilkinson (1974) claims that parental relationship is a subjective ideological trend and should be carefully utilized when attempting to understand its relationship to delinquency. Linden and Hackler (1973) expounded the importance of family ties and their value for predicting delinquency.

${ }^{30}$ Sutherland, Hirschi and Linden, and Hackler stressed the importance of analyzing delinquency from a perspective of peer influence. Linden and Hackler (1973) distinguished between youths who had close ties to conventional peers and those who had close ties to deviant peers. However, they failed to acknowledge that shoplifting also occurs among members of the conventional group. 
To gauge the relationship between peers and shoplifting, four questions were included in the self-report survey. $[13,14,65,69]$ Bonding: Questions 49, 50, 62, 63, 66, 67 and 71 were used to gauge the duration, intensity, attachment commitment, involvement and belief that youths state for their bonding level.

Attitudes: Questions $30,31,32,41,44,48,51,52$, and 54 are asked to assess the respondents' general attitude toward shoplifting. It is felt that those adolescents possessing pro-shoplifting attitudes would engage in the behavior more frequently than those who do not share the same attitude.

Situational Stimuli: Whether shoplifting is a result of these kinds of stimuli is an open question. 31 Questions $54,55,56,57,75$ and 76 gauged this.

Attitude toward the Situational Stimuli: Questions 53, 54, 55, 56 and 57 gauged the respondents' attitude toward the situational stimuli used to minimize shoplifting activity.

Age: 13-17. [Questions 1, 22]

\section{Population}

The questionnaire was administered to 312 adolescents between the ages of 13-17, obtained from two sources: (1) neighborhood youth service centers and (2) shopping malls selected on both a random and stratified basis from a total of 1500 (See Appendix I).

${ }^{31}$ Kryter (1970) and Miller (1974) suggested that unwanted stimuli can have a deleterious effect on behavior. Siligman (1975) argued that continual exposure to stimuli, which one can do nothing about, results in a psychological state of helplessness, a state which includes a lessening in one's perception of control over outcomes. 
To insure that the YSC sample was not comprised primarily of known shoplifters, intake staff were interviewed about the nature of the youths' referrals, and case files were examined to cross-check information.

The average weekly intake was 30 , from which seven questionnaires were collected every 10 calendar days in order to maximize confidentiality and to minimize matching. Sampling was conducted over a one year period (1986). Based on this procedure, 79 questionnaires were deleted for behavioral claims which could not be substantiated generally by the type of offenses reported in the sampling cycle, netting 312 adolescents. The reported frequency for this period was compared to those reported in 1984 and 1985 to see if there was a significant difference. This analysis revealed no significant difference in the referrals. $65 \%$ of the 209 youths referred to the Youth Service Centers for shoplifting $(N=135)$ were added to the $N=38(58.5 \%)$ of the youths sampled at the malls, who admitted to shoplifting, to comprise one segment of the population. The remaining segment (139 or $44.5 \%$ ) of the population was selected from those youths who received services for reasons other than diversion (see Appendix III). 32

In order to maintain uniformity in gauging the type and strength of the situational stimuli elements it was necessary to limit analysis

32 This group was comprised of 112 youths who visited the Service Center for reasons other than referral for shoplifting, and the additional 27 youths sampled at the malls. This population segment was used to determine if there were differences in their perception regarding the traditional variables, their attitudes toward them and their attitudes toward the situational stimuli. 
to the shopping malls in the Greater Portland area. These malls were easily accessible to the adolescents. ${ }^{33}$

One of the sites missing from this analysis is the downtown core area. There are three reasons for its exclusion. Of the 401 referrals (official police reports) only five were for complaints from this core area. Furthermore, based on the prior study for one of the service centers, youths in this age group generally refrained from frequenting the core area except to go to Pioneer Square Park, Goochies (a teen dance hall) or to dine. These visits were primarily after 9 p.m. when the department stores were closed.

Malls and stores were selected for spatial accessibility.

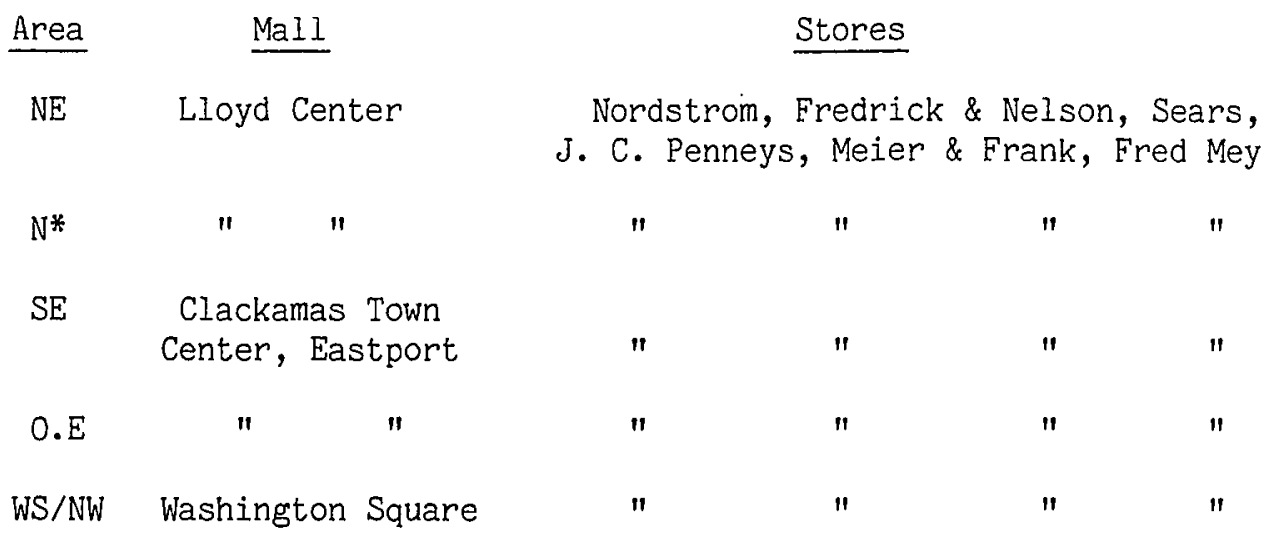

Figure 3. Units used for analysis.

*The distance to this site was greater for these adolescents than the nearest site for the other youths.

$33_{\text {While it is acknowledged that adolescents steal at sites other }}$ than those located in malls, standardization of the units is imperative. The reader should be aware that the situational and stimuli are vastly different when you consider sites, e.g., Payless, Coast-to-Coast, 7-11, Plaid Pantry and Ma-Pa operations. To further compound the problem, these units are not spatially arranged so that they are accessible to the target population. 
DATA ANALYSIS

Partialing of variables to develop measurement instruments

Partialing the effects of the independent variables enabled assessment of the effects of each variable independently. This procedure was accomplished by adducing and grouping the dimensions of the variables from the $S-R$. Owing to the $S-R$ items, some commonalities among the dimensions were evident. Once the dimensions were grouped, a regression analysis was run on the elements to determine their statistical properties. Those with a + value of less than 1.67 (.05 Level of Significance) were dropped from further consideration. Those statistically significant elements were grouped to comprise an instrumental variable for further analysis.

1. Bonding: The basic tenet of bonding theory asserts that youths acquire skills and values through primary group interactions which are important in their interpersonal relations and attitudes. These skills and values are also deemed to be necessary for the maintenance of the social order. In this research the differential bonding levels were construed to be additive of sub-elements (e.g., attachment, commitment, involvement and belief).

The elements for bonding contained in the questionnaire were generally equivalent to those used in the sociology literature. Bonding was initially operationalized using surrogate indicators. For example, $B=f[X 49, X 50, X 62, X 63, X 66, X 67, X 71]$ where: $[X 49]=$ school (involvement $) ;[X 50]=$ teachers $($ attachment $) ;[X 62]=$ personal school reputation (belief); $[X 63]$ = relationship toward the school reputation (belief); 
$[X 66]=$ relationship with parents (attachment); $[X 67]=$ values in common' with parents (commitment); $[X 71]=$ effort at school (commitment) (see Appendix).

A multiple linear regression was used to reduce these indicators to an instrument which captured the elements of the variable bonding. This bonding was expressed as being $v 66=f(49,50,62,63,67,71)$ (see Appendix III, Self-Reporting Questionnaire, question 非6). The bonding variable, $\mathrm{V} 66$, is a surrogate used to assess the youths' relationship with primary socialization agencies, the school and parents. Because the family is generally the normative reference group in which sustenance, recognition, approval and appreciation are received by an individual, it is felt that within this context the primary learning of attitudes and behaviors occur which directs the individual to conform with popular consensus.

There is a perception that the extenuation of bonding factors could lead to socialization with peers who share similar bonding characteristics and problems. Haskell contended that bonding extenuation occured when: (1) the youth applies the standards taught and experienced at school and by peers to those conditions at home and surmises that the family and/or home standards differ significantly or are undesireable; (2) there is a low probability of succeeding at school; (3) there is a dysjunction between the home and school in regard to goals and motivation; (4) the youth perceives 'self'' as being an economic burden; (5) he/she has a perception of inferiority among family members and seeks out a group where the perception is negated; (6) gravitation is toward others sharing similar perceptions; (7) new reference 
grouts are formed which constitutes a delinquent subculture. 34

While the above conditions reveal much about the parent-child relationship of lower class youth, they particularly shed light upon the extent to which the family is capable of sanctioning behavior that is not in the direction of conformity as well as indicating the importance of the family and the school in preventing non-conforming behavior.

2. Peer Association: A basic 'truism' in the sociological literature regarding delinquents is that delinquency is essentially group behavior. 35 Although it is not explicitly stated in the delinquency theories, (e.g., the differential association hypothesis) there is a belief that the close friends of the delinquent are most often delinquents possessing similar attitudes, values and behavior.

To demonstrate that these close friends are also delinquents does not necessarily imply anything of substance regarding effect on behavior as a consequence of the relationship. In this research no attempt was made to ascertain the intensity of peer relationships or concommitant

${ }^{34}$ Haskell's (1960:61) systematic hypothesis was formulated to explain why lower class boys become a part of a delinquent sub-culture. It also attempts to explain the relationship between socializing forces and involvement in delinquent sub-cultures. Operationalization of Haskell's systematic hypothesis depicts the role that both the family and reference groups have on behavior.

Haskell does not address peer socialization for middle class youths. I feel that these extenuating factors also account for middle class peer delinquent association.

35 Breckinridge and Abbot (1917), Shaw and McKay (1931) and more recently Enyon and Reckless (1961) pointed out that not only is delinquency most of ten committed as a part of group activity, but also that most lone offenders are influenced by companions. The fact that this hypothesis has failed to be demonstrated has been troublesome for criminologists. Criticism of this hypothesis rests on the logical argument that empirical evidence of association in delinquency merely demonstrates concommitant of behavior but not a link between a temporal sequence and behavior (For more see: Marshall 1959, and Glueck 1956). 
behavior. Instead the peer association ${ }^{36}$ was specified as follows: $P A=f[X 3, X 13, X 21, X 35, X 35, X 65, X 69]$ where: $[X 3]=$ familial makeup; $[X 13]=$ close friend who had shoplifted; $[\mathrm{X} 21]=$ race; $[X 35]=$ comparison of relationship with parents; $[X 38]=$ respondent reporting shoplifting behavior in the past five years; $[X 65]$ = friends who shopIift; $[\mathrm{X69}]=$ older sibling who has shoplifted. A MLR combined these elements to yield an instrument representing the peer association variable (see Appendix II). As expected, youths who had friends who shoplifted [X65] was the best indicator for current shoplifting activity. However, this finding offers nothing in the attempt to predict shoplifting behavior. Instead, it can be interpreted to mean that when studying shoplifting behavior, it may be best to use cohorts who admit to the same behavior in the effort to determine the effect of the behavior on each other rather, than to use cohorts who admit to a variety of delinquent acts. Similarly, if one studied auto theft exclusively, it would be necessary to include only those peers who engage primarily in the same behavior.

Perhaps peer association should be perceived as a form of modeling and a way for individuals to learn behavior vicariously rather than being perceived as a coercive force. This modeling process could teach an individual the mechanics of shoplifting in the same way that it is argued that films or television teach one how to defraud, rape or commit mayhem. However, one still has the difficulty of ascertaining precisely how influence, through passive peer association and the modeling

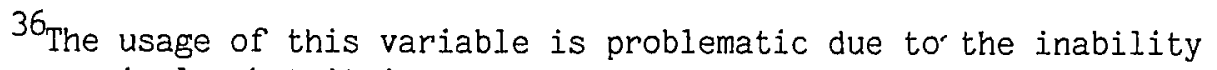
to know precisely what it is. 
process, serves to impact behavior. ${ }^{37}$ Despite these perceptions, it seems illogical to use peer association as both a cause for delinquent behavior and an effect for the behavior at the same time.

3. Need: There are methodological limitations when anonymous S-Rs are used to obtain results which reflect the rates and patterns of delinquent behavior among adolescents from different social classes in the general population. 38 While the majority of official statistics report that the incidence of delinquency is most heavily concentrated among lower class juveniles, available data regarding the correlation between social status and delinquency is both limited and contradictory. One major problem confronted by the researcher when operationalizing the economic dimension is the difficulty of understanding what it means. From a societal perspective 'economics' may mean the ubiquitous conflict between groups over economic and political interest which appear to be linked.

${ }^{37}$ Bandura, Ross and Ross (1963) claimed to demonstrate a link between stimuli and behavior. They said that two groups, aggressive and non-aggressive children, when shown a film of aggressive behavior by adults toward an inflated doll, became both mildly frustrated and aggressive toward the doll. A control group not shown aggressive behavior toward the doll did not exhibit behavior shown by the aggressive children.

38 The most provocative research challenges the accepted conclusion that youths from the lower socio-economic classes have higher rates of delinquency than do the middle and upper classes. (For more on this subject, see: Nye, et al, 1958; and Dentler and Moore, 1961.)

This perspective is prominently found in the writings of Dahrendorf (1959) and Quinney (1970). On a more individual level, Cohen (1955) argued that the relative position of the youth's family in the social structure determines the quality of experiences the child will face. The implication is, lower class families lack the ability to both teach and provide opportunities for their children which allows them to have basic skills and values. This premise suggests that social conditions, rather than individual personality traits, produce delinquency. Economics predicate social conditions. 
In this research the determinents of the need ${ }^{39}$ instrument are: $V 26=f[X 15, X 16, X 19, X 20, X 26, X 27, X 28, X 30]$ where: $[X-15]$ and $[X 16]=$ access to money; $[X 19$ and $X 20]=$ the adolescent's perception of the family's economic status; $[\times 26,27$ and 28$]=$ access to money in relation to perceived needs; $[X 30]=$ shoplifting and the relationship to need.

4. Parental Relationship: There are many factors, e.g., marital adjustment, parental affection and psychological defect, which can determine the parent-child relationship and the youths' subsequent involvement in shoplifting. ${ }^{40}$

In order to assess this dimension of parental affection, the $S-R$ contained five questions to capture the youths' perception. Therefore, parental relationship instrument was operationalized as $P R=f[X 58, X 59$, $\mathrm{X60}, \mathrm{X61}, \mathrm{X73}]$ where: $[\mathrm{X58}$ and 59$]=$ the ability to get along with parent(s); $[X 60$ and 61$]=$ which parent the youth interacts with best; $[X 73]=$ involvement with parents.

In this research, the conceptual partialling out of parental relationship from bonding was of particular importance. Whether or not delinquency is the result of psychological strain, there is some general agreement among psychologists and sociologists that family tension makes

${ }^{39}$ Interchangeable with economic in this dissertation.

${ }^{40}$ There is a remarkable consistency in both the official and selfreport data in regard to the impact of the quality of the family structure and the incidence of delinquency (Biron and LaBlanc, 1977). McCord, McCord and Gudenman (1960) and Shulman (1957) reported that, in their studies of alcoholism and delinquency they found that only a small percentage of the parents had affectionate relatiionships with their children, and that the parents were deeply disturbed with each other. Andry (1962) and Slocum and Stone (1963) reported that children most often honored parental affection with conforming behavior. 
the youth more susceptible to the delinquent influences prevalent in the youths' social enviroment. ${ }^{41}$

Whether the benefits from parental relations are direct or not, it is clear that the more external the controls over the adolescent's behavior, the less likely is the chance to encounter delinquent influences. Therefore, adolescents who know that their parents are aware and concerned about them tend to give more consideration to their own behavior (see Appendix II).

5. Attitude: This variable is complex in that it implies meaning across other independent variables listed in this research. However, it stands apart because it attempts to focus primarily on the situations adolescents find themselves in and their reaction to specific attitudinal stimuli. In addition, this variable assesses the individual's stated attitudes toward shoplifting. It is unclear which attitude(s) the amateur offender brings to the situation. Some youths, when queried in regard to their attitude and motive for shoplifting, provide answers ranging from 'I do not know' to 'everyone does it'. Responses of this type make it difficult to generalize about attitudes prior to, during and after shoplifting behavior. It was not necessary to address this issue in this research.

However, it is possible to gauge attitudes about youths' feelings toward shoplifting in general, the situation as a target, and their

${ }^{41}$ Some literature suggests that delinquency is a symptom of parental rejection, hostility or inconsistency (Savitz and Johnson, 1962). Hirsch contends that the parent-child relationship influences behavior indirectly. He states that the "child is less likely to commit delinquent acts not because his parents actually restrict his activities, but because he shares his activities with them..." (1969:53). 
However, it is possible to gauge attitudes about youths' attitudes about the ease or difficulty of shoplifting. 42

While attitude is operationalized as an independent variable, its properties cannot be strictly isolated from the traditional and situational factors. This fact makes for colinearity across the variables. Nevertheless, the attitude variable is specifically expressed as the additive of the gaming aspect, justification, and the perceived ease or difficulty of shoplifting. Therefore: $A T T=f[X 31, X 32, X 41, X 44, X 51$, X52].

6. Situation: The situation instrument was estimated using five elements and can be expressed as $S=f[X 53, X 54, X 56, X 57]$ where: $[553,54,55,56$ and 57] capture the youths' perception of risk to the 43 situation.

${ }^{42}$ It is felt that situational inducement has a temporary effect on both attitude and behavior (Hepburn, 1984). The understanding of a specific attitude is compounded by the youths' changing or vascillating toward their identity formation, personality consolidation, character formation and individualization. For more on these issues and the consequences for varying attitudes, see Blos (1968) and Freud (1965).

43 Jeffery's (1965) theory of differential reinforcement postulates that, when past delinquent acts are met with aversive consequences that do not control or alter the acts, the environment then serves as a reinforcing entity. The basic assumptions underlying this theory are: (1) the reinforcing quality of stimuli differ depending on the individual's bonding level; (2) the environmental stimuli has reinforced delinquent behavior for some and not others through selective enforcement; and (3) delinquent behavior can be learned in situations not containing delinquents or delinquent attitudes.

Differential reinforcement is a learning theory and can be used as a phenomenological method to analyze how youths become shoplifters. Jeffery's postulates are similar to Matza's (1969) analysis of how one becomes delinquent and intentionally runs the risk of apprehension. Matza suggested three stages in the process: affinity, affiliation and signification. Affinity characterizes the youths' attraction to a [continued on next page] 
Analytic Mode1

The nature of the sampling made it impossible to determine if a change in the social bond was initiated by shoplifting behavior, or if the change(s) in bond initiated shoplifting. Therefore the stated bonding, peer association, parental relationship, need, attitude and situation elements were regressed independently to obtain predictive scores for each instrument pertaining to the subject. Age, sex and race were combined with these predicted scores and regressed on shoplifting frequency to determine their combined and individual effects.

In the following analytic model (Figure 4), the individual characteristic elements are considered to be multi-dimensional. Structurally, the individual's perceptions define self image and behavior these perceptions were contrived from the individual's reflective measurements, which represent a classical approach to measuring an underlying concept, reversing assumed causal direction between scale items and the assumption that they are the function of underlying variable and measurement error, and assumes they form the variable without measureable error). These perceptions are combined with the situational elements to

${ }^{43}$ cont.: potential deviant situation. Matza contends that affinity is dormant until a conscious choice is made by the youth to engage in delinquent behavior. When this occurs, the individual may seek opportunities to act out the impulse. Finally, if the youth agrees with the perception that shoplifting is delinquent behavior, a delinquent self-concept is actualized. Therefore, from a phenomenological perspective, shoplifting is not a predictable or static phenomenon.

Lemert (1972) discussed situational factors which lead to crime as 'risk taking'. In this context, 'risk taking' refers to youths, confronting ambiguous or conflicting values, who become delinquent because the situation contains risks for delinquency. While it is difficult to clearly ascertain the role that the situation plays in behavior, this research postulates that the situational inducement leads to differential and/or associational learning. 
determine their collective impact on shoplifting and the statistical importance of the situational variable for predicting the behavior.
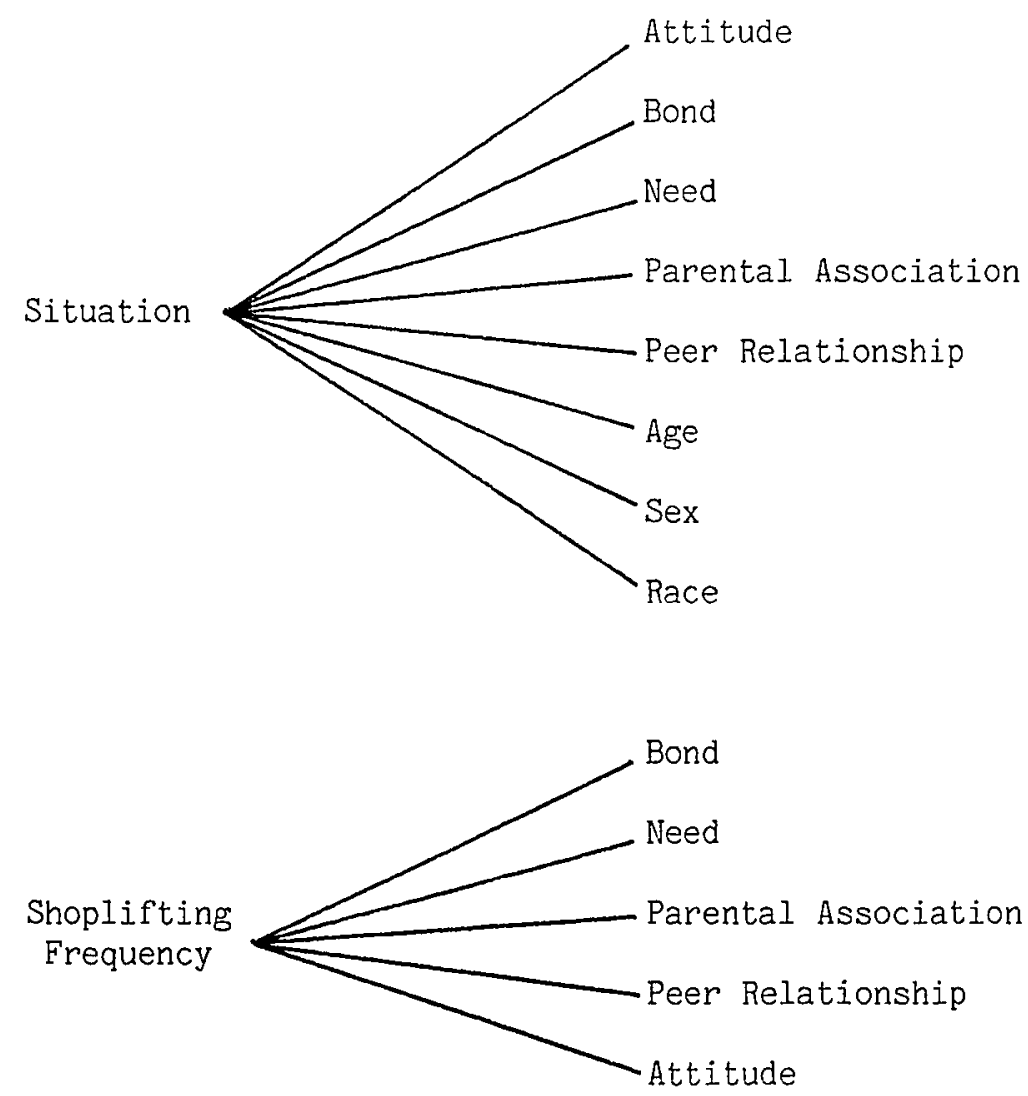

Figure 4. Multidimensional individual stated characteristics (image) and the theorized impact of the situation and the behavior on that image.

The use of reflective measurement is often appropriate for measuring concepts like socio-economic status, attitude and preference. This is accomplished by using different modes as scale items. Some inherent problems with this type of measurement are: (1) Unreliability of cross sectional data; (2) Each scale item weight is model specific and is determined by the relationship that the underlying variable has with other variables in the model; and (3) There must be an assumption that 
all relevant aspects of the underlying variables are contained within the scale item.

The individual characteristic elements make measurement and structural assumptions in that these characteristic evaluations are weighted initially with respect to the 'desired' behavior underlying that characteristic (e.g., the desired 'peer association' would be fraternization with non-shoplifters). The model does not make any assumption of relationships between the latent values of the variables and/or shoplifting.

This model conceptually and empirically specifies the relational link(s) between the elements that represent social bonding and the empirical indicators, e.g., sex, age, and race. These are regressed on shoplifting behavior. The model does not measure the specific global attributes of bonding; instead it uses indices from the self-report to determine if they constitute the dynamics of bonding. This dynamic perception of bonding is then combined with the situational elements to determine their relationship to shoplifting.

The model is based upon the following assumptions: (1) each element, excluding situational stimuli, is a part of the individuals' perception of their bonding, and that the perception can be evaluated; (2) the elements can be combined to form distinct instruments; (3) the predicted scores associated with the instruments can serve as indices for a global scale for the elements; (4) there is enough heterogenity among the elements to minimize impacts from exogenous elements. Therefore, the variables are defined simply as being the linear combination of the individuals' predicted scores. 
The data in this study were analzed using multiple linear regression. MLR was used because it enabled the effects of each independent variable to be assessed and to be interpreted independently. The zero order correlation technique was also used to determine if the independent variables functioned as intervening variables on the dependent variable. Because none of the independent variables had a $[r=0]$, it was impossible to state that the independent variables explicated from the literature did not act as intervening variables.

The joint effect of the variable elements was regressed on the dependent variable to gauge their independent effect 'due to' or 'accounted for' by the manipulation of the independent variables. In order for the independent variable, operationalized as an intervening variable, to be a good predictor of the dependent variables, it had to have a low R2. This was interpreted to mean that the intervening variable was not accounting for the movement $(+)$ in the dependent variable. A (-) value indicated this 'good fit' for that variable to the model. MLR enabled the use of eight independent variables to be regressed on shoplifting frequency. These eight variables were scaled to provide a prediction equation:

$$
Y 1=(a+b 1 \times 1,+b 2 \times 3,+b 4+X 4,+b 5+X 5 \ldots)
$$

Where: $a=$ constant

$\mathrm{X} 1$ = value of score on the independent variable

b1 = the weight the independent variable has in the equation

(the lower the coefficient the less weight).

One of the primary reasons for conducting this research was to determine whether traditional variables, e.g., the bonding elements, 
could predict shoplifting behavior. It was posited that there are a number of different aspects of bonding, and that adolescents differed on these facets.

Because this study relied on cross-sectional data, the problem of ordering the 'causal' variables became evident. For example, the use of a self-report anonymous questionnaire makes it impossible to determine if a defect in the milieu led to a change in bonding, or vice verse. In the attempt to avert this problem, this research focused on adolescents who stated that they 'had' or 'had not' shoplifted at least once in the past five years, and on their current perception of their bonding level. This emphasis foregoes the ordering problem. ${ }^{44}$

The responses to specific items were scaled to represent the youths' perceived bonding level. This scaling enabled me to subdivide the population according to perceived bonding level and shoplifting.

The research design operationalizes adolescents' stated attitudes, situational stimuli and stated perception of their bonding levels to their stated frequency of shoplifting.

It was expected that research results would reveal an inverse relationship between shoplifting and traditional variables, e.g., the level of bonding. However, anticipation of this finding would not permit addressing the method of ordering the variables to determine that which constitutes normal or abnormal bonding. The sampling approach made it impossible to compare the youths' perception of bonding level to that customarily used by sociologists. (Note: Data from case studies

${ }^{44}$ One problem with this procedure resides in the fact that individual bonding levels could have changed significantly in direction over the five year span. 
rather than cross-sectional analysis are generally more reliable in adducing the similarities.)

In Figure 5, Model 1 shows a behavioral outcome consistent with the bonding level. However, an alternative formulation (Model 3) can be constructed to depict an attenuation of the bonding level and the subsequent behavior.

Model 1

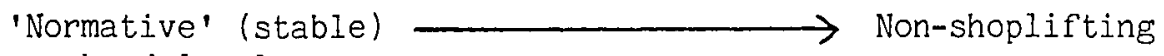

$\underline{\text { Model }} \underline{2}$

'Abnormal' (unstable) $\longleftrightarrow$ Intervening $\longrightarrow$ Shoplifting bond level factor(s)

Model 3

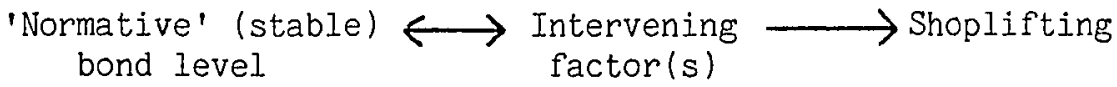

Figure 5. Bonding level and expected behavior.

Models 2 and 3 provide useful frameworks for analyzing the effect of intervening factor(s), e.g., situational stimuli, on youths experiencing stable or unstable bonding.

These configurations enhance the ability to investigate the intervening variables to determine their impact on the youths' stated attitudes and behaviors, and to discern if there is consistency with the stated bond level.

The three major weaknesses of Model 1 are its inability to: (1) determine whether shoplifting or contemplated shoplifting behavior 
affects the bond level; (2) discern if and how 'drifting' affects the stated bond level; and (3) determine what impact behavioral outcomes have on the stated bond perception.

Responding to the limitations of the analytic model reported here, it was imperative to marshall some evidence from the literature to build a logical case for one or both of the remaining models. While there is support in the literature for Model 1, it was necessary to build a case for Models 2 and 3. The best method was one proposed by Liska (1969). 45 The procedure makes it possible to test competing sociological variables derived from a common base. The purpose of this is to statistically reject variables or theories not supported by the data.

${ }^{45}$ A Pearsonian Correlation Coefficient was computed for each of the zero-order correlations to examine the effects of these intervening variables on shoplifting behavior. The logic behind this is: the relationship between each bonding element and the dependent variable (shoplifting) should be reduced to zero if the test is one of measuring the intervening variables. Reduction provided an indication of whether or not the bonding factors operate on shoplifting behavior through the situational stimuli. However, this method was rejected (see beginning of Chapter $V$ ) in favor of partial correlation because analyses of this type would constitute a complete dissertation. 
CHAPTER IV

RESULTS

Prior to presenting the results of the statistical analysis as it relates to the research question, descriptive information regarding the population and partialling of the variables used to construct measurement instruments is discussed.

The population and data were obtained by sampling youths from five youth service centers (see Appendix I), and the area immediately adjacent to these, in the Portland-Metropolitan area. It was determined that through the use of these groups, it was possible to: (1) select a sample which approximated the characteristics of Portland's general adolescent population (see Appendix I); (2) gauge the attitudes of these youths in regard to shoplifting; (3) get some sense of the frequency of shoplifting and the place of its occurrence; (4) determine if the adolescents' stated behavior was consistent with their bonding indices; and (5) determine if situational factors militated behavioral expectancy.

SAMPLE CHARACTERISTICS

Demographics

Table I presents the distributions by race, age, sex and the percentage of that age group included in the total sample. 
TABLE I

$$
\begin{aligned}
& \text { RACE, AGE, SEX DISTRIBUTION AND PERCENTAGE } \\
& \text { COMPRISING SAMPLE POPULATION } \\
& \text { (SEE APPENDIX I) }
\end{aligned}
$$

\begin{tabular}{|c|c|c|c|c|c|c|}
\hline Age & Male & {$[\underline{W}$} & $\underline{B}]^{*}$ & Female & {$[\mathrm{W}$} & B] \\
\hline 13 & 32 & 29 & 3 & 40 & 36 & 4 \\
\hline 14 & 34 & 29 & 5 & 38 & 34 & 4 \\
\hline 15 & 35 & 30 & 5 & 33 & 30 & 3 \\
\hline 16 & 29 & 26 & 3 & 31 & 28 & 3 \\
\hline 17 & 24 & 20 & 4 & 16 & 14 & 2 \\
\hline & 154 & 134 & 20 & 158 & 142 & 16 \\
\hline
\end{tabular}

* Black subjects represent $11.5 \%$ of the sample population. This figure is commensurate with the city's ratio.

Specific characteristics of adolescents completing the questionnaire at the shopping malls are described in Table II.

Table II

AGE, SEX AND THOSE WHO ADMITTED TO SHOPLIFTING AND NON-SHOPLIFTING

AT THE STIPULATED MALLS*

$\underline{\operatorname{Sex}}$

Age

Shoplifted

13 B-W 14 B-W 15 B-W 16 B-W 17 B-W $\quad \underline{\text { Yes }}$ B-W № $\underline{B}-\underline{W}$

$M=39 \quad 5-1-4 \quad 2-0-2 \quad 5-1-4 \quad 4-0-4 \quad 3-0-3 \quad 11 \quad 1-10 \quad 8-1-7$

$F=26 \quad 5-0-5 \quad 4-1-3 \quad 4-0-4 \quad 3-1-2 \quad 3-1-2 \quad 16-1-15 \quad 9-2-7$

*Respondents were randomly sampled by using every tenth youth who met the age criteria over three successive weekends.

Shoplifting Behavior

Table III describes the frequency that the sample admitted to shoplifting at various retail stores during a five year period. 
TABLE III

STATED SITE AND FREQUENCY OF SHOPLIFTING

1982-1986 (SEE APPENDIX I)

\begin{tabular}{|c|c|c|c|c|c|}
\hline Store & $\underline{f}$ & $\underline{\%}$ & Male & $\underline{\%}$ & Female \\
\hline Nordstrom & 312 & 23 & 35 & 6 & 280 \\
\hline Fredrick \& Nelson & 225 & 17 & 87 & 15 & 138 \\
\hline Meier \& Frank & 63 & 5 & 46 & 8 & 17 \\
\hline Fred Meyer* & 460 & 34 & 219 & 37 & 241 \\
\hline J. C. Penney & 74 & 5 & 39 & 7 & 35 \\
\hline Sears & 219 & 16 & 167 & 28 & 52 \\
\hline $\mathrm{N}$ & , 353 & & 593 & & 763 \\
\hline
\end{tabular}

*Fred Meyer is not located in the mall areas; however it was included because of its close proximity to the malls and its characteristics similar to the stores included in this sample.

\section{PARTIALLING OF THE VARIABLES}

This technique was used to determine the relative beta weights of the sub-elements of each variable. Those sub-elements which did not achieve a significant T-value at .05 provided a basis for elimination, thus enabling interpretation of the importance of the sub-elements. It also enabled deciphering of the importance of the sub-elements from the predicted scores compiled for each subject.

\section{Bonding}

Each of the sub-elements under bonding were regressed on each other, and those which had a significant direct $(T)$ value were included in the multivariate analysis where shoplifting was the dependent variable. Sub-element BD4 (see Table IV) is concerned with attachment and 
it, in turn, was measured using number 66 from the $S-R$. Because the T-value was 3.237 , it was chosed as the instrument for bonding.

TABLE IV

PARTIALLING OUT THE BONDING ELEMENTS

\begin{tabular}{cccc} 
Element & Partial Correlation & $\underline{\text { Partial }}$ &.$\frac{\mathrm{T}}{1}$ \\
\cline { 2 - 2 } 1 & -.081835 & -.081835 & -1.434 \\
Bd 2 & -.180719 & -.180719 & -3.209 \\
Bd 3 & .045560 & .047978 & .839 \\
Bd 4 & .175789 & .182228 & 3.237 \\
Bd 5 & .122538 & .123754 & .415 \\
Bd 6 & .083930 & .088141 & 1.545
\end{tabular}

Peer Association

A regression analysis of these sub-elements (see Table V) revealed two significant elements, PA1 and PA2. Due to the fact that PA3, PA4, PA5 and PA6 were statistically insignificant, they were dropped from further analysis. However PA1 could not be similarly dismissed due to the possibility of colinearity between PA3, PA4, PA5 and PA6. 
TABLE $V$

PARTIALLING OUT THE PEER ASSOCIATION ELEMENTS

$\begin{array}{lccc}\text { Element } & \text { Partial Correlation } & \text { Partial } & \text { T } \\ \text { PA } 1 & -.108418 & -.109571 & -1.925 \\ \text { PA } 2 & .125050 & .126129 & 2.220 \\ \text { PA } 3 & -.021044 & -.021391 & -.374 \\ \text { PA } 4 & -.004374 & -.004447 & -.078 \\ \text { PA } 5 & -.050642 & -.051422 & -.899 \\ \text { PA } 6 & -.020080 & -.020412 & -.357\end{array}$

Need

Partialling the sub-elements of need (see Table VI) presented the same problems encountered with Peer Association, therefore Need, N3 and N5 were used as surrogates. An analysis of the S-R items reveals that they specifically gauged the respondents' responses to perceived need. These two sub-elements are a bit stronger than surrogate measures.

TABLE VI

PARTIALLING OUT THE NEEDS ELEMENTS

\begin{tabular}{|c|c|c|c|}
\hline Element & Partial Correlation & Partial & $\underline{T}$ \\
\hline N 1 & -.035839 & -.036585 & -.638 \\
\hline $\mathrm{N} 2$ & -.033985 & -.034695 & -.605 \\
\hline N 3 & -.115836 & -.117508 & -2.063 \\
\hline N 4 & -.027327 & -.027904 & -.419 \\
\hline N 5 & -.165645 & -.166837 & -2.950 \\
\hline N 6 & -.023535 & -.024034 & -.419 \\
\hline N 7 & .065179 & .066434 & \\
\hline
\end{tabular}


Parental Relationship

Sub-element PRI (see Table VII), due to its high T-value, was the only one statistically worth further analysis.

TABLE VII

PARTIALLING OUT THE PARENTAL RELATIONSHIP ELEMENTS

\begin{tabular}{|c|c|c|c|}
\hline Elements & Partial Correlation & Partial & $\underline{T}$ \\
\hline PR 1 & .356618 & .362188 & 6.808 \\
\hline PR 2 & .059990 & .065225 & 1.145 \\
\hline PR 3 & .022974 & .159743 & 2.835 \\
\hline PR 4 & .022974 & -.025024 & .439 \\
\hline
\end{tabular}

Attitude

Sub-element AT4 (see Table VIII) was selected as the instrument because its direct $\mathrm{T}$ value was the greatest. This decision was made acknowledging the potential serial colinearity between sub-elements AT1, AT3 and AT4.

TABLE VIII

PARTIALLING OUT THE ATTITUDE ELEMENTS

$\begin{array}{ccccc}\text { Elements } & \text { Partial } \text { Correlation } & & \text { Partial } & \text { I } \\ \text { AT 1 } & .144095 & .162894 & 2.888 \\ \text { AT 2 } & .038645 & .044239 & .775 \\ \text { AT 3 } & .162693 & .183252 & 3.261 \\ \text { AT 4 } & .235882 & .260905 & 4.728 \\ \text { AT 5 } & .003750 & .004297 & .075\end{array}$


EXPLANATORY POWER OF VARIABLES

The standardized scores for each subject were regressed on each

of the sub-elements to obtain a predicted score (pred) for each instrument. The instruments were regressed on the sub-elements to determine their relative weight. The F-statistic was used to determine the goodness of fit of the sub-elements, and the T-statistic was used to identify those sub-elements that contribute to explaining the variance in the instrument. If the F-statistic was significant, all of the subelements were included in the final equation.

TABLE IX

ATTITUDE INSTRUMENT (AT4)

REGRESSED ON THE ATTITUDE

SUB-ELEMENTS

$\begin{array}{ccccc}\text { Element } & \underline{B} & \underline{\text { BETA }} & \underline{\text { Partial }} & \underline{T} \\ 1 & .176778 & .180997 & .162894 & (2.888)^{*} \\ 2 & .044104 & .044222 & .044239 & (0.775) \\ 3 & .190175 & .186987 & .183252 & (3.261)^{*} \\ 5 & .261492 & .254167 & .260905 & (4.728)^{*} \\ 6 & .003770 & .003808 & .004297 & (0.075)\end{array}$

$R 2=.23826 \quad F=19.14268 \quad$ Sign. $F=.0000$

* Significant (.05)

Because the F-statistic was significant, each of these elements including (4) were included in the equation in order to provide a redicted score (pred) for the attitude instrument. 
TABLE X

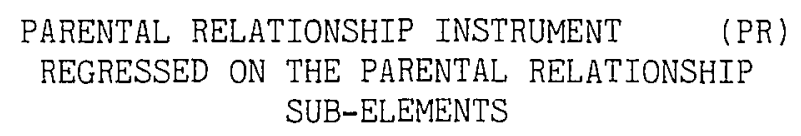

$\begin{array}{ccccc}\text { Elements } & \underline{B} & \underline{\text { BETA }} & \underline{\text { Partial }} & \underline{T} \\ 1 & .366874 & .359275 & .362188 & (6.808) * \\ 3 & .058861 & .061451 & .065225 & (1.145) \\ 4 & .154058 & .152101 & .159742 & (2.835) * \\ 5 & -.068692 & -.023130 & -.025024 & (-.439)\end{array}$

$$
R 2=.15769 \quad F=14.36899 \quad \text { Sign. } F=.0000
$$

* Significant (.05)

Due to the $(F)$ statistical value, all elements were used to derive a (pred) for inclusion in the equation.

\begin{tabular}{|c|c|c|c|c|}
\hline \multirow[b]{2}{*}{ Element } & \multicolumn{3}{|c|}{$\begin{array}{l}\text { BONDING INSTRUMENT (B) } \\
\text { REGRESSED ON BONDING } \\
\text { SUB-ELEMENTS }\end{array}$} & \multirow[b]{2}{*}{$\underline{T}$} \\
\hline & $\underline{B}$ & BETA & Partial & \\
\hline 1 & .192025 & .179904 & . 182228 & $(3.237)^{*}$ \\
\hline 2 & -.145827 & -.147340 & -.140340 & $(-2.475) *$ \\
\hline 3 & .059289 & .057400 & .046621 & $(.815)$ \\
\hline 4 & -.030983 & .028679 & -.024485 & $(-.428)$ \\
\hline 6 & -.211828 & -.215457 & -.217840 & $(-3.898) *$ \\
\hline 7 & -.088439 & -.027573 & -.028502 & $(-.498)$ \\
\hline $\mathrm{R} 2$ & 12313 & $F=7.13809$ & Sign. F & 0000 \\
\hline
\end{tabular}


The F-statistic warranted inclusion of all of the sub-elements into the final equation.

\begin{tabular}{|c|c|c|c|c|}
\hline \multirow[b]{2}{*}{ Element } & \multicolumn{3}{|c|}{$\begin{array}{l}\text { SITUATIONAL INSTRUMENT (S) } \\
\text { REGRESSED ON THE SITUATION } \\
\text { SUB-ELEMENTS }\end{array}$} & \multirow[b]{2}{*}{$\underline{T}$} \\
\hline & $\underline{B}$ & $\underline{B E T A}$ & Partial & \\
\hline 1 & .185596 & .176317 & .170717 & $(3.036) *$ \\
\hline 2 & .084846 & .073668 & .069505 & $(1.221)$ \\
\hline 3 & .034992 & .035491 & .035414 & $(.621)$ \\
\hline 4 & .036456 & .032964 & .030300 & $(.531)$ \\
\hline $\mathrm{R} 2=$ & & $=4.07467$ & Sign. & 0031 \\
\hline
\end{tabular}

All of the the situational sub-elements were included in the final equation.

TABLE XIII

PEER ASSOCIATION INSTRUMENT (PA1, PA2)

REGRESSED ON THE PEER ASSOCIATION

SUB-ELEMENTS

$\begin{array}{ccccc}\text { Elements } & \underline{B} & \underline{\text { BETA }} & \underline{\text { Partial }} & \underline{T} \\ 1 & -.135309 & -.109129 & -.109571 & (-1.925) * \\ 2 & .187150 & .125512 & .126129 & (2.220)^{*} \\ 3 & -.101032 & -.021336 & -.021391 & (-.374) \\ 4 & -.004654 & -.004723 & -.004447 & (-.078) \\ 5 & -.089375 & -.055045 & -.051422 & (-.899) \\ 7 & -.091237 & -.020306 & -.020412 & (-.357) \\ \text { R2 }=.03268 & F=1.71739 & \text { Sign. F }=.1165\end{array}$


Because the (F) statistic was not significant at .05 , a decision was made to extract the two elements (PA1 and PA2) that were significant at .05 and include the ( $\mathrm{Bi}$ 's) (raw scores) into the overall equation. The remaining four elements were deleted from further analysis. Therefore, PA 1 and PA 2 shown in Table XIV were used. The Beta weights, as well as the T-statistics, were used to justify their inclusion.

TABLE XIV

RESULT OF THE PRED SCORES ON THE
PEER ASSOCIATION SUB-ELEMENTS
EXPRESSED IN BETA WEIGHTS

XTX Matrix PA1 and PA2

PA1 -.10913

PA2 $\quad .12551$

TABLE XV

NEED INSTRUMENT (N3, N4)

REGRESSED ON THE NEED

SUB-ELEMENTS

$\begin{array}{ccccc}\text { Elements } & \underline{B} & \underline{\text { BETA }} & \underline{\text { Partial }} & \underline{T} \\ 1 & -.050784 & -.046411 & -.036585 & (-.638) \\ 2 & -.031129 & -.029303 & -.024034 & (-.419) \\ 3 & -.041640 & -.029189 & -.027904 & (-.487) \\ 4 & -.090619 & -.034836 & -.034695 & (-.605) \\ 5 & -.199775 & -.180243 & -.166837 & (-2.950) * \\ 6 & -.128955 & -.118338 & -.117508 & (-2.063) * \\ 7 & .078452 & .070600 & .066434 & (1.161) \\ \text { R2 }=.04167 & F=1.88845 & \text { Sign. F }=.0710\end{array}$


Because the (F) statistic was not significant at .05 , a decision was made to extract the two elements statistically significant and include them ( $B \mathrm{i}$ 's) in the overall equation.

Therefore, N5 and N6, as shown in Table XVI, were included in the final analysis.

TABLE XVI

RESULT OF THE PRED SCORES ON THE
NEED SUD-ELENENTS AS EXPRESSED
IN BETA WEIGHTS

XTX Matrix N5 and N6

N5 -.18024

N6 $\quad-.02930$

In addition to the above pred scores, those for age, sex and race were included in the final analysis.

$\mathrm{SL}=\mathrm{f}(\mathrm{B}, \mathrm{PA} 1, \mathrm{PA} 2, \mathrm{PR}, \mathrm{N5}, \mathrm{N6}, \mathrm{S}, \mathrm{ATT}$, Age, Sex, Race $)$

TESTING THE ANALYTICAL MODEL

Because there was a concern with the ability of the traditional variables to explain snitch variety adolescent shoplifting across the social-economic classes, other factors were examined. The one constant factor seeming to confront these youths was the homogeneity of the situational stimuli.

Therefore the situational stimuli was operationalized as both a dependent and an independent variable to determine its importance in regard to shoplifting. The situational stimuli when operationalized as the dependent variable and with shoplifting excluded $(S=f[B 1, P A 1$, 
PA2, PR, N3, N5, ATT, Sex, Race]), yielded a R2 of $.10014, F=-1.63412$ and a Sign. F of .0068 . This finding means that there was an inverse relationship between the independent variables and situational stimuli. It can also be interpreted to mean that the situational stimuli subelements were orthognal to the other variables and their sub-elements.

This finding provided a rationale for including the situational stimuli sub-elements in the final analysis as an independent variable. It is expected that the regression would show a significant direct relationship.

Therefore, the statistical equation to test the analytical model became:

$S L=f(B, P A 1, P A 2, P R, N 3, N 4, S, A T T$, Age, Sex, Race $)$. When the regression estimates (beta values) are inserted, the linear equation becomes ( $\mathrm{T}$ values are in brackets):

$$
\begin{aligned}
& \mathrm{SL}=1.090536[\mathrm{~B}]+.005343[\mathrm{PA} 1]=-.025360[\mathrm{PA} 2]+.023038[\mathrm{PR}] \\
& {[1.536] \quad[.096] \quad[-.451] \quad[.397]}
\end{aligned}
$$$$
+-.052647[\mathrm{~N} 3]+-.012728[\mathrm{~N} 4]+-.123775[\mathrm{~S}]+-.080707[\mathrm{ATT}]+
$$$$
[-.918] \quad[-.226] \quad[-2.117] \quad[-1.310]
$$$$
.033862[\mathrm{~A}]+.116914[\mathrm{Sx}]+.207097[\mathrm{R}] \text {. }
$$$$
[.592] \quad[2.060] \quad[3.727]
$$

$$
R 2=.11237 \quad F=3.45254 \quad \text { Sign. } F=.0002
$$

Formulation and use of the instruments provided standardized Beta weights which could be used like percentages to compare the effects of the independent instruments upon the dependent variable. The sign of the coefficients has nothing to do with the strength of the relationship of the instruments. A (-) means that one of the instruments and the dependent variable increases while the other decreases. A (+) means that the two increase together. The signs merely tell the 
direction of the relationship. The Beta weights can be compared and used to establish a hierarchy.

The linear equation suggests that a hierarchy which uses the situation, sex and race instruments would be superior to the use of a hierarchy comprised of bonding, peer association, parental relation and need. The $\mathrm{T}$ statistic at .05 level also suggests that the situation, sex and race variables are the most important when adolescent snitch shoplifting is being analyzed. However, when a zero order correlation was run using the instruments individually to determine its relationship to shoplifting, only the situation instrument was reduced to show that no (zero) relationship existed between the other independent in.. struments and shoplifting.

Multiple linear regression does exactly what it implies. It provides a coefficient, a statistic, $R$, which reveals how well we may predict the dependent variable from the several independent variables used in the equation. The R2 explains the variations caused in the dependent variable by multiple independent variables.

Delinquency problems can rarely be stated in terms of a simple relationship between $A$ and $B$. Normally the behavior involves some type of relationship between $A, B$ and some other variables.

Shoplifting has been associated with many variables believed to be interrelated to some degree. The Beta values are often used to make definitive interpretations. The use of these values often leads the researcher to treat the variables as a set despite statistical findings that they should not. To conduct research in this fashion precludes 
the search for the real relation of particular variables necessary for the understanding of this behavior.

Statistically, this study suggests that some of the variables thought to account for adolescent shoplifting are no more than adventitious or symptomatic. These extraneous variables appear to be important because they are found together with other variables which appear to be meaningful in the enhancement of a statistical understanding.

Lombroso (1942) provided an explanation for crime which is all encompassing, except for the proverbial kitchen sink. ${ }^{46}$ This illustrates the difficulty in attempting to explicate from the array of possible factors which seem to constitute a rational combination for explaining shoplifting behavior. Regardless of the configuration of multiple factors used to explain shoplifting, these factors can only, at best, pertain to those individuals from whom the factors were explicated. Because of this, these factors cannot be used to discuss causation - only the tentative relationship between the factors. Because these relationships may be spurious, due to the subjective quantification and/or operationalizing of the factors, this research assiduously avoids addressing causation.

\footnotetext{
${ }^{46}$ Lombroso advanced the following factors for the explanation of crime:

Meteorological and climatic influence, mountain formation, race, civilization or barbarism, density of population, ease of obtaining subsistence, alcoholism, education, wealth, religion, early training, heredity not only of certain characteristics but of criminality, age, sex, civil status, unemployment, prison, sense impression, imitation and suggestion. (MacIver, 1942:83)
} 
ANSWERING THE RESEARCH QUESTIONS

Traditional Bonding and Social Variables (1a-1d)

The emphasis on bonding as a primary factor in delinquency is profoundly rooted in the literature. Bonding can be seen as inversely related to delinquency involvement (Hirschi, 1969).

The below statistical findings suggest that the research questions 1a through $1 \mathrm{~d}$ centered around the elements of bonding can not be substantiated. This raises questions concerning the efficacy of using prosocial values, quality of involvement in scholastic activities, and belief in the social order as predictors to determine which adolescents will engage in shoplifting.

$$
\text { BETA } .090536 \quad T=1.536
$$

This finding should not be construed as a statement that the bonding elements are irrelevant. However, it does point to a need to rethink the emphasis placed on some aspects of the socialization factors commonly used to account for all delinquent behavior.

Deprivation (1e) and Economic Need (1g)

The finding is not necessarily consistent with Klemke's statement that "Youths with lower class backgrounds were somewhat more likely to shoplift than youths with higher backgrounds." (1980:73-90) However, he did not discuss the correlation between social class status and bonding level.

The below statistical results do not confirm this relationship. In order to accept the premise that adolescents not experiencing perceived deprivation shoplift more than do those who do, the $T$ value 
at .10 would have to be 1.65 . While 1.536 was not significant, one can surely state that it is weakly related to shoplifting. These findings are somewhat consistent with Hirschi (1969), Kelly and Pink (1973) and Elliott and Voss (1974). All of these researchers point out that there is a 'moderate' relationship between social class and shoplifting. The argument focuses on the statistical value that constitutes a weak or moderate association between (1e), (1g) and shoplifting behavior. Perhaps part of this confustion can be attributed to the use of a generic variable. I contend that utilization of definitive elements, e.g., (N5) and (N6) are better representations of social-economic class than direct measurements.

There is also a difference in the way I interpreted the critical T-values which, in effect, is methodological. It is encumbent upon the researcher to identify the acceptance and rejection regions prior to doing the analysis. For this research I arbitrarily determined that derived $(T)$ values of $+(1.6)$ and less would be construed to be a weak correlation. A critical value of 1.536 is .114 less than the proscribed value and therefore must be characterized as weekly rather than moderately correlated to shoplifting.

BETAS $.052647[\mathrm{~N} 3], .012728[\mathrm{~N} 5] ; \mathrm{T}=-.918[\mathrm{~N} 3],-.226[\mathrm{~N} 5]$;

Sign. $T=.3594[\mathrm{~N} 3], .8216[\mathrm{~N} 5]$.

This finding was expected because the measuring of a youth's access to money, rather than reliance on the ascribed measurement of the father's occupation, best captures the youth's perception of economic well being. Curiously, the majority of youths reported that they had enough money to spend on 'extra items' (82\%). Still, $48 \%$ of these 
youths reported shoplifting activity. Of the youths who did not report shoplifting behavior, only $20 \%$ reported that they had enough money to buy the things that they needed.

What this suggests is that lack of money may not be a primary factor in shoplifting - a paradox to modern criminology which tends to infer that shoplifting is caused by both deprivation and affluence.

Peer Association (1f)

Hollingshead found that most youths have one to four friends with whom they spend the majority of their leisure time (1975:154). Lerman stated that most delinquencies, peaking at ages 15-16, occurred with two or three peers (1967:67). Erickson contended that 60-65 percent of the misconduct by juveniles is committed with one or more peers (1971: $120-123 ; 1973: 451$.

Regarding peer association, only two of the elements were found to be significant (question 1 , 'One or more of my close friends have shoplifted.' and $\$ 2$, 'One or more of my close friends have been caught [arrested] for shoplifting').

The inclusion of these two elements creates a potential problem because of colinearity. The obvious remedy is to delete one from further analysis, but both elements had significant $(T)$ values $(-1.925$ and 2.220). There are remedies for this problem, but they were not used in this analysis. 47

${ }^{47}$ One method is to run a MLR on the two elements and take the one that is statistically significant and the residual of the other one and include both in the equation. The residual is the opposite of the stat. sign. one and cannot be correlated. The MLR value can also be devided by the residual to get a $1+$ number. The residual cannot be correlated. 
Because of these potential problems, I am tentative in regard to accepting or rejecting research question $1 \mathrm{f}$. Will adolescents who lack companions, shoplift less than those who do have such companions? An affirmative (statistical) finding would suggest that as adolescents accept the rationality of shoplifting, they will increase their interaction with others who share their lack of commitment to conformityproducting values. Despite my tentativeness, when these two elements (PA1 and PA2) and the other elements were regressed on shoplifting, they were found to be statistically insignificant $(r=.096$ and -.451$)$ for those youths who had peer associates who had also shoplifted or who had been caught (arrested) for the behavior.

$\underline{\text { Sex }}$

Contemporary delinquiency literature reveals a revived interest in sex variation (e.g., Hildelang (1973) and Cernkovich and Giordano (1979)). However this research effort did not attempt to apportion shoplifting frequency to sex. Instead it was operationalized as a factor in accounting for shoplifting behavior. When sex and the other variables were regressed on shoplifting frequency, its $B$ value was .67 . Interpreted, it means that males shoplifted almost one time more often than females. This finding is in accord with Klemke's. When sex was operationalized within the equation, its values were:

$\begin{array}{cccc}\text { B } & \text { SE-B } & \text { BETA } & \text { Sign T } \\ .670568 & .325561 & .116914 & .0403\end{array}$


Attitude (2) and Situational Stimuli (3)

There is no general model that is universally agreed upon: which can encompass all the causes of human behavior. However, this thesis has used a general theory of social learning which has gained broad support because it suggests that direct and vicarious experience, accompanied with rewards and punishment, leads to the acquisition of specific beliefs about the consequences of attitudes toward a situation. Based on the postulate, it. is these beliefs that shape behavior, the theory also suggests that how one interacts with a social situation necessitates a degree of social learning.

This dissertation depicted one aspect of social learning, shoplifting. Social learning theory was applied to a simultaneous equation model. This model enabled a test of relevant dimensions and their interactions, given a specific situation. It assumed that there is a reciprocal effect between behavior and attitude, that attitude was the result of the delineated elements, and that these effects, attitudes and behavior would be simultaneous, or at least proximated in time. The model enabled the use of instrumental variables (predicted scores) to determine their effect on the dependent variable (shoplifting), using multiple linear regression.

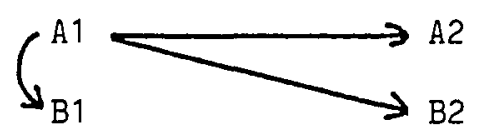

Let: $A 1=$ Current attitude B1 = Situational stimuli A2 = Situated behavior (Behavior attributed to the situational stimuli) B2 = Non-situated behavior (Behavior consistent with the bonding level)

Figure 6. Simultaneous Model 
The research findings reveal that the attitude reciprocal (A1) and (B1) depends on the presence of various conditions attributed to ( $B$, $\mathrm{PA} 1, \mathrm{PA} 2, \mathrm{PR}, \mathrm{N} 3, \mathrm{~N} 5, \mathrm{~S}$, Age Sex, Race). These reciprocals can bring about (A2) or (B2). When these reciprocals were assessed in reference to shoplifting frequency, it was found that the situational stimuli does have an impact on the attitude-behavior reciprocals. In other words, one would expect the greater the situational stimuli, the greater the effect on one's attitude and a commensurate change in behavior regarding shoplifting. This lends credence to the defect in the operating milieu proposition. Although (B1) has an inverse relationship to shoplifting, its value escalates when regressed on (A1) when shoplifting frequency is used as the intervening variable. This relationship is expected because the situation is neutral and can only have relevance for those whose attitudes can be attuned to or perceive the situation as providing opportunities to engage in this behavior.

However, this research was not an issue of simply estimating and explaining the relative effects of the attitude-behavior correlates and their regression on situational stimuli. Rather, the focus was on estimating the extent to which (A1) depended upon (B1) to explain shoplifting behavior. It is generally understood that events in one's environment shapes one's attitude and behavior. It is also true that behavior shapes one's environment. Therefore, all shoplifting behavior cannot be accounted for or attributed to (A2). Whether this condition can be attributed to (B2) is speculative because (B2) does not account for those youths whose behavior is not situationally determined. 
Summary of Findings

Insofar as snitch variety adolescent shoplifting is concerned, bonding factors, peer association, parental relationship, need, attitude and age factors were found to be less important when statistically operationalized than previously thought. However, the situational stimuli, sex and race factors were important. The attitude factor was difficult to interpret and basically unnecessary, due to its statistical significance. However, some critjcal comment about this variable is made in the conclusion section, Chapter 5 .

This research was driven by the hypothesis that impulse (snitch) variety shoplifting is predicated more on the situational stimuli and the adolescents' reaction to them rather than on the antecedent factors which these youths bring to the situation. The research strategy attempted to assess the attitudes of both shoplifters and non-shoplifters toward a limited number of stimuli encountered at the units of analysis. Insofar as snitch shoplifting is concerned, the research findings suggest that: (1) The individual's attitude toward the situational stimuli is more important than that in regard to personal image; (2) The situational stimuli does have a differential impact on individual behavior which is contingent upon the attitude toward the situational stimuli and perceived intensity of that stimuli; (3) Situational stimuli can generate situational behavior; and (4) The situational can be operationalized to assess differential attitudes. 
CHAPTER V

CONCLUSION

The reader may find many faults with this research, and I am accountable for each one. There appears to be one seemingly apparent problem, the low R2 (the total variance between the independent variables and their effect on the dependent variable less the error term), that should be discussed so that it does not fall in the above category. A criticism of the $R 2$ value (.11237) can be dismissed at the onset by referring to the $F$ value. Nevertheless, the low $R 2$ value can be explained by pointing to the limited range of item scaling (1-7), use of predicted scores rather than operationalizing the statistically significant elements for each variable, and failure to delete those which did not meet this criteria.

Although the F-statistic, 3.45254, is relatively small, the probability that the findings reported in regard to the relationship between shoplifting and the independent variables occurred by chance, is less than .01 .

One can also conclude from the results that the individual's attitude toward the situational stimuli $(-1.310)$ is more important than the stimuli (1.226) when regressed on shoplifting. This suggests that the current defensive mechanisms used by merchants to curb shoplifting behavior may be ineffective. These results also suggest that the situational stimuli variable may need to be operationalized differently than 
it was to obtain a more comprehensive understanding of the relationship between the attitude-behavior correlates. For example, the use of a gravity model would be sensitive to the differences in individual exposure to the situational stimuli, the effect of exposure frequency to attitude and the differential resulting behavior.

RELATION OF RESULTS TO OTHER STUDIES

This research agrees with Klemke's by suggesting that the relationship between peer association and shoplifting behavior has been overstated. My findings reveal both an inverse and weak relationship between peer association and shoplifting $(-.451$ and .096$)$. They do not address the issue of whether adolescent shoplifting is group-related behavior, or whether it involved behavior neutralization or psychological pathologies.

However, the issue of race is addressed. Analysis of the Beta weight (.207097) and $T$ value (3.727) shows that it is a significant variable. The beta value revealed that white adolescents were two times as likely, given these elements, to shoplift, as their minority counterpart. The issue of possible target hardening at the Lloyd Center mall is specious because the minority youths were dispersed throughout the sampling area and had access to the other malls. This finding is significant because it clashes with Robin and Cameron's findings.

The study by weiner, which focused on the phenomonological observation of behavioral neutralization, was not validated. My results suggest that behavior neutralization is not a factor which can be used 
to explain the occurrence of this behavior by youths who are differentially bonded.

The $F$ value (3.45254) suggests that the operationalized variables may be more appropriate indicators for white male shoplifters than for White females, non white males and females. This suggestion clashes with Klemke's. The $F$ values would have to be in the (1.) and (2.) ranges respectively to be construed as appropriate indicators for youths who are not white males.

\section{LIMITATIONS OF THE STUDY}

The interpretation of attitude may be ambiguous, and therefore subsequent research needs to make more clear the distinction between both the active and passive elements of attitude when a situation is analyzed. This study is further limited by its use of a narrowly defined minority group. There is also the issue of whether there is consistency in perceptions by rural and urban adolescents.

\section{IMPLICATION OF FINDINGS}

The situational stimuli idea lends additional credence to Glaser's theory of differential-anticipation and discussions by Goffman, Alexander and Epstein, Becker, Lofland and Gibbons on the importance of the situation as a crimino-genic factor.

The notion of situation stimuli needs to be expanded to account for the heterogeneity of stimuli at different sites. Attempts to understand the situational stimuli more coherently requires the use of more sophisticated models. 
Subsequent research could focus more on the situational elements, e.g., video cameras, unmanned dressing rooms, to determine if their presence or absence serve as motivation for a form of gamemanship among the adolescents rather than act as deterrents for shoplifting behavior. Considering these results (the importance of analyzing the situation for what it does or does not contribute to a specific behavior, and the inconsistency of behavior expectation when confronting ambivalent stimuIi), Matza's theory of 'drift' and the defect in the operating milieu propositions provide added credence.

It is difficult to assess one's contribution to the literature of a specific field of study. This research, nevertheless, suggests that the traditional variables used to explain this behavior, without considering the situational stimuli, must be considered as being intervening rather than precipitating in nature. These intervening variables are better predictors of shoplifters who are white males rather than universal predictors.

Although the methodology is not unique, this, or similar methodologies, must be used to gauge cause and effect rather than rely on seeming associations and profiles to understand the complexity of the relationships between the basic, intervening, temporal and precipitating factors and their effect on subsequent behavior. 
REFERENCES

Abrahamsen, David 1960. The Psychology of Crime, New York: Columbia Press.

Adler, F. 1975. Sisters in Crime: The Rise of the New Female Criminal, New York: $\overline{\text { McGraw-Hill, Co. }}$

Aichhorn, August 1968. Wayward Youth, New York: The Viking Press.

Alexander, C. Norman, Jr. and Joyce Epstein 1969. "Problems of Dispositional Inference in Person Perception Research," Sociometry, Vol. 32, 381-395.

Allport, G. W. 1935. "Attitudes" in C. Murchison (ed.) Handbook of Social Psychology, Worcester, Mass.: Clark University Press.

Andry, R. G. 1962. "Parental Affection and Delinquency," in M. E. Wolfgang, L. Savitz and N. Johnson (ed.) The Sociology of Crime and Delinquency, New York: Wiley.

Angeline, H. 1959. "Shoplifting: A Critical Review", Midwest Sociologist, Vol. 1, 5-17.

Arboleda-Florez, J., H. Durie and J. Costello 1977. "Shop-lifting: An Ordinary Crime?" International Journal of Offender Therapy and Comparative Criminology, Vol. 21 , No. $3,201-207$.

Arieff, A. J. and C. G. Bowie 1947. "Some Psychiatric Aspects of Shoplifting," Journal of Clinical Psychopathology, Vol. 8, 565.

Arnold, William R. and Terrence M. Brungardt 1983. Juvenile Misconduct and Delinquency, Boston: Houghton Mifflin Co.

Astor, S. D. 1970. Study of 1,647 Customers Shows 1 in 15 is a Shoplifter; Unpublished Manuscript.

Astor, S. D. 1971. Anti Shoplifting Guide for Retailers, New York: Loss Prevention Institute, Inc.

Aselord, M. and D. Elkind 1976. "Merchants' Response to Shoplifting: An Empirical Study," Stanford Law Review, Vol. 28, 589.

Bandura, A.; D. Ross and S. Ross 1963. "Imitation of Film Mediated Aggressive Models," Journal of Abnormal and Social Psychology, Vol. 66, 3-11. 
Barrett, William 1962. Irrational Man, Garden City, New York: Doubleday.

Barron, Milton L. 1955. The Juvenile in Delinquent Society, New York: Alfred A. Knopf, Inc.

Baylen, R. 1975. Cited in: S. M. Meyer 1976. "A Crusade Against Shoplifting," Police Chief, June, No. 41, 34-36.

Beck, E. and S. McIntyre 1977. "MMPI Patterns of Shoplifters Within a College Population," Psychological Reports, No. 41, 1035-1040.

Becker, Howard S. 1963. Outsiders, New York: Free Press.

Becker, Howard S. 1964. "Notes on the Concept of Commitment," American Journal of Sociology, LXVI, 1 (July), 32-40.

Becker, Howard S. 1965. "The Booster and the Snitch," review of M. 0. Cameron's effort with same title, American Journal of Sociology, Vol. 70 (Mar.), 635-636.

Berman, S. 1964. "Antisocial Character Disorder," in R. S. Cavan (ed.) Readings in Juvenile Delinquency, Philadelphia: Lippincott.

Birenbaum, Arnold and Edward Sagarin 1976. Norms and Human Behavior, New York: Praeger Publishers.

Biron, L. and M. LeBlanc 1977. "Family Components and Home Based Delinquency," British Journal of Criminology, Vol. 17, 157-168.

Blos, P. 1968. "Character Formation in Adolescents," The Psychoanalytic Study of the Child, XXIII, New York: International University Press.

Blumstein, A. and E. Graddy 1982. "Prevalence and Recidivism in Index Arrests: A Feedback Model Approach," Law and Society Review, Vol. 16, No. 2, 265-290.

Bowlby, J. 1956. "The Effects of Mother-Child Separation: A Followup Study," British Journal of Medical Psychology, Vol. 29, 211-247.

Boyd, J. and T. Harrell 1975. Cited in W. A. French 1981. National Research Report on Shoplifting 1980-1981, National Coalition to Prevent Shoplifting, August, $\overline{\text { NCJ } 76688 .}$

Bradford, J. and R. Balmaceda 1983. "Shoplifting: Is There a Specific Psychiatric Syndrome?" Canadian Journal of Psychiatry, Vol. 28, No. 4, June, 248-253.

Breckenridge, Sophonisba P. and Edith Abbot 1917. The Delinquent Child and the Home, New York: The Russell Sage Foundation. 
Briar, Scott and Irving Piliavin 1965. "Delinquency, Situational Inducement and Commitment to Conformity," Social Probiems, \#13 (Summer), 35-45.

Briar, Scott and Irving Piliavin, 1965. "Police Encounters with Juveniles," American Journal of Sociology, No. 70, Sept., 206214.

Buckman, L., et al 1979. National Evaluation Program - Phase 1 Assessment of Shoplifting and Employee Theft Programs -Final Report - Programs and Strategies, Vol. 1, Nov. Substantive Findings, NCJ $735 \overline{35 .}$

Burt, C. 1925. The Young Delinquent, London: University of London Press.

Byrness, J. 1886. In M. E. Schiffer 1978. Mental Disorder and the Criminal Trial Process, Toronto: Butterworth and Co.

Cameron, Mary 0. 1964. The Booster and the Snitch: Department Store Shoplifting, New York: Free Press of Glencoe.

Campbell, Ann 1981. Girl Delinquents, New York: St. Martin Press.

Carrol1, John S. 1978. "A Psychological Approach to Deterrence: The Evaluation of Crime Opportunity," Journal of Personality and Social Psychology, Vol. $36(12), 1 \overline{512-1520}$.

Cernkovich, S. A. and P. C. Giordano 1979. "A Comparative Analysis of Male and Female Delinquency," The Sociological Quarterly, Vol. 20 (Winter), 131-145.

Chilimsky, E. 1978. Security Techniques for Small Businesses, Metro Corp., Criminal Justice System, U. S. Department of Justice.

Clark, John P. and Eugene P. Weeninger 1962. "Socio-economic Class and Area as Correlates of Illegal Behavior Among Juveniles," American Sociological Review, Vol. 27, (Dec.), 826-834.

Clarke, R. V. 1982. "Crime Prevention through Environmental Management and Design," Abnormal offenders, Delinquency and the Criminal Justice System, (eds.) J. C. Gunn and D. P. Farrington, New York and London: Wiley.

Clinard, Richard A. and Richard Quinney 1967. Criminal Behavior Systems, New York: Holt Rinehart and Winston.

Cloward, Richard A. and Lloyd E. Ohlin 1960. Delinquency and Opportunity: A Theory of Delinquent Gangs, New York: Free Press. 
Cobb, W. E. 1973. "The Economics of Shoplifting," PhD. Dissertation, Virginia Polytechnic Institute and State University, Department of Economics.

Cohen, Albert K. 1955. Delinquent Boys: The Culture of the Gang, Glencoe, Ill.: Free Press.

Cohen, Albert K. 1959. "The Study of Social Disorganization and Deviant Behavior," Sociology Today, (eds.) Robert K. Merton, Leonard Broom and Leonard S. Cottrell, Jr., New York: Basic Books.

Cohen, L. E. and M. Felson 1979. "Social Change and Crime Rate Trends: A Routine Activity Approach," American Sociological Review, Vol. $44,588-608$.

Cohen, L. and R. Stark 1974. "Labeling Theory and the Five-Finger Discount: An Empirical Test of Shoplifting," Journal of Research in Crime and Delinquency, January, 25-39.

Cunningham, C. 1975. "Absent Mind Versus Guilt Mind in Cases of Shoplifting," Medico - Legal Journal, Vol. 43, 101-106.

Cupchik, W. and J. Atcheson 1984. "Shoplifting: An Occasional Crime of the Moral Majority," Bulletin of the American Academy of Psychiatry and Law, Vol 11, No. $4,3 \overline{43-354 .}$

Curtis, P. 1969. Cited in "Volume Stores Make It Easy to Steal," Merchandising Week, Sept. 14, 1970, Vol. 102, 5.

Dahrendorf, R. 1958. "Toward a Theory of Social Conflict," Journal of Conflict Resolution, Vol 2.

Dahrendorf, R. 1959. Class and Conflict in Industrial Society, Palo Alto, Calif.: Stanford University Press.

Dahrendorf, R. 1959. Class and Class Conflict in Industrial Society, Stanford, Conn.: Stanford University Press.

Davis, Allison and John Dollard 1940. Children of Bondage, Washington: American Council on Education, 264-265.

Dentler, R. A. and L. J. Monroe 1961. "Social Correlates of Early Adolescent Theft," American Sociological Review, Vol. 26, 733743.

Downes, D. and P. Rocks (eds.) 1979. Deviant Interpretations, Oxford: Martin Robertson.

Durie, Costello 1977.

Edwards, Loren 1958. Shoplifting and Shrinkage Protection for Stores, Springfield, IIl.: Chas. C. Thomas. 
Eldridge, J. and T. Watts 1897. In D. Chiswick 1976. "Shoplifting, Depression and an Unusual Intracranial Lesion (A Case Report)," Medical Science Law, Vol. 16, 266-268.

Elliot, D. S. and H. L. Voss 1974. Delinquency and Dropout, Lexington, Mass.: D. C. Heath and Co.

Enyon, Thomas G. and W. C. Reckless 1961. "Companionship at Delinquency Onset," The British Journal of Criminology, Vol. 2 (Oct.), 167168.

Erickson, Maynard L. 1967. "The Group Context of Delinquent Behavior," Social Problems, Vol. 19, No. 1, (Summer).

Erickson, Maynard L. 1973. "Group Violations, Socio-economic Status and Official Delinquency," Social Forces, L11, 1, (Sept.).

Eysenck, J. J. 1964. Crime and Personality, Boston: Houghton-Mifflin.

Eysenck, H. J. and S. B. G. Eysenck 1978. "Psychopathy, Personality and Genetics," in R. D. Hare and D. Schalling, (eds.), Psychopathic Behavior: Approaches to Research, New York: Wiley, 197-224.

Farin, A. J. 1977. "Minimizing Shoplifting Losses: Some Practical Guideline," Journal of Small Business Management, No. 15, October, 41.

Farrington, D. P. 1983. Further Analyses of a Longitudinal Survey of Crime and Delinquency, Cambridge: Cambridge University, Institute of Criminology.

Farrington, D. P. and B. J. Knight 1979. "Two Non-Reactive Field Experiments on Stealing from a Lost 'Letter'," British Journal of Social and Clinical Psycholugy, Vol. 18, 277-284.

Farrington, D. P. and D. J. West 1971. "A Comparison Between Early Delinquents and Young Aggressives," British Journal of Criminology, Vol. 11, 341-358.

FBI Uniform Crime Report, U. S. Department of Justice 1979, 27-31.

Federal Bureau of Investigation 1984. Crime in the United States, 2933.

Fenichel, T. 1945. Cited in T. C. N. Gibbens 1962. Shoplifting, London: The Institute for the Study and Treatment of Delinquency, 68 .

Fischer, M., J. E. Rolf, J. E. Hasazi and L. Summings 1984. "Follow-up of a Preschool Epidemiological Sample: Cross-Age Continuities and Predictions of Later Adjustment with Internalizing and Externalizing Dimensions of Behavior," Child Development, Vol. 55:137-150. 
French, W. A. 1980-1981. "National Research Report on Shoplifting."

French, W. A. 1981. "National Coalition To Prevent Shoplifting." August 31 .

Freud, A. 1965. Normality and Pathology in Childhood: Assessments of Development, New York: International University Press.

Freud, Sigmund. Studies of Hysteria, Vol. 2, Standard Edition, James Strachey (ed.), London: Hogarth Press.

Gasset, Jose Oretgo 1941. Toward a Philosophy of History, New York: W. W. Norton and Company.

Gergen, Kenneth J. 1968. "Personal Consistency and the Presentation of Self," in Chad Gordon and Kenneth J. Gergen (eds.), The Self in Social Interaction, New York: Wiley, 299-308.

Gergen, Kenneth J. 1971. The Concept of Self, New York: Holt Rinehart and Winston.

Gibbens, T. C. N. and J. Prince 1962. Shoplifting, London: The Institute for the Study and Treatment of Delinquency.

Gibbens, T. C. N., C. Palmer and J. Prince 1971. "Mental Health Aspects of Shoplifting," British Medical Journal, Vol. 3, 612-615.

Gibbons, D. C. 1971. "Observations on the Study of Crime Causation," American Journal of Sociology, Vol. 77, 262-278.

Gibbons, D. C. 1976 (2nd ed.). Delinquent Behavior, Englewood Cliffs, New Jersey: Prentice-Hall, Inc.

Gibbons, Don C. 1977. Society, Crime and Criminal Careers: An Introduction to Criminology, Englewood Cliffs, New Jersey: Prentice-Hall, Inc.

Gibbons, D. C. and Marvin D. Krohn 1986 (4th ed.). Delinquent Behavior, Englewood Cliffs, New Jersey: Prentice-Hall.

Gibson, Lorne, Rick Linden and Stuart Johnson 1979. "A Situational Theory of Rape," A revised version of a paper presented at the Canadian Sociology and Anthropology Assn.

Giordano, Peggy C. and Stephen A Cernkovich 1979. "On Complicating the Relationship Between Literation and Delinquency," Social Problems, Vol. 26 No. 4 (Apr.), 467-481.

Glaser, Daniel 1978. Crime in Our Changing Society, New York: Holt, Rinehart and Winston, Inc. 
Glueck, Sheldon 1956. "Theory and Fact in Criminology," British Journal of Delinquency, Vol. 7 (July), 92-109.

Glueck, S. and E. T. Glueck, 1930. 500 Criminal Careers, New York: Knopf.

Goffman, Irving 1959. The Presentation of Self in Everyday Life, Garden City, New York: Doubleday.

Gould, L. C. 1969. "A Comparison of Self-Reported Indices of Delinquency for Three Racial Groups," Social Problems, Vol. 16, 325-335.

Gould, Leroy C. 1969. "Juvenile Entrepreneur," American Journal of Sociology, LXXIV, No. 6, May, 710-720.

Greenwood, P. W. 1986. "Differences in Criminal Behavior and Court Responses among Juvenile and Young Adult Defendants," Crime and Justice: An Annual Review of Research, (eds.) M. Tonry and $\bar{N}$. Morris, Chicago: University of Chicago Press, Vol. 7, 151-188.

Greenwood, P. W., A. Abrahamse, A. Lipson and F. Zimring 1983. Youth Crime and Juvenile Justice in California: A Report to the Legislature, Santa Monica, Calif.: Rand.

Griffins, R. K. 1978. "Shoplifting," Security World, Vol. 10, 16-19.

Guttman, L. 1949. "A Basis for Scaling Qualitative Data," American Sociological Review, Vol. 9, 139-150.

Hal1, Calvin S. and Lindzey Gardner 1960. Theories of Personality, New York: John Wiley \& Sons.

Harris, A. R. 1977. "Sex and Theories of Deviance: Toward a Functional Theory of Deviant Type Scripts," American Sociological Review, Vol. 12 (Feb.), 3-16.

Hardt, R. H. and S. P. Hardt 1977. "On Determining the Quality of the Delinquent Self-Report Method," Journal of Research in Crime and Delinquency, July, 247-261.

Hartshorne, H. and M. A. May 1928. "Studies in the Nature of Character," Studies in Deceit, New York: MacMillan, Vol. 1.

Haskell, Martin R. 1960. "Toward a Reference Group Theory of Juvenile Delinquency," Social Problems, Vol. 8 (Winter), 61-81.

Hepburn, John R. 1963. "Testing Alternative Models of Delinquency Causation," Journal of Criminal Law and Criminology 非XVII.

Hepburn, John 1984. "Occasional Criminal," in Robert Meier (ed.) Major Forms of Crime, Beverly Hills, Calif.: Sage Publications. 
Hildelang, Michael J. 1973. "Causes of Delinquency: A Partial Repication and Extension," Social Probiems, \#20 (Spring), $471-$ 487.

Hindelang, M. 1973. Decisions of Shoplifting Victims to Invoke the Criminal Justice Process, N. C. J. R. S., November.

Hirschi, Travis 1969. Causes of Delinquency, Berkeley: University of California Press, 1969.

Hirschi, Travis 1985. "Crime and Family Policy," in Juvenile Delinquency: A Justice Perspective, Ralpha A. Weisheit and Robert G. Culbertson, Prospect Heights, Ill.: Waveland Press, Inc., 5367.

Hirschi, T. and M. Gottfredson (eds.) 1980. Understanding Crime: Current Theory and Research, Beverly Hills, Calif.: $\frac{\text { Sage }}{\text { Publicat }}$ Publication.

Holcomb 1973.

Hollingshead, August B. 1975. Elmtown's Youth and Elmtown Revisited, New York: Wiley.

Ivan, F., J. S. Short and V. J. Olson 1958. "Socio-Economic Status and Delinquent Behavior," Americal Journal of Sociology, Vol. 63 (Jan.), 381-389.

Jeffery, Clarence R. 1965. "Criminal Behavior and Learning Theory," Journal of Criminal Law, Criminology and Police Science, Vol. 56, September, 294- $\overline{300 .}$

Jeffrey, C. R. 1971. Crime Prevention through Environmental Design, Beverly Hills, Calif.: Sage Publication.

Johnson, Elmer 1974. Crime, Correction and Society, 3rd ed., Homewood, IIl.: The Dorsey Press.

Kaplan, J. T., A. M. Freedman and B. J. Sadock 1980. Comprehensive Textbook of Psychiatry, No. III, Baltimore, London: Williams and Wilkin.

Kelly, D. H. and W. T. Pink 1973. "Social Origins, School Status, and the Learning Experience," Pacific Sociological Review, Vol. 10 (Jan.), 121-134.

Klein, Malcolm W. 1984. "Offense Specialization and Versatility Among Juveniles," British Journal of Criminology, Vol. 24 No. 2, Apr., 195-192. 
Kirsch, T. 1972. Cited in: L. A. Conner 1981. "Impact of New Educational Techniques Developed to Convert Shoplifters Into Honest Consumers," Shoplifters Anonymous, Aston, Penn., 38.

Klemke, Lloyd W. 1982. "Exploring Juvenile Shoplifting," Sociology and Social Research, Vol. 67 \#1, Oct., 59-75.

Knudten, Richard 1970. Crime in a Complex Society, Homewood, Ill.: Dorsey Press.

Kraus, P. E. 1973. Yesterday's Children: A Longitudinal Study of Children from Kindergarten into Adult Years, New York: Wiley.

Kryter 1970.

LaBurtis, T. 1975. Cited in: New York Time Review, December 24, 1975, 26, col. 1.

Lemert, Edwin M. 1959. Human Deviance, Social Problems and Social Control, Englewood Cliffs, New Jersey: Prentice-Hall.

Lerman, Paul (ed.) 1970. Delinquency and Social Policy, New York: Praeger.

Levy, Sheldon 1968. Inferential Statistics in the Behavioral Sciences, New York: Holt, Rinehart and Winston, Inc.

Lillyquist, M. J. 1980. Understanding and Changing Criminal Behavior, Englewood Cliff, N. J.: Prentice Hall.

Linden, Hackler 1973.

Linga, T, and Keinke, C. 1974. Cited in D. H. Robertson 1980. Shoplifting - Problems and Perceptions, Atlanta: Office of Juvenile and Delinquency Prevention, September.

Liska, A. E. 1969. "Interpreting the Causal Structure of Differential Association Theory," Social Problems, Vol. 16, 485-492.

Loeber, R. 1986. "The Natural Histories of Juvenile Conduct Problems, Sutstance Use, and Delinquency: Evidence for Developmental Progressions," Unpublished Manuscript, Pittsburg: University of Pittsburg, Interns Psychiatric Institute and Clinic.

Loeber, R. and M. Stouthamer-Loeber 1986. "The Prediction of Delinquency," in Handbook of Juvenile Delinquency, (ed.) H. C. Quay, New York: Wiley.

Lofland, John 1969. Deviance and Identity, New Jersey: PrenticeHall. 
Lowrey, Lawson G. 1944. "Delinquent and Criminal Personalities," in J. McV. Hunt (ed.) Personality and the Behavior Disorder, Vol 2, New York: Ronald Press Co. Chapt. 26.

MacIver, R. M. 1942. Social Causation, New York: Ginn and Company.

Mansfield, R., L. C. Gould and J. Z. Namenwirth 1974. "A Socio-economic Model for the Prediction of Societal Rates of Property Theft," Social Forces, Vol. 52, 462-472.

Marshal, A. 1959. Cited in: M. Hildelang, 1971. "Decisions of Shoplifting Victims to Invoke the Criminal Justice Process," N.C.J.R.S., November.

Mathey and Marc 1980. Cited in: Comprehensive Textbook of Psychiatry, No. III, Kaplan, et al, London: Williams and Wilkin.

Matza, D. 1964. Delinquency and Drift, New York: Wiley.

Matza, David 1969. Becoming Deviant, Englewood Cliffs, New Jersey: Prentice-Hall.

Matza, David and Gresham M. Sykes 1957. "Techniques of Neutralization: A Theory of Delinquency," Americal Sociological Review, \#22 (December), 664-670.

McCord, W., J. McCord and J. Gudeman 1960. Origins of Alcoholism, Palo Alto, Calif.: Stanford University Press.

Medlicott, R. W. 1968. "Fifty Thieves," New Zealand Medical Journal, Vol. $67,183-188$.

Merton, Robert K. 1938. "Social Structure and Anomie," American Sociological Review, Vol. 3, Oct., 672-682.

Meyers, S. M. 1970. "A Crusade Against Shoplifting," Police Chief.

Meyers, T. 1970. "A Contribution to the Psychopathology of Shoplifting," Journal of Forensic Sciences, Vol. 15, No. 3.

Miller, P. Y. 1974. Youth and Society in Illinois: Adolescent Theft, Chicago: The Institute for Juvenile $\overline{\text { Research. }}$

Miller, Walter B. 1958. "Lower Class Culture as a Generating Milieu of Gang Delinquency," Journal of Social Issues, Vol. 15, 5-19.

Mills, C. Wright 1942. "The Professional Ideology of Social Pathologists," American Journal of Sociology, Vol. XLIX, Sept., 179. 
Moore, R. 1984. "Shoplifting in Middle America: Patterns and Motivational Conrelates," International journal of of fender Therapy and Comparative Criminology, Vol. 28, No. 1, 53-64.

Murray, J. P. 1983. "Status Offenders, Roles, Rules and Reactions," Status Offenders: A Source Book, in Weisheit, R. A. and R. G. Culbertson (eds) Juvenile Delinquency: A Justice Perspective, 1726.

National Council on Crime and Delinquency, 1966. NCCD News, MarchApril), 45.

National Evaluation Program - Phase I Assessment of Shoplifting and Employee Theft Programs, Summary Report, March 1980, MCJ, 76688.

National Retail Merchants, Assn., 1976, 37-40.

Neville, J. 1972. Cited in L. A. Conner 1981. "Impact of New Educational Techniques Developed to Convert Shoplifters into Honest Consumers," Shoplifters Anonymous, Aston, Penn., 39.

Newberg, Paula 1968. "A Study in Deviance: Shoplifting," International Journal of Comparative Sociology, Vol. 9, Jan.

Newberg, Paula 1974. "No City Limits on Shrink," Chain Store Executive, oct., 35-37.

Ohlin, L. E. 1970. A Situational Approach to Delinquency Prevention, Washington D.C.: Youth Development and Delinquency Prevention Administration, U. S. Department of Health, Education and Welfare.

Olson, D. H., H. I. McCubbin, M. Barnes, A. Larsen, M. Muxen, and M. Wilson 1983. Families: What Makes Them Work, Beverly Hills, Calif.: Sage Publication.

Patterson, G. R. 1980. "Children who Steal," in Travis Hirschi and Michael Gottfredson, Understanding Crime, Beverly Hills: Sage Publication, 73-90.

Quinney, L. A. 1970. The Social Reality of Crime, Boston: Little, Brown.

Ray, J., G. Solomen, M. Doncaster, and R. Melina 1983. "First Offender Adult Shoplifters: A Preliminary Profile," Journal of Clinical Psychology, Vol. 39, No. 5, 769-770.

Reckless, W. C. 1961. "A New Theory of Delinquency and Crime," Federal Probation, Vol. 25, Dec., 42-46.

Reckless, Walter C. 1973 (5th ed.). The Crime Problem, Englewood Cliffs, New Jersey: Prentice-Hall. 
Reckless, Walter C., Simon Dinitz and Ellen Murray 1956. "Self Concept as an Insulator Against Delinquency," American Sociological Review, Vol. 21, 744-746.

Reiss, Albert J. 1951. "Delinquency as the Failure of Personal and Social Control," American Sociological Review, Vol. 16, 196-206.

Richman, J., J. Stevenson and F. J. Grahemin 1982. Pre-School to School: A Behavioral Study, London: Academic Press.

Rittenhaus, J. D. and J. D. Miller 1984. "Social Learning and Teenage Drug Use - An Analysis of Family Dyads," Health Psychology, Vol. 3, 329-346.

Robertson, D. H. 1980. Shoplifting - Problems and Perceptions, Atlanta: Office of Juvenile and Delinquency Prevention, Sept., 4.

Robin, Gerald D. 1963. "Patterns of Department Store Shoplifting," Crime and Delinquency, 163-172.

Robins, L. N. 1966. Deviant Children Grown Up, Baltimore: Williams and Williams.

Ross, L. 1977. "The Intuitive Psychologist and His Shortcomings: Distortions in the Attribution Process," in Advances in Experimenta]. Social Psychology, Vol. 10, ed. Leonard Berkowitz, New York: Academic Press.

Russell, D. H. 1973. "Emotional Aspects of Shoplifting," Psychiatric Annals, Vol. 67, 183-188.

Schwartz, M. and S. Stryker 1970. "Deviance, Selves and Others," American Soc. Assn.; Rose Monograph Series

Serdahely, T. 1977. Cited in W. A. French 1981. National Research Report on Shoplifting 1980-1981, National Coalition to Prevent Shoplifting, August, NCJ 76688.

Shave, P. L. 1978. "Shoplifting in the State of Washington," The Crime and Its Prevention, Seattle, Wash.: Washington Crime Watch, $\overline{\operatorname{Mar} c h}$.

Shaw, Clifford R. and Henry D. McKay 1931. "Social Factors in Juvenile Delinquency: A Study of the Community, the Family and the Gang in Relation to Delinquent Behavior," National Commission on Law Observance and Enforcement, Report on the Causes of Crime, Washington, D. C.: USGPO, VOI. II, NO. 13, Chapter IV, 194-199.

Shulman, Harry M. 1949. "The Family and Juvenile Delinquency", The Annals of the American Acadamy of Political and Social Science, No. 261, January, 21-31. 
Shulman, H. M. 1959. "The Family and Juvenile Delinquency," in S. Glueck (ed.) The Problem of Deiinquency, New York: Joughton Mifflin.

Shuster, R. L. 1982. "Violent Juveniles and Proposed Changes in Juvenile Justice: A Case of Overkill?" Juvenile and Family Court Journal, Nov., 27-35.

Siligman, A. 1975. "Spokane's Anti-Shoplifting Campaign," Banking, April, 26.

Simmel, Georg 1950. The Sociology of Georg Simmel, K. H. Wolff (ed.), New York: MacMillan.

Slom, S. H. 1971. "Thou Shalt Not - Not Easy to Stop Shoplifting," Wall Street Journal, No. 178, Oct. 11., 1.

Small Markers Aids 1969. U. S. Small Business Admininistration, No. $135, \overline{p p} .9,129$.

Small Markers Aids 1978. "Reducing Shoplifting Losses," U. S. Small Business Administration, No. 179, 2.

Sohier, J. 1969. "Shoplifting", International Criminal Police Review, Vol. 299, 163-166.

Sparks, R. F. 1980. "Criminal Opportunities and Crime Rates," in "Indicators of Crime and Criminal Justice: Quantitative Studies," (eds.) S. E. Feinberg and A. J. Reiss, Jr., Bureau of Justice Statistics, Department of Justice, Washington D. C.: U. S. Government Printing of fice.

Spergel, Irving 1964. Racketville, Slum Town and Hautberg, Chicago: University of Chicago Press.

Steckel, 1911. Cited in: Gibbens, T. C. N. and J. Prince 1962. Shoplifting, London: The Institute for the Study and Treatment of Delinquency.

Stinchcombe, Arthur L. 1964. Rebellion In A High School, Chicago: Quadrangle.

Sutherland, Edwin H. 1939. Principles of Criminology, 3rd ed.

Sutherland, Edwin H. 1974. Principles of Criminology, 9th ed. revised by Donald R. Cressey, Philadelphia: J. B. Lippincott Company, 77-80.

Sutherland, E. H. 1977. "The Swan Song of Differential Association," in Paul F. Cromwell, Jr., George G. Killinger, Rosemary C. Sarri and H. M. Solomon (eds.), Text and Readings: Introduction to Juvenile Delinquency, St. Paul, Minn.: West Publishing Co. 
Sykes, Gresham M and David Matzà 1961. "Juvenile Delinquency and Subterranean Values," American Sociological Review, 712-719.

Tannenbaum, David J. 1977. "Personality and Criminality: A Summary and Implication of the Literature," Journal of Criminal Justice, Vol. 3, Fall, 225-235.

Tannenbaum, Frank 1938. Crime and The Community, New York: Ginn and Company.

Taylor, I., P. Walton and J. Young 1973. The New Criminology, London: Routledge and Kegan Paul.

Taylor, I., P. Walton and J. Young 1973. The New Criminology: For A Social Theory of Deviance, New York: Harper and Row.

Teeters, Megley K. and John 0. Reinemann 1950. The Challenge of Delinquency, Englewood Cliffs, New Jersey: Prentice-Hall

Theo 1974.

Tims, A. R. and J. D. Masland 1985. "Measurement of Family Communication Patterns," Communication Research, Vol. 12, 35-58.

Toby, A. 1957. Cited in: New York Time Review, December 24, 1975, 26, col. 1 .

Toby, Jackson 1957. "The Differential Impact of Family Disorganization", American Sociological Review, 非2 (October), 505-512.

Trasler, Gordon 1962. The Explanation of Criminology, London: Routledge and Kegan, Paul.

Turk, Austin T. 1969. Criminality and Legal Order, Chicago: Rand McNally and Co.

Turk, A. T. 1980. "Analyzing Official Deviance: For Nonpartisan Conflict Analysis in Criminology," in J. Inciardi (ed.) Radical Criminology: The Coming Crisis, 78-91.

U. S. News and World Report, June 1978, 63-65.

Vold, George 1958. Theoretical Criminology, New York: Oxford University Press.

Walsh, D. P. 1978. Controlling a Major Crime, London: MacMillan.

Weiner, N. L. 1970. "The Teenage Shoplifter: A Microcosmic View of Middle Class Delinquency," in J. Douglas (ed.) Observations of Deviance, New York: Random House.

Weinstein 1975. 
Weisheit, R. A. and R. C. Culbertson (eds) 1980. Juvenile Delinquency: A Justice Perspective

Wilkinson, K. 1974. "The Broken Family and Juvenile Delinquency: Scientific Explanation or Ideology?" Social Problems, No. 21, June, 726-739.

Williams, Robin 1960. American Scciety, New York: Knopf.

Wilson, H. W. 1979. "Crime Wave Against Business", in E. Oatman, Crime and Society, 7.

Wirth, Louis 1964. "The Urban Way of Life," in On Cities and Social Life, Chicago, Ill.: University of Chicago Press.

Wolfgang, M., R. E. Figlio and T. Sellin 1972. Delinquency in a Birth Cohort, Chicago: University of Chicago Press.

Voll, George B. 1979. Theoretical Criminology, 2nd ed. prepared by Thomas J. Bernard, New York: Oxford University Press.

Won, George and George Yamamoto 1968. "Social Structure and Deviant Behavior: A Study of Shoplifting," Sociology and Social Research, Vol. 53, 44-55.

Yates, Elizabeth 1986. "The Influence of Psycho-Social Factors in NonSensical Shoplifting," International Journal of Offender Therapy and Comparative Criminology, Vol. 30 No. 3, 203-211. 


\section{APPENDIX I \\ POPULATION CHARACTERISTICS}

\section{YOUTHS FROM SERVICE CENTERS REFERRED BY COURT AND POLICE FOR DIVERTIBLE OFFENSES DURING SAMPLE PERIOD}

\begin{tabular}{|c|c|c|}
\hline Diversion Offense & Number & Percent \\
\hline Status offenses & 109 & 27.1 \\
\hline Shoplifting & 209 & 52.1 \\
\hline Other Misdemeanors & 83 & 20.7 \\
\hline
\end{tabular}

\section{CHARACTERISTICS OF YOUTHS SAMPLED AT THE MALLS}

ALSO INCLUDED IN THE SAMPLE

\begin{tabular}{|c|c|c|c|c|c|c|c|}
\hline Sex & & & $\mathrm{Ag}$ & & & Shor & ted \\
\hline & 13 & 14 & 15 & 16 & 17 & Yes & No \\
\hline$M-39$ & 5 & 2 & 5 & 4 & 3 & 11 & 8 \\
\hline$F-26$ & 5 & 4 & 4 & 3 & 3 & 16 & 9 \\
\hline
\end{tabular}


AGE AND SEX

$\begin{array}{lccc}\text { Age } & \text { Male } & \text { Female } & \% \\ 13 & 32 & 40 & 23 \\ 14 & 34 & 38 & 23 \\ 15 & 35 & 33 & 21 \\ 16 & 29 & 31 & 19 \\ 17 & 24 & 16 & 13\end{array}$

$$
N=154 \quad N=158
$$

It was impossible to determine accurately if these youth had prior referrals to jurisdictions outside the designated sampling area. (Multnomah County)

YOUTHS FROM SERVICE CENTER PROGRAMS IN SAMPLE

\begin{tabular}{|c|c|c|c|c|}
\hline Service & Number & $\begin{array}{l}\text { Service } \\
\text { Center \% }\end{array}$ & $\begin{aligned} & \text { Pop. } \% \\
& \text { of } \text { Category } \\
&\end{aligned}$ & No. \\
\hline Counseling & 310 & 20.6 & 11.9 & 37 \\
\hline Employment & 314 & 20.9 & 14.9 & 47 \\
\hline Tutoring & 105 & 7.0 & 9.5 & 10 \\
\hline Drug Education & 140 & 9.3 & 7.1 & 10 \\
\hline Big Brother/Sister & 230 , & 15.3 & 15.2 & 35 \\
\hline Diversion & 401 & 26.7 & 33.6 & 135 \\
\hline Shopping Mall & 65 & 0.0 & 18.6 & 38 \\
\hline
\end{tabular}

$52 \%$ of the 401 youths referred for diversion had been charged with shoplifting. 
SHOPLIFTING FREQUENCY BY MONTH - SEX

YOUTH SERVICE CENTER 1984-1985

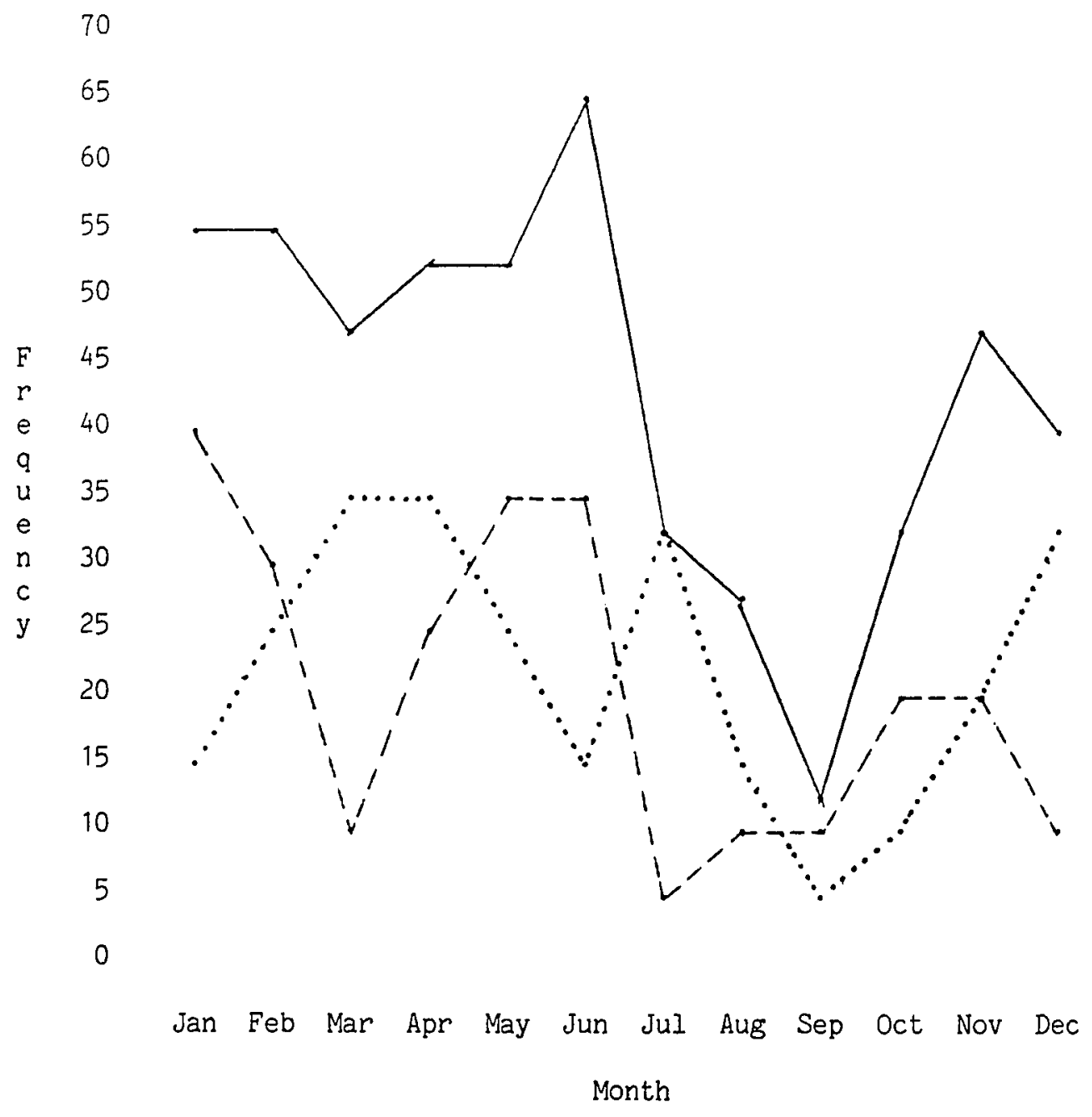

Female...

Male - - -

Total 
APPENDIX II

PARTIALLING OUT VARIABLES

BONDING

\begin{tabular}{|c|c|c|c|c|}
\hline Element & Partial Correlation & Partial & $\underline{T}$ & $\underline{B D 5}$ \\
\hline \multicolumn{5}{|l|}{ Bd 1} \\
\hline $\mathrm{Bd} 2$ & -.081835 & -.081835 & -1.434 & \\
\hline $\mathrm{Bd} 3$ & -.180719 & -.180719 & -3.209 & \\
\hline Bd 4 & .045560 & .047978 & .839 & \\
\hline Bd 5 & .175789 & .182228 & 3.237 & \\
\hline Bd 6 & .122538 & .123754 & .415 & \\
\hline Bd 7 & .083930 & .088141 & 1.545 & \\
\hline \multicolumn{5}{|c|}{ PEEIR ASSOCIATION } \\
\hline Element & Partial Correlation & Partial & $I$ & $\underline{P A 6}$ \\
\hline PA 1 & -.108418 & -.109571 & -1.925 & .10913 \\
\hline PA 2 & .125050 & .126129 & 2.220 & -.12551 \\
\hline PA 3 & -.021044 & -.021391 & -.374 & .02134 \\
\hline PA 4 & -.004374 & -.004447 & -.078 & .00472 \\
\hline PA 5 & -.050642 & -.051422 & -.899 & .05505 \\
\hline \multicolumn{5}{|l|}{ PA 6} \\
\hline PA 7 & -.020080 & -.020412 & -.357 & .02031 \\
\hline
\end{tabular}


NEEDS

\begin{tabular}{|c|c|c|c|}
\hline Element & Partial Correlation & Partial & $\underline{T}$ \\
\hline N 1 & -.035839 & -.036585 & -.638 \\
\hline $\mathrm{N} 2$ & -.033985 & -.034695 & -.605 \\
\hline N 3 & -.115836 & -.117508 & -2.063 \\
\hline N 4 & -.027327 & -.027904 & -.487 \\
\hline N 5 & -.165645 & -.166837 & -2.950 \\
\hline N 6 & -.023535 & -.024034 & -.419 \\
\hline N 7 & .065179 & .066434 & 1.161 \\
\hline
\end{tabular}

PARENTAL RELATIONSHIP

\begin{tabular}{|c|c|c|c|c|}
\hline Element & Partial Correlation & Partial & $\underline{T}$ & $\underline{P R} \underline{2}$ \\
\hline PR 1 & .356618 & .362188 & 6.808 & -.35927 \\
\hline \multicolumn{5}{|l|}{ PR 2} \\
\hline PR 3 & .059990 & .065225 & 1.145 & -.06145 \\
\hline PF 4 & .022974 & .159743 & 2.835 & -.15210 \\
\hline PR 5 & .022974 & -.025024 & -.439 & .02313 \\
\hline
\end{tabular}


ATTITUDE

\begin{tabular}{|c|c|c|c|c|c|}
\hline Elements & \multicolumn{2}{|c|}{ Correlation } & \multicolumn{2}{|c|}{ Partial } & $\underline{T}$ \\
\hline AT 1 & \multicolumn{2}{|l|}{.144095} & \multicolumn{2}{|c|}{.162894} & 2.888 \\
\hline AT 2 & \multicolumn{2}{|l|}{.038648} & \multicolumn{2}{|c|}{.044239} & .775 \\
\hline AT 3 & \multicolumn{2}{|l|}{.162693} & \multicolumn{2}{|c|}{.183252} & 3.261 \\
\hline \multicolumn{6}{|l|}{ AT 4} \\
\hline AT 5 & \multicolumn{2}{|l|}{.235882} & \multicolumn{2}{|c|}{.260905} & 4.728 \\
\hline AT 6 & \multicolumn{2}{|l|}{.003750} & \multicolumn{2}{|c|}{.004297} & .075 \\
\hline STATED SITE AND & FREQUENCY & \multicolumn{2}{|c|}{ F SHOPLIFTING, } & \multicolumn{2}{|c|}{$1982-1986$} \\
\hline Store & $\underline{f}$ & Male & $\underline{\%}$ & Female & $\%$ \\
\hline Nordstrom & 315 & 35 & 11 & 280 & 89 \\
\hline Fredrick \& Nelson & 225 & 87 & 39 & 138 & 61 \\
\hline Meier \& Frank & 63 & 46 & 73 & 17 & 27 \\
\hline Fred Meyer* & 460 & 219 & 48 & 241 & 52 \\
\hline J. C. Penney & 74 & 39 & 53 & 35 & 47 \\
\hline Sears & 219 & 167 & 76 & 52 & 24 \\
\hline$=$ & 1,356 & 593 & & 763 & \\
\hline
\end{tabular}

* Note: Fred Meyer is not located in the mall areas, however it was included because it is in close proximity to the malls and possesses similar characteristics as the stores included in this sample. 


\begin{tabular}{|c|c|c|c|c|c|c|c|c|c|}
\hline \multirow[b]{3}{*}{ Site } & \multirow{3}{*}{$\begin{array}{l}\text { STATEI } \\
\text { Ereq. }\end{array}$} & \multicolumn{6}{|c|}{$\begin{array}{r}\text {, FREQUENCY OF } \\
\text { NTAGE, AGE, SE } \\
1982-1986\end{array}$} & & \\
\hline & & \multicolumn{2}{|c|}{ Males } & \multicolumn{2}{|c|}{ Percentage } & \multicolumn{2}{|c|}{ Females } & \multicolumn{2}{|c|}{ Percentage } \\
\hline & & $\underline{B}$ & $\underline{W}$ & $\underline{B}$ & $W$ & $\underline{B}$ & W & $\underline{B}$ & $W$ \\
\hline Nordstrom & 312 & 3 & 32 & .94 & 10.16 & 40 & 240 & 12.7 & 76.2 \\
\hline \multicolumn{10}{|l|}{ Fredrick \& } \\
\hline Nelson & 225 & 4 & 83 & 1.8 & 36.9 & 19 & 119 & 8.4 & 52.9 \\
\hline Meier \& Frank & 63 & 2 & 44 & 3.2 & 69.8 & 1 & 16 & 1.6 & 25.4 \\
\hline Fred Meyer & 460 & 126 & 93 & 27.4 & 20.2 & 84 & 157 & 18.3 & 34.1 \\
\hline J. C. Penney & 74 & 12 & 16 & 16.2 & 21.6 & 9 & 37 & 12.2 & 50.0 \\
\hline Sears & 219 & 43 & 124 & 19.6 & 57.0 & 11 & 41 & 5.0 & 18.7 \\
\hline $\mathrm{N}=$ & 1,353 & 190 & 392 & 14.0 & 29.0 & 164 & 610 & 12.0 & 45.1 \\
\hline
\end{tabular}


SPATIAL DISTRIBUTION OF SAMPLE POPULATION BY AGE, SEX AND RACE*

\begin{tabular}{|c|c|c|c|c|c|c|c|c|c|}
\hline \multirow[b]{2}{*}{ Area } & \multirow[b]{2}{*}{ Age } & \multicolumn{2}{|c|}{ Sex } & \multicolumn{2}{|c|}{ Percentage } & \multicolumn{2}{|c|}{ Race } & \multicolumn{2}{|c|}{ Fercentage } \\
\hline & & $\underline{M}$ & $\underline{F}$ & $\underline{M}$ & $\underline{F}$ & $\underline{B}$ & $\underline{W}$ & $\underline{B}$ & $\underline{\mathrm{W}}$ \\
\hline North & 13 & 8 & 10 & 44 & 56 & 2 & 16 & 11 & 89 \\
\hline & 14 & 9 & 10 & 47 & 53 & 2 & 17 & 10.5 & 88.5 \\
\hline & 15 & 8 & 8 & 50 & 50 & 2 & 14 & 12.5 & 87.5 \\
\hline & 16 & 7 & 8 & 47 & 53 & 2 & 13 & 13.3 & 86.7 \\
\hline & 17 & 6 & 4 & 60 & 40 & 2 & 8 & 20.0 & 80.0 \\
\hline & $=$ & 38 & 40 & 48.7 & 51.2 & 10 & 68 & 12.8 & 87.1 \\
\hline
\end{tabular}

$\begin{array}{lrrrrrrrrr}\text { Northeast } & 13 & 8 & 10 & 44 & 56 & 1 & 17 & 5.5 & 94.5 \\ & 14 & 9 & 9 & 50 & 50 & 3 & 15 & 17.0 & 83.0 \\ & 15 & 9 & 9 & 50 & 50 & 2 & 16 & 11.0 & 89.0 \\ & 16 & 8 & 7 & 53 & 47 & 2 & 13 & 13.3 & 86.7 \\ & 17 & 6 & 4 & 60 & 40 & 1 & 9 & 10.0 & 90.0 \\ N= & 40 & 39 & 51 & 49 & 9 & 70 & 11.4 & 88.6\end{array}$

$\begin{array}{lrrrrrrrrr}\text { Northwest } & 13 & 8 & 10 & 44 & 56 & 2 & 16 & 11 & 89 \\ & 14 & 8 & 10 & 44 & 56 & 2 & 16 & 11 & 89 \\ & 15 & 9 & 8 & 53 & 47 & 2 & 15 & 12 & 88 \\ & 16 & 7 & 8 & 47 & 53 & 1 & 14 & 7 & 93 \\ & 17 & 6 & 4 & 60 & 40 & 2 & 8 & 20 & 80 \\ N= & 38 & 40 & 49 & 51 & 9 & 69 & 11.5 & 80.5\end{array}$

$\begin{array}{llllllllll}\text { Southwest } & 13 & 8 & 10 & 44 & 56 & 2 & 16 & 11 & 89\end{array}$

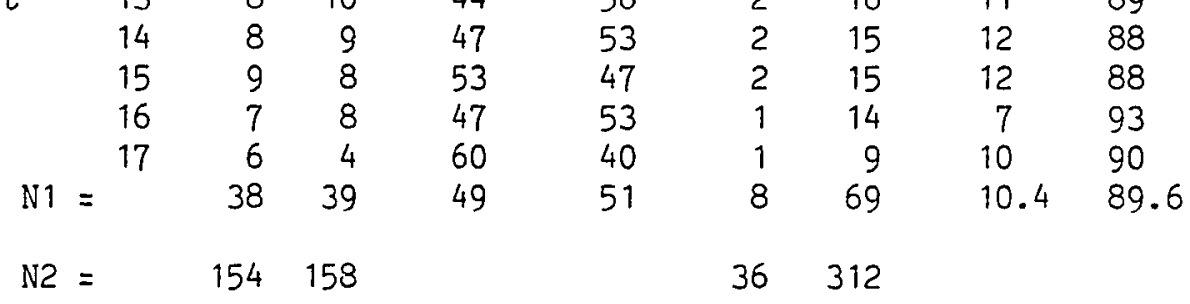

*The sampling strategy was both random and stratified to ensure a population which approximated Portland's Black and White adolescent population. 


\begin{tabular}{|c|c|c|c|c|c|c|c|c|c|}
\hline \multirow[b]{4}{*}{ Age } & \multicolumn{9}{|c|}{ REPORTED SOCIO-E } \\
\hline & \multirow[t]{2}{*}{ Upper } & Clas3 & \multicolumn{2}{|l|}{$N=34$} & \multicolumn{2}{|r|}{ Middle } & Class & \multicolumn{2}{|l|}{$N=125$} \\
\hline & & Sex & \multicolumn{2}{|c|}{ Race } & \multirow[b]{2}{*}{ Age } & \multicolumn{2}{|c|}{ Sex } & \multicolumn{2}{|c|}{ Race } \\
\hline & $\underline{M}$ & $\underline{F}$ & $\underline{B}$ & $\underline{W}$ & & $\underline{M}$ & $\underline{F}$ & $\underline{B}$ & $\underline{W}$ \\
\hline 13 & 6 & 11 & 2 & 15 & 13 & 12 & 16 & 4 & 24 \\
\hline 14 & 3 & 7 & 0 & 10 & 14 & 17 & 20 & 3 & 34 \\
\hline 15 & 0 & 3 & 0 & 3 & 15 & 6 & 15 & 1 & 20 \\
\hline 16 & 1 & 2 & 0 & 3 & 16 & 6 & 13 & 1 & 18 \\
\hline 17 & 0 & 1 & 0 & 1 & 17 & 7 & 13 & 1 & 19 \\
\hline$N=$ & 10 & 24 & 2 & 32 & & 48 & 77 & 10 & 115 \\
\hline & Lower & Class & $N=136$ & & & Do Not & Know & $\mathrm{N}=17$ & \\
\hline 13 & 17 & 13 & 1 & 29 & 13 & 3 & 2 & 1 & 4 \\
\hline 14 & 19 & 16 & 2 & 33 & 14 & 1 & 1 & 0 & 2 \\
\hline 15 & 17 & 8 & 4 & 21 & 15 & 4 & 2 & 0 & 6 \\
\hline 16 & 13 & 8 & 4 & 17 & 16 & 1 & 3 & 0 & 4 \\
\hline 17 & 15 & 10 & 8 & 17 & 17 & 0 & 0 & 0 & 0 \\
\hline$N=$ & 81 & 55 & 19 & 117 & & 9 & 8 & 1 & 17 \\
\hline
\end{tabular}


ADPNDTX III

QUESTIONNAT:

- 


\section{QUESTIONNAATE}

Please check ( $V$ ) the correct response(s) for the following questions:

1. My surrent age i

- a. 12

b. 13

c. 14

d. 15

- e. 16

f. 17

- - None of the above.

2. I am a

- a. Male

3. I live with

a. Natural mother and father.

b. Natural motier and stepfather.

c. Stepmother and natural father.

- o. Single parent -- mother.

- E. Single parent -- father.

f. Other relative.

- g. None of the above.

4. Within the past five (5) years I have stolen from

- a. A store.

- b. A relative.

- c. A friend.

- d. A stranger.

Z e. A school.

f. None of the above.

Note: If you answered "None of the above" on $\$ 4$, go to question $\# 11$.

5. Within the past five (5) years I have

- a. Entered a place of entertainment without paying.

- b. Eaten at a restaurant and left wi thout paying.

- c. Ridden a bus further than I paid for.

d. None of the above.

6. Within the past five (5) years I have stolen

- a. Cigarettes, cigars, chewing tobacco or snuff.

- b. Beer, wine or other alcoholic beverages.

c c. Jewelry or cosmetics.

d. Clothing.

e. Toys, snack foods or soft drinks.

f. Money. 
7. Within the past ine is years I have stolen

a. An automobile.

- b. Gasoline.

- c. Tires.

c. Other items for a car, bicycle or motor bike.

_e. None of the above.

8. Within the past five 5 years 1 have stolen

a. Radio or TV.

b. Video game.

c. Records or music tapes.

d. Stereo or stereo equipment.

- e. None of the above.

9. Within the past five (5) years 1 have stolen

a. Information from a computer.

b. Food from a store or restaurant.

c. Parts for an auto, motor bike or bicycle.

d. From a friend's house.

- e. None of the above.

10. I have been arrested for

a. Shoplifting.

b. Burglary.

c. Stealing outside of a store.

d. Kiting.

- e. None of the above.

11. I am currently going to a

a. Public school

b. Alternatiue school (ie. Vocational Village, Metro Learning Center, etc.)

c. Working on a G. E. D.

d. Private school.

e. None of the above.

12. I am in grade

a. 7 or 3

b. 7 or 10 .

c. 11 or 12 .

d. Vocational school.

e. None of the above.

13. One or more of my close friends have

a. Shoplifted.

b. Possessed and/or used druge.

c. Possessed and/or used al cohol.

d. Stolen something outside of a store.

e. None of the above. 
14. One or more of my clese friends have been baught (arrested) for

- a. Shoplifting.

- b. Stealing outeide of a siore.

- c. Possessing and/or using drugs.

- d. Possessing andor using alcohol.

_ e. None of the above.

15. My weekly allowance is

a. $\$ 1.00$ to $\$ 3.79$

— b. $\$ 4.00$ to $\$ 0.99$.

—c. $\$ 7.00$ to $\$ 10.00$.

- d. More than $\$ 10.00$.

- e. I do not receive an allowance.

16. The largest part of my money comes from

a. A weekly or monthly allowance.

- b. From my parents for work 1 do around the house.

- c. From my parents for work 1 do outside the home (ia. their business).

d. I work for someone other than my parents.

e. I do not get an allowance and I do not have a job.

- f. None of the above.

17. I am presently going to a

a. Public grade school.

—b. Public middle school.

—c. Public high sehool.

d. Private school.

- e. None of the above.

13. When I go to places other than school I usually

a. Drive my own car.

- b. Drive my own motorcycle, motor bike or bicycle.

- c. Ride with friends.

d. Ride with parentis).

e. Use public trensportation (ie. Trimet).

- f. Waik.

- 9. None of the above.

19. My family's total yearly income is

a. 0 to $\$ 11,999$.

b. $\$ 12,000$ to $\$ 17,999$.

c. $\$ 18,000$ to $\$ 24,999$.

d. \$25,000 and atove.

- e. I do not know.

20. I consider my family to be

a. Upper class.

b. Middle elass.

c. Lower class.

— a. I do not know. 
21. I $\mathrm{a} m$

- 3 . White.

- b. Black.

- C. Asian.

- d. Other.

22. I was born in

- a. 196́-ót.

b. $1968-70$.

- c. $1971-73$.

- d. 1974-75́.

Ze. None of the above.

23. ! live in

a. Northeast Portland.

b. Southeast Portland.

c. Nor thwest Portland.

- d. Southivest Portiand.

- e. None of the above.

Please circle the phrase or number which most elosely describes your feelings about earh statement.

24. I use drugs or alcohol for fun.

$$
\text { Strongly agree } \quad \begin{array}{llllll}
1 & 2 & 3 & 4 & 5 & \text { Strongly disagree }
\end{array}
$$

25. When I buy drugs or alcohol I usually get the money for them by shoplifting.

$$
\text { Strongly agree } \quad \begin{array}{llllll}
1 & 2 & 3 & 4 & 5 & \text { Strangly disagree }
\end{array}
$$

26. I have enough money to meet my basic needs.

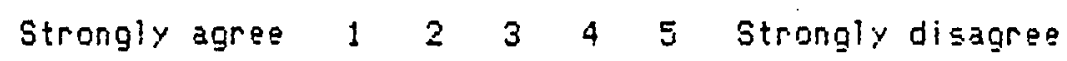

27. Most of my money is spent on school lunches, bus fare, auto expenses or personal entertainment.

$$
\text { Strongly agree } \quad \begin{array}{llllll}
1 & 2 & 3 & 4 & 5 & \text { Strongly disagree }
\end{array}
$$

25. I receive enough money to buy the clothes that 1 need and want.

$$
\text { Strongly agree } \begin{array}{lllllll}
1 & 2 & 3 & 4 & 5 & \text { Strongly disagree }
\end{array}
$$

29. When I go shopping, I generally know what I want and have the money to pay for it.

$$
\text { Strongly agree } \quad \begin{array}{llllll} 
& 2 & 3 & 4 & 5 & \text { Strongly disagres }
\end{array}
$$


30. If I snoolift it is because I do not have the money to buy what I 1, Ifint.

$$
\text { Strongly agree } 1254 \quad 4 \quad 5 \text { Strongly disagree }
$$

31. It is Q.K. to steal from stores because they usually rip you off by charging more than the item is worth.

$$
\text { Etrongly agree } 1 \quad 2 \quad 3 \quad 4 \quad 5 \text { Strongly disagree }
$$

32. Dining and dashing (eating and leaving without paying is more of a game than something serious.

$$
\text { Strongly agree } \quad \begin{array}{llllll}
2 & 3 & 4 & 5 & \text { Strongly disagree }
\end{array}
$$

33. My parent(s) or guardian(s) are too strict.

$$
\text { Strongly agree } \quad \begin{array}{llllll}
2 & 2 & 3 & 4 & 5 & \text { Strongly disagree }
\end{array}
$$

34. At a party or social gathering I usually plan the entertainment.

$$
\text { Strongly agree } \quad \begin{array}{llllll}
1 & 2 & 3 & 4 & 5 & \text { Strongly disagree }
\end{array}
$$

35. I get along better with my parents than my friends do with theirs.

$$
\text { Strongly agree } \quad \begin{array}{llllll} 
& 2 & 3 & 4 & 5 & \text { Strongly disagree }
\end{array}
$$

36. I generally know what I am looking for when I go shopping.

$$
\text { Strongly agree } 1 \begin{array}{llllll}
2 & 3 & 4 & 5 & \text { Strongly disagree }
\end{array}
$$

37. I regularly stay out past curfeus.

$$
\text { Strongly agree } 142534545 \text { Strongly disagree }
$$

38. I have shoplifted at least one item within the past five ( 5 ) years.

$$
\text { Strongly agree } \quad \begin{array}{llllll}
1 & 2 & 3 & 4 & 5 & \text { Strongly disagree }
\end{array}
$$

39. I get along pretty well with other people in my house.

$$
\text { Strongly agree } \quad \begin{array}{llllll}
1 & 2 & 3 & 4 & 5 & \text { Strongly disagree }
\end{array}
$$

40. I have stolen something from a friend or a stranger but the value of the item(s) was small.

$$
\text { Strongly agree } \quad \begin{array}{llllll}
1 & 2 & 3 & 4 & 5 & \text { Strongly disagree }
\end{array}
$$

41. It is okay for people to steal if they are hungry or needy.

$$
\text { Strongly agree } \quad \begin{array}{llllll}
1 & 2 & 3 & 4 & 5 & \text { Strongly disagree }
\end{array}
$$


42. Last year I went to school regulary excapt for illness or entergencies.

$$
\text { Etrongly agree } \quad 1 \quad 2 \quad 3 \quad 4 \quad 5 \text { strongly disagree }
$$

43. When I skip sisss or scheol I do not go shopping.

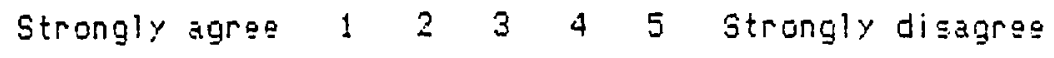

44. It I saw something I really wanted and there bas no possibility of getting caught, I would probably steal it.

$$
\text { Strongly agree } \quad \begin{array}{llllll} 
& 2 & 3 & 4 & 5 & \text { Strongly disagree }
\end{array}
$$

45. I shoplift only when I am drinking or using drugs.

$$
\text { Strongly agree } \quad \begin{array}{llllll} 
& 2 & 3 & 4 & 5 & \text { Strongly disagree }
\end{array}
$$

46. I usually browse through stores that have things of interest to me when I have free time.

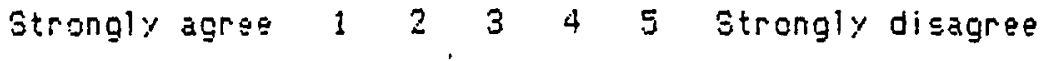

47. I cften trace clothes on a temporary basis with a close friend.

$$
\text { Strongly agree } \quad \begin{array}{llllll}
1 & 2 & 3 & 4 & 5 & \text { strongly disagree }
\end{array}
$$

43. People who rip off other people deserve to be ripped off.

$$
\text { strongly agree } \quad \begin{array}{llllll} 
& 2 & 3 & 4 & 5 & \text { Strongly disagree }
\end{array}
$$

49. I like my school, teachers and activities more than the average student in my Echeol.

$$
\text { Strongly agree } \quad \begin{array}{llllll} 
& 2 & 3 & 4 & 5 & \text { strongly disagree }
\end{array}
$$

50. My teachers to not like me and I do not like them.

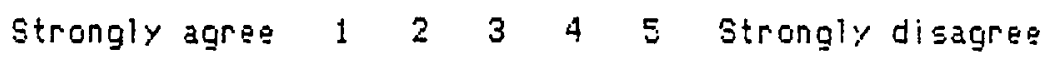

51. If I really wanted to I could shoplift and not get caught.

$$
\text { Strangly agres } \quad \begin{array}{llllll} 
& 2 & 3 & 4 & 5 & \text { Strongiy disagree }
\end{array}
$$

52. I would never shoplift.

$$
\text { Strongly agreg } \quad 1 \quad 2 \quad 3 \quad 4 \quad 5 \text { Strongly diexgree }
$$

52, When I shoplifted I did not thirik about myself, my attention was on the item.

$$
\text { Strong!y agres } \quad \begin{array}{llllll} 
& 2 & 3 & 4 & 5 & \text { Strongly disagree }
\end{array}
$$


54. Stores are tho easy to steal from.

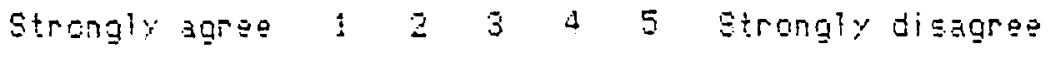

55. Cameraz, sezurity guards or sales clerks could not preyent me from sheolitting $i \div$ l really wanted to.

$$
\text { Strongly agree } \quad \begin{array}{llllll} 
& 2 & 3 & 4 & 5 & \text { Strongly disagree }
\end{array}
$$

5j. The way storos display their mershandise makes it easter to shopli $\div$.

$$
\text { Strongly agree } 1 \quad 2 \quad 3 \quad 4 \quad 5 \text { Strongly disagree }
$$

57. When I shoplifted I did not go into the store to do so.

$$
\text { Strongly agree } 12345 \text { Strongly disagree }
$$

58. My parents understand me.

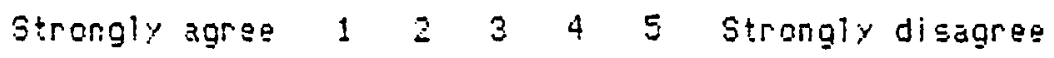

59. I can talk to my parents.

$$
\text { Strongly agree } 1 \quad 2 \quad 3 \quad 4 \quad 5 \text { Strongly disagree }
$$

o0. I get along better with my mother than I do with my father:

$$
\text { Strongly agree } 12 \quad 2 \quad 3 \quad 4 \quad 5 \text { strongly disagree }
$$

61. My father understands me better than my mother does.

$$
\text { Strongly agree } 125345 \text { strongly disagree }
$$

62. At school I'm known as a trouble maker.

$$
\text { Strongly agree } 123 \quad 345 \text { strongiy disagree }
$$

63. I think that I am a trouble maker at schoo?.

$$
\text { Strongly agree } \quad \begin{array}{llllll}
1 & 2 & 3 & 4 & 5 & \text { Strongly disagree }
\end{array}
$$

64. More people distrust me than trust me.

$$
\text { Strongly agree } \quad \begin{array}{llllll} 
& 2 & 3 & 4 & 5 & \text { strongly disagree }
\end{array}
$$

65. Most of my friends shoplift.

$$
\text { Strongly agree } 1425345 \text { Strongly disagree }
$$


bó. I am emotionally close enough to my parentis to confide in them if I choose to.

$$
\text { Etrongly agres } 12345 \text { Etrongly disagres }
$$

67. My parentis) and I have very little in common.

$$
\text { Strongly agree } 12 \quad 345 \text { strongly disagree }
$$

62. I do not seend time pith my parent(s) but l,we are still close.

$$
\text { Strongly agres } \quad 2 \quad 345 \text { Strongly disagree }
$$

67. I have an o?der brother or sister who has shoplifted.

$$
\text { Yes No }
$$

70. I have never been arrosted.

$$
\text { Yes No }
$$

71. I work hard a school and usually get grades that are higher than "C’"s".

Yes No

72. I spend at least half of my froe time with my parents.

$$
\text { Yes No }
$$

73. I usually do something with my parent(s) at least ones a weok.

$$
\text { Yes No }
$$

74. My Zip Code is

ㄴ. $\quad 97203,97217,97227$

b. $97211,97212,97213,97218,97220,97222$

— c. $97201,97209,97210,97219,97221,97223,97229$

—d. 97292, 97206, 97214, 97215, 972!6, 97222, 97266

- e. Hone of the aboue.

75. Using a system of 1-7, please rank the following stores in regard to how easy you think they are to shoplift from, \#1 being the easiest and $\$ 7$ the most difficult.

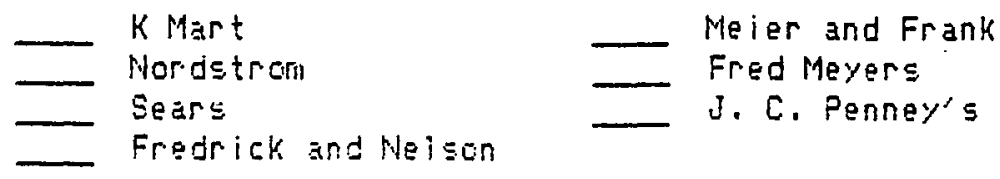


76. Please write the number of times that you have shoolifted within the past fiue is) vase next to path store listeo below.

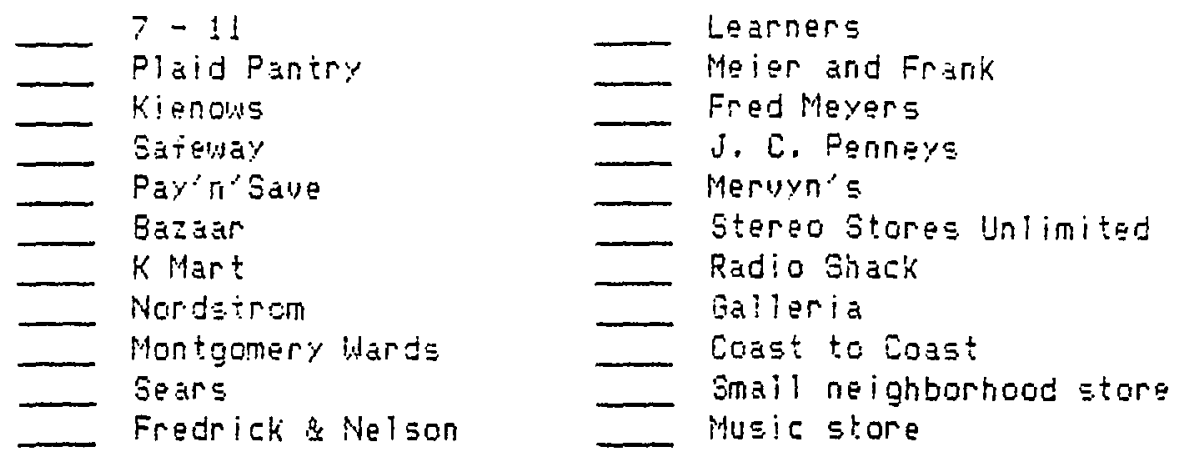

Thank you for your time. 